\title{
Numerical Modelling OF IMPACT DAMAGE ON \\ Carbon Fiber Reinforced Polymer LAMinates
}

\author{
By \\ Kavya Roy, B.Eng \\ Aerospace Engineering \\ Ryerson University, 2012
}

A thesis presented to Ryerson University

in partial fulfillment of the requirements for the degree of

Master of Applied Science

in the program of Aerospace Engineering

Ryerson University

Toronto, Ontario, Canada

(C) Kavya Roy, 2014 
(this page has been intentionally left blank) 
I hereby declare that I am the sole author of this thesis. I authorize Ryerson University to lend this thesis to other institutions or individuals for the purpose of scholarly research.

(Signature)

I further authorize Ryerson University to reproduce this thesis by photocopying or by other means, in total or in part, at the request of other institutions or individuals for the purpose of scholarly research.

(Signature) 


\title{
Numerical Modelling OF IMPaCt DAMAge On CARbon Fiber ReinforCed Polymer Laminates
}

\author{
Master of Applied Science, 2014 \\ Kavya Roy \\ Aerospace Engineering \\ Ryerson University
}

\begin{abstract}
In recent years, the usage of carbon fiber reinforced polymers in the aviation industry has increased significantly. While numerous advancements have been made in the field of testing and analysis of advanced composites, improvements can still be made in terms of time and cost. This thesis is focused on numerical modelling of nonlinear three-dimensional transient-dynamic impact damage, and also assesses various numerical techniques for reducing computational costs while maintaining the accuracy of results under impact loadings. This thesis does so using three studies and the computational package LS-DYNA. The first study is performed to elucidate the behaviour of a stiffened thin-walled fuselage section subjected to low-velocity, high-energy blunt impact. The fuselage section is comprised of thin skin panels, stringers, frames and shear ties, all of which are modelled as multidirectional carbon fiber laminates. The critical locations during the impact, the failure sequence, and the failure loads, locations and times are all identified. The obtained numerical results are compared to experimental results on low-velocity impacts on composite fuselage sections. It is observed that the overall failure mechanisms and sequence are the same for the experimental and numerical studies. Such findings demonstrate the capabilities of a judiciously formulated numerical simulation in accurately capturing the main failure events as well as their sequence and therefore providing a viable substitution for more tedious and time-consuming experimental studies for preliminary design purposes. The second study is on impact of a HTA/6376C carbon fiber/epoxy cantilever plate using an Aluminum 7075-T6 impactor. The study is meant to understand the effectiveness of using supernodes in analyses rather than complete models. The study looks at the methodology of creating supernodes in the first part and then extracting the supernodes in the second part, and testing them against impact. The results
\end{abstract}


are compared to those of the complete model of the same nature. The results demonstrate supernodes are a feasible subsitituion where only the actual impact is of importance; the supernode model deviates from the complete model during the post-impact stages. The last numerical study is on AS4/3501-6 laminate impacted via a hardened steel impactor to understand the effects of ply compaction and mesh refinement on LS-DYNA's computation time and solution accuracy. Material behaviour during the impact and a preliminary understanding of the delamination locations and sequence are also understood. The general trend in the study indicates that the number of plies has a more significant effect on the solution accuracy and a lesser effect on the computation time than the mesh refinement. 


\section{ACKNOWLEDGMENTS}

I would like to thank my supervisor, Dr. Zouheir Fawaz, whose guidance and support throughout my graduate studies have helped me gain the required knowledge and understanding in the subject area. Without his assistance, belief and financial support, my thesis would not have been possible. Dr. Fawaz's vast knowledge of advanced composite materials and his undying support for his students has helped me greatly. Thank you for the countless hours you spent on helping me to achieve my goals.

I would like to thank Dr. Li of National Research Council Canada (Aerospace) for her assistance throughout the course of my thesis. Without her knowledge of impact damage, her willingness to provide me with information on the latest technological achievements, and her updates on the current industrial challenges, this work would not have been as significant. I would also like to thank Dr. Hamid Ghaemi and Dr. John Montesano for providing me with constructive criticisms on my numerical code that challenged me to make my work more robust and reliable. Your thoughts and ideas helped me evaluate and tackle the problem from multiple angles, and to help me see the bigger picture.

I would like to thank my peers, Larkin Lee and Dr. Ihab El Sawy, for all the support, criticism and humor that you have brought to our research facility. Without you two, my time would not have been as much joyful and I would not have been as motivated to complete my thesis. The memories brought on by you two will always be very valuable to me.

Lastly, I would like to thank my friends and family for all their support in seeing me finish my thesis. Your words of encouragement inspired me to dig deeper into my research and finish it to the best of my abilities. 


\section{TABLe OF CONTENTS}

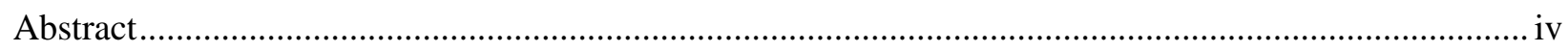

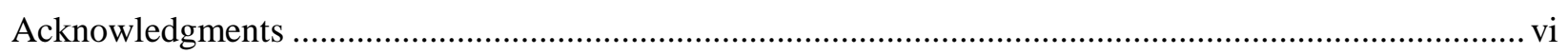

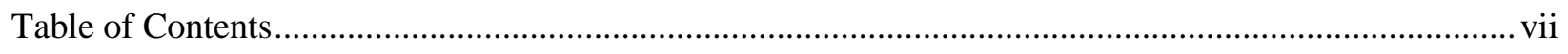

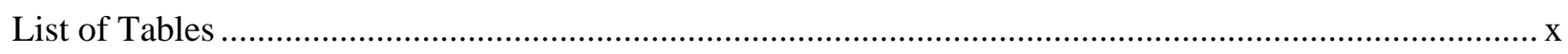

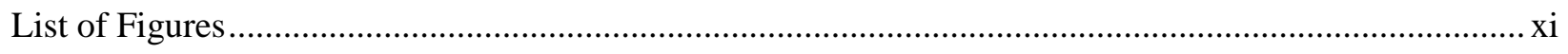

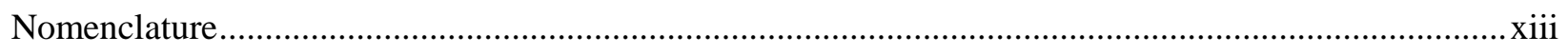

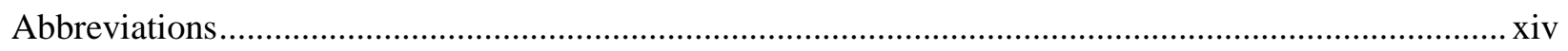

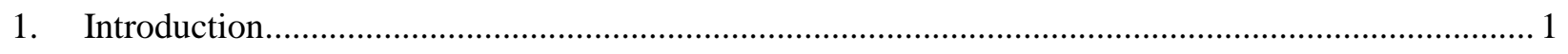

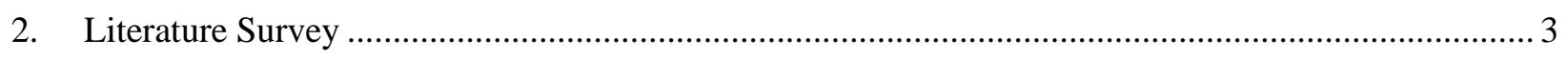

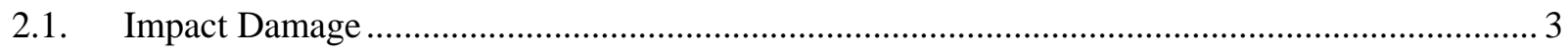

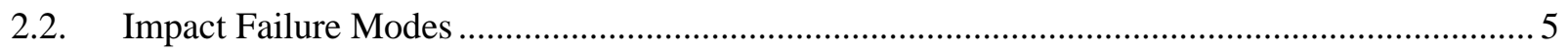

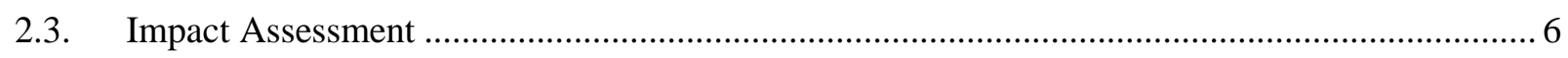

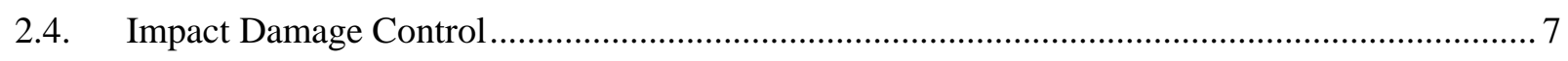

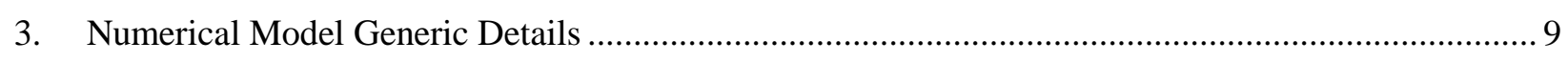

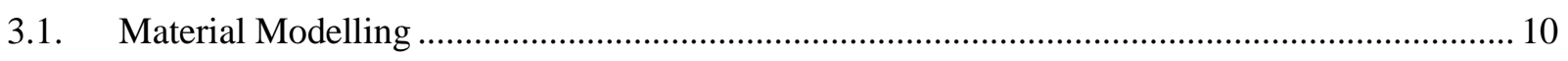

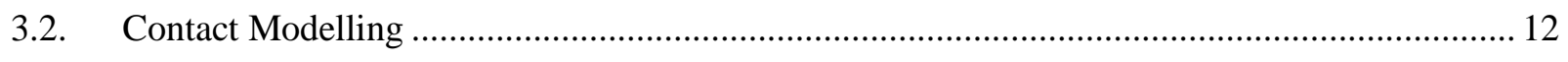

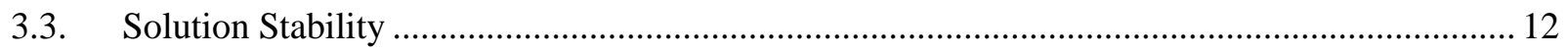

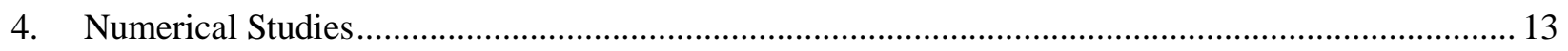

4.1. Low-Velocity and High-Energy Blunt Impact Response of All-Composite Fuselage Section .. 13

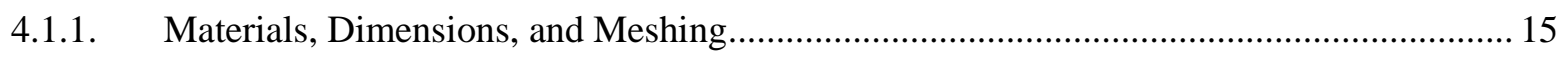

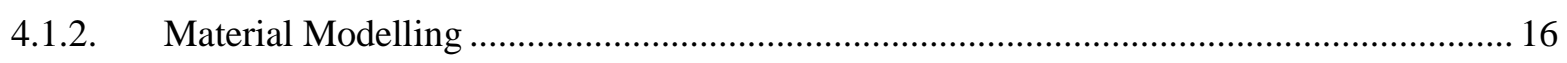

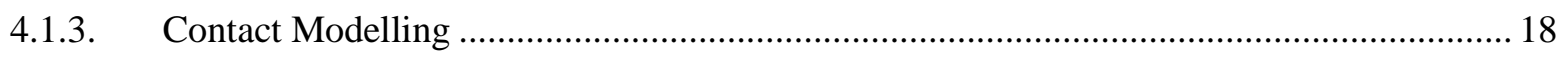

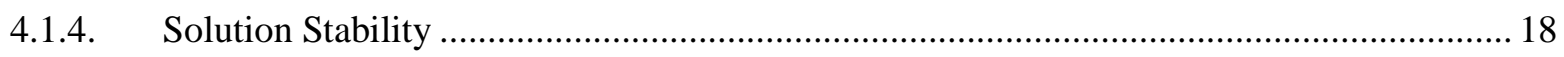

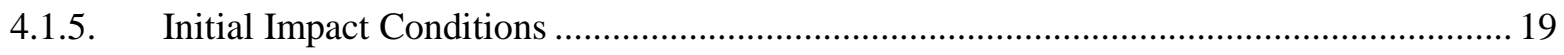

4.2. Condensation and Extraction of Super-Nodes .............................................................. 19 


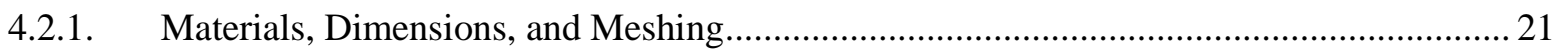

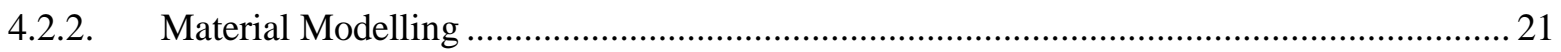

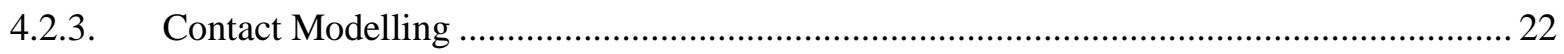

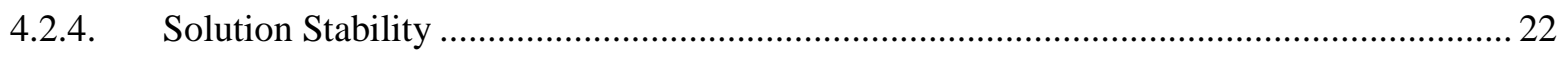

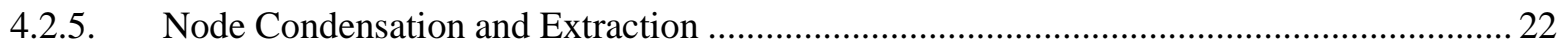

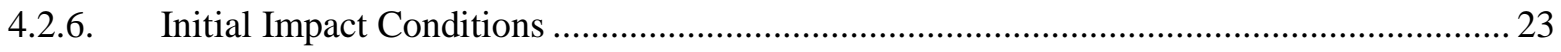

4.3. Effect of Ply-Compaction and Mesh Refinement on Computation Time and Solution Accuracy

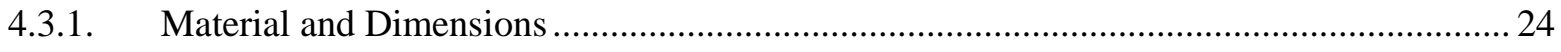

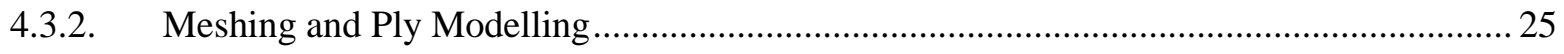

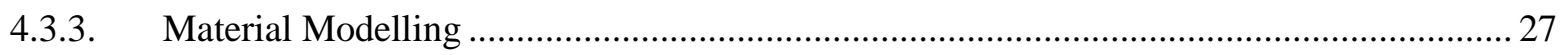

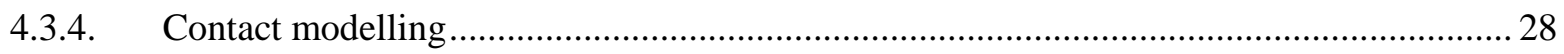

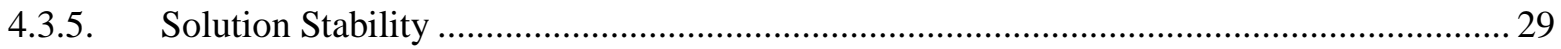

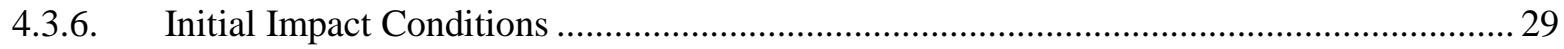

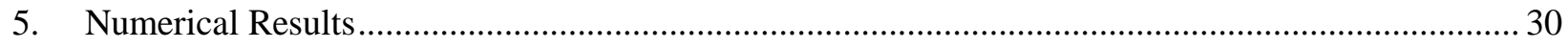

5.1. Low-Velocity and High-Energy Blunt Impact Response of All-Composite Fuselage Section .. 30

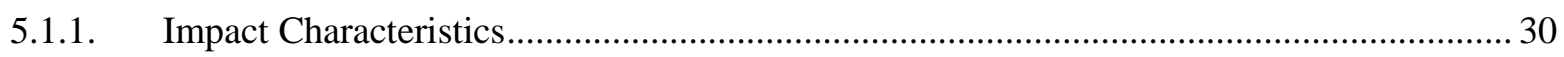

5.1.2. Damage Accumulation and Failure Sequence ........................................................... 32

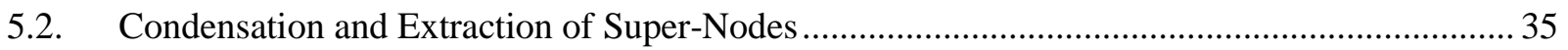

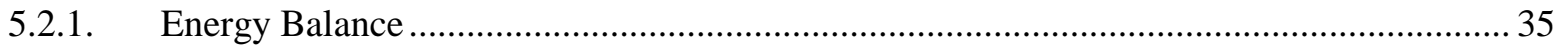

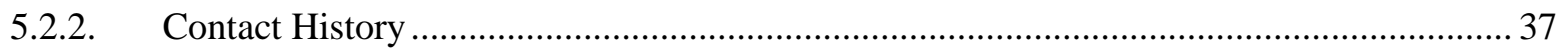

5.3. Effect of Ply-Compaction and Mesh Refinement on Computation Time and Solution Accuracy

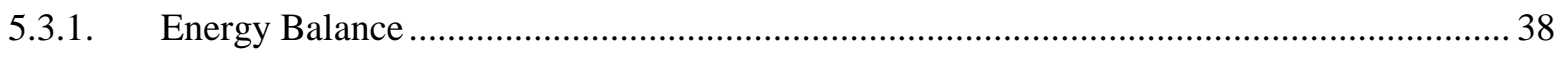

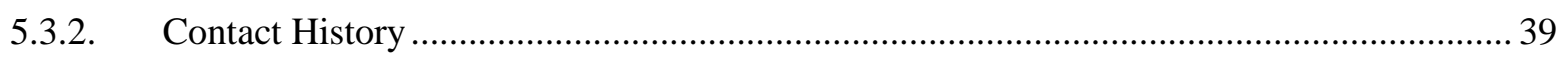

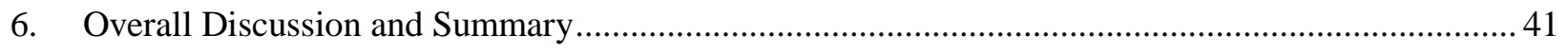

6.1. Low-Velocity and High-Energy Blunt Impact Response of All-Composite Fuselage Section .. 41 
6.2. Condensation and Extraction of Super-Nodes

6.3. Effect of Ply-Compaction and Mesh Refinement on Computation Time and Solution

Accuracy 46

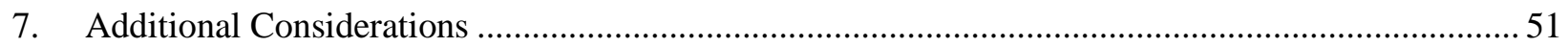

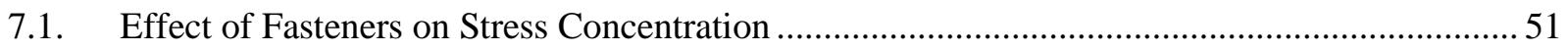

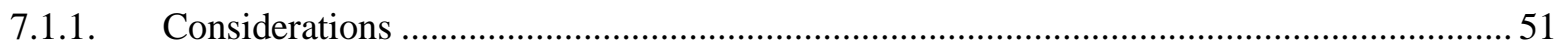

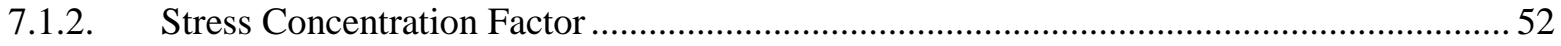

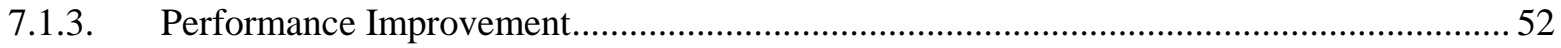

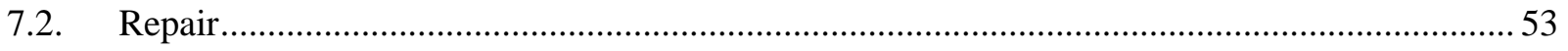

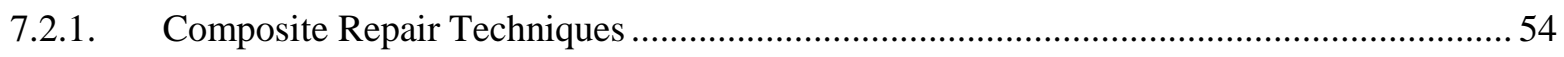

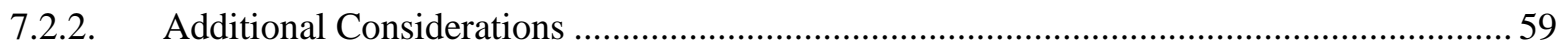

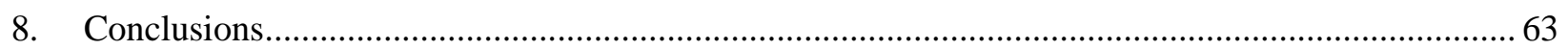

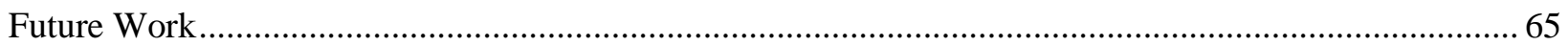

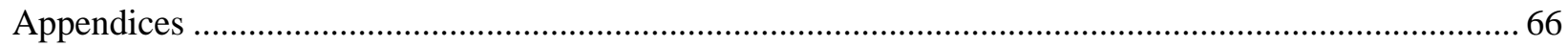

Source Code 1: Low-Velocity and High-Energy Blunt Impact........................................................... 66

Source Code 2: Supernodes - Part A (Original Case - Without Supernodes) ....................................... 74

Source Code 2: Supernodes - Part B1 (Creation of Supernodes) ..................................................... 78

Source Code 2: Supernodes - Part B2 (Supernode Implementation) ................................................ 81

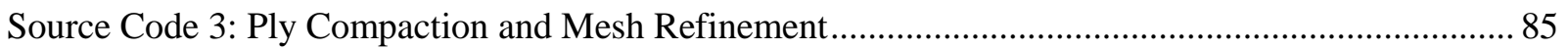

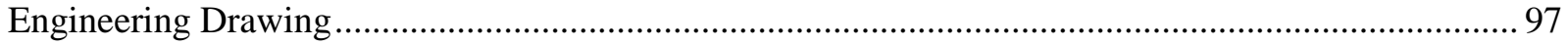

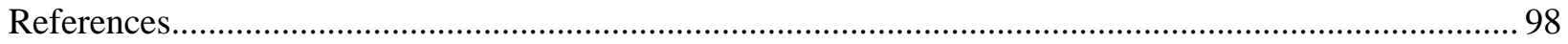




\section{LIST OF TABLES}

Table 4.1: Material properties for TORAY unidirectional (UD) and plain weave (PW) fabric [52-53] ... 17

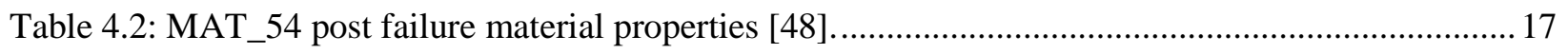

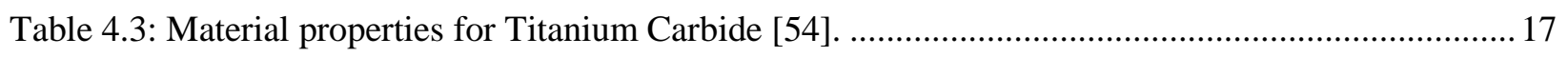

Table 4.4: Material properties for HTA/6376C carbon fiber/epoxy [5]..............................................21

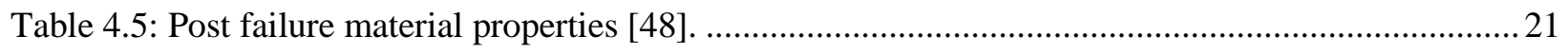

Table 4.6: Material properties for Al 7075-T6 [58] .......................................................................22

Table 4.7: Material properties for AS4/3501-6 carbon fiber/epoxy unidirectional prepreg [6, 62]...........27

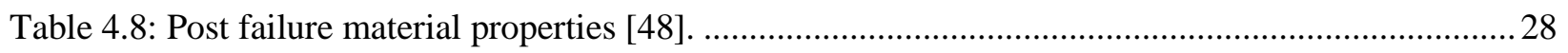

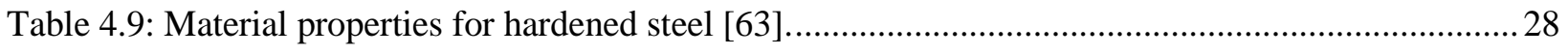

Table 6.1: Deviation in results between the original and supernode cases during impact........................45

Table 6.2: Experimental Results of 4.61 J and 6.24 J impact studies.................................................. 46

Table 6.3: Numerical results for $4.61 \mathrm{~J}$ impact energy. .................................................................... 46

Table 6.4: Numerical results for $6.24 \mathrm{~J}$ impact energy. ..................................................................... 47

Table 6.5: Computational time and solution accuracy deviation comparison for $4.61 \mathrm{~J}$ impact energy..... 49

Table 6.6: Computational time and solution accuracy deviation comparison for $6.24 \mathrm{~J}$ impact energy.....50 


\section{LiST OF FigURES}

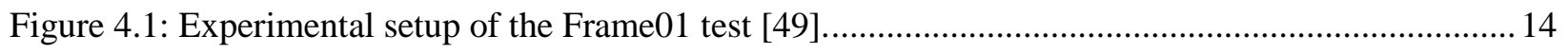

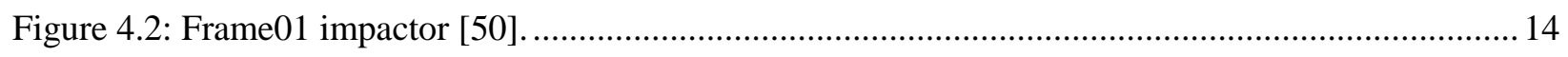

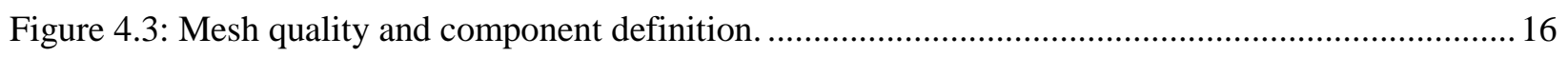

Figure 4.4: Model comparison for the two cases - original case (top) and supernode case (bottom).........20

Figure 4.5: Mesh comparison of the different element sizes. From top to bottom: coarse mesh, moderate

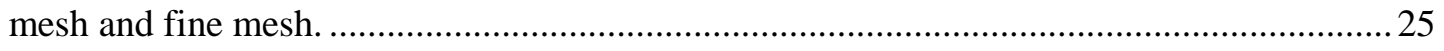

Figure 4.6: Illustration of different ply compactions. From top to bottom: first ply, second ply, third ply,

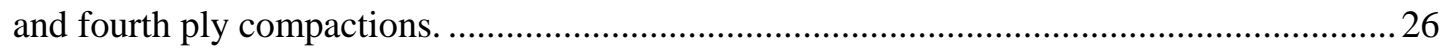

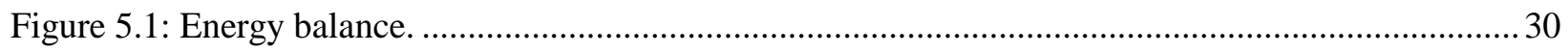

Figure 5.2: Force-time response for the skin-impactor contact. ......................................................... 32

Figure 5.3: Principal stress $(\mathrm{Pa})$ distribution prior to shear tie failures................................................... 33

Figure 5.4: Principal stress $(\mathrm{Pa})$ distribution at maximum internal energy ........................................... 33

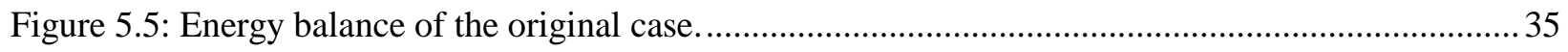

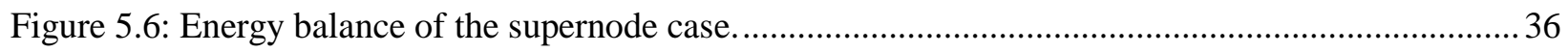

Figure 5.7: Contact force history for the original case ..................................................................... 37

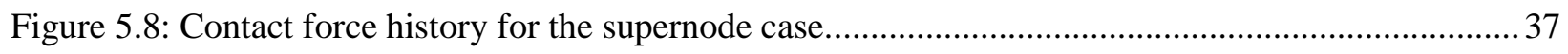

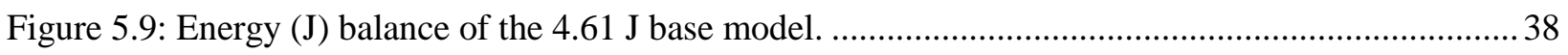

Figure 5.10: Force (N) vs. Time (s) response of the $4.61 \mathrm{~J}$ fourth ply moderate mesh compaction........... 40

Figure 6.1: Experimental force-displacement results of Frame01 test (left) and numerical study (right) [49].

Figure 6.2: Failures of shear-ties (top-left) and frames (top-right) in the Frame01 test, compared with end

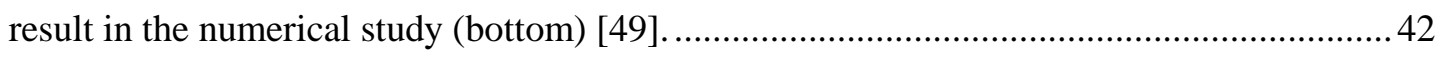

Figure 6.3: Principal stress (top) and deflection (bottom) comparison of the original (left) and supernode (right) cases. .43 
Figure 6.4: Principal stress comparison of the original and the supernode cases.................................. 44

Figure 6.5: Deflection comparison of the original and the supernode cases.......................................... 44

Figure 6.6: Load history response of the impactor-laminate. From left to right: experimental data and 4.61 $\mathrm{J}$ impact numerical response [6] 47

Figure 6.7: Force vs. Displacement response of the impactor-laminate of the experimental data and the 4.61 $\mathrm{J}$ impact response [6]. The numerical results are in ' $\mathrm{N}$ ' for load and ' $\mathrm{m}$ ' for displacement..... 48

Figure 6.8: Delamination and ply failure in multi-layered laminates. 49

Figure A.1: Engineering drawing of the low-velocity and high-energy blunt impact. 


\section{NomenClature}

$\begin{array}{cl}\sigma_{\mathrm{aa}} & \text { longitudinal applied stress } \\ \sigma_{\mathrm{bb}} & \text { transverse applied stress } \\ \tau_{\mathrm{ab}} & \text { applied in-plane shear stress } \\ \mathrm{E}_{\mathrm{A}} & \text { longitudinal elastic modulus } \\ \mathrm{E}_{\mathrm{B}} & \text { transverse elastic modulus } \\ \mathrm{G}_{\mathrm{AB}} & \text { in-plane shear modulus } \\ v_{\mathrm{ba}} & \text { minor Poisson's ratio } \\ v_{\mathrm{ab}} & \text { major Poisson's ratio } \\ \mathrm{B} & \text { transverse strength under tension } \\ \mathrm{S}_{\mathrm{C}} & \text { shear strength } \\ \mathrm{Y}_{\mathrm{T}} & \text { transverse strength under compression } \\ \mathrm{X}_{\mathrm{T}} & \text { longitudinal strength under tension } \\ \mathrm{X}_{\mathrm{C}} & \text { longitudinal strength under compression } \\ & \\ & \\ & \\ & \\ & \\ & \end{array}$




\section{AbBreviations}

FRP fiber reinforced polymer

BVID barely visible impact damage

CFRP carbon fiber reinforced polymer

FE finite element

CDM continuum damage mechanics

PMC polymer matrix composite

UD unidirectional

PW plain weave

BMI bismaelemide 


\section{INTRODUCTION}

In recent years, the usage of carbon fiber reinforced polymers in the aviation industry has increased significantly. While numerous advancements have been made in the field of testing and evaluation of advanced composites to increase its reliability, maintainability, and safety, improvements can still be made in the areas of design and analysis in order to save time and cost.

This thesis evaluates and presents several numerical methodologies for performing preliminary stress and structural analysis. These methods are compared against existing experimental data to validate their capabilities. The goal of the thesis is to effectively and efficiently reduce the time consumption and monetary expenses during the preliminary-stage of aircraft design and analysis, while maintaining the accuracy of results. Such studies have not been previously conducted and the author feels the results will help the aerospace industry greatly.

This thesis focuses on nonlinear 3D transient dynamic impact behaviour of composite structures. The impact behaviour is studied by means of three numerical studies and using the industry-standard finite element solver - LS-DYNA, a commercial code that can: 1) potentially replace the time-consuming and expensive experiments in the preliminary stage of aircraft design, 2) focus on the critical damage sites and thus reducing the model size (and computational cost) by creating supernodes and superelements and accurately solve for the loads being generated, and 3) determine the ideal combination of the number of plies and mesh refinement to save computational costs while maintaining solution accuracy.

The main aim of the first study is to develop and present a robust, reliable, yet computationally efficient preliminary design numerical simulation tool that can substitute or compliment experimental studies that are typically resorted to in order to understand the behaviour of stiffened aircraft skin panels under low-velocity, high-energy, blunt impacts. In particular, the tool is aimed to generate an adequate understanding of such important design issues as the damage and failure sequence, and the failure loads, locations and times in order to ultimately help structural designers develop optimal designs for impact resistance purposes.

The second study is a parametric study that analyzes the effectiveness of supernodes on design compliance and load generation. The first part of the study is to perform impact stress analysis on a composite plate under certain boundary conditions and loading condition. The second part recreates the first part by performing the same impact stress analysis, but instead using supernodes to reduce the model size and therefore increase the computational efficiency. For supernodes to be effective, the results of the two models should be the same, meaning, the loads generated are the same and the design being condensed and extracted using supernodes is the same. 
The third study is again a parametric study to understand the effects of ply compaction and mesh refinement on the computation time and the solution accuracy. The study is aimed to understand the critical parameters in composite numerical stress analysis that can enable the stress analysts to increase work efficiency. Due to the nature of the study, the material behaviour during the impact and the delamination locations and sequence will also be analyzed.

This thesis begins with a brief literature review on impact and the related damage types, associated failure modes, assessment techniques, and ways of controlling damage, presented in Chapter 2. Next, the generic details of the numerical model are presented in Chapter 3. The generic details are numerical modelling options that are applied to all the studies, and include the similar steps used in material modelling, contact modelling, and solution stability. Following, the individual numerical model details are presented in Chapter 4. These details are case-specific options applied, and include the differences in each study's material properties, laminate geometry and dimensioning, meshing, material modelling, contact modelling, solution stability, and initial impact conditions. After that, the results, discussion, and summary of each study is presented in Chapter 5 and Chapter 6. This chapter compares the effectiveness of the numerical studies and modelling techniques employed against the true experimental solutions in terms of loads generated, distribution of stresses and deformation, and the order of failure. Ensuing, Chapter 7 presents additional considerations that should be considered to make the model more accurate. These considerations include the effect of fasteners on stress concentration, and post-impact repair techniques. Finally, conclusions from the previous chapters and final remarks are presented in Chapter 8 . This chapter reiterates the most important findings, and discusses the usefulness of the numerical studies and modelling techniques employed. 


\section{LITERATURE SURVEY}

\subsection{Impact Damage}

In many industries, the application of fiber reinforced polymer (FRP) materials has seen a rapid growth in the past decade. FRPs allow for numerous direct and indirect benefits over the traditional metals and metallic alloys, which generally results in lighter weight structures. FRPs also have a better fatigue performance and resistance to corrosion compared to metals [1]. FRPs are naturally brittle and generally display a linear-elastic response up to failure without any plastic deformation [1]. One central issue in designing new FRP-based composite structures is the characterization of their mechanical properties and failure mechanisms [2]. This is because even slight deviations in the constituent materials (base materials or volume fraction) have a severe effect on the material properties. Moreover, damage in composites are different from those in metals because composite failure is a progressive accumulation of damage, including multiple damage modes and complex failure mechanisms [3].

Most primary aircraft structures are of the stiffened thin-walled types, which are now often manufactured using FRP composite materials. For implementation of FRP materials in aviation, an important consideration is their behaviour under dynamic loads such as impact, and their resistance to fatigue [3]. In aircraft structures, the dynamic interactions between structure and surrounding mediums are significant, and these interactions lead to a vast number of failure modes that need to be considered in the design process [4]. These composite materials are particularly vulnerable to impact damage and can result in numerous modes of failures, ranging from barely visible impact damage (BVID) to complete penetration [5]. Impact damage and accordingly complex progressive collapse of composite structures is very complex because of the highly nonlinear and dynamic event [3]. The complexity is further amplified because impact is a multiscale problem, since the composite damage is microscale level and the crash and impact loads are applied at a structural macroscopic level [3]. These impact induced damages can have a significant effect on the strength, durability, and stability of the structure [6]. The physical phenomena involved in an impact event are complex due to simultaneous damage mechanisms [7-8]. The resulting failure mode is a function of the type of loading, the lay-up sequence, and the boundary conditions of the structure [9]. Failure initiation can be in the form of fiber breakage, matrix cracking, and delamination between plies [10], which can lead to the significant decrease of material strength and stiffness, thus, severely reducing structural integrity and stability [1]. For safety reasons, it is important to have predictive design tools for simulating the response of the laminated composite structures under impact loading in order to understand the mechanisms of delamination, energy absorption and failure [1].

Fiber properties vary from excellent impact damage resistance as exhibited by glass fiber composites, good penetration resistance of Kevlar composites (aramid fibers), to the low damage resistance 
of carbon fibers [4]. The high toughness of glass fibers that leads to dispersal of deformation energy to large portions of the structure makes them favourable against impact. Conversely, despite the high elastic modulus, the intrinsic brittleness of carbon fibers make them highly sensitive even to small amounts of impact energy [4]. For this reason, impact damage is an even a bigger concern when Carbon Fiber Reinforced Polymers (CFRPs) are used [11-13], as is the case in more recent applications. CFRPs are among the most commonly used advanced composite materials in the aerospace and automotive industries. Therefore understanding impact damage is a key objective in these industries since impacts result in significant strength loss and accounts for a considerable part of the repair costs [7, 12-13].

Impact damage may arise during manufacturing, maintenance and/or service operation [7]. During service operation, such as take-off, landing or taxiing phases, impact damage can occur in the form of lowvelocity or high-velocity impacts. A key difference between the two is in the form of damage developed. Damage is much more localized in high-velocity impact since the impact energy is dissipated to a very small volume. High-velocity impact is categorized by penetration-induced fiber breakage. On the other hand, during low-velocity impacts, damage is initiated by matrix cracks which create delaminations at interfaces between plies of different orientations [3]. Furthermore, the energy level of the impacts can be categorized into two types: low-energy (low-velocity/low-mass) and high-energy (low-velocity/high-mass, high-velocity/low-mass or high-velocity/high-mass). According to Faggiani and Falzon [5], low-velocity impact is associated with an impact event which is long enough for the whole structure to respond to the impactor by absorbing energy elastically and possibly through the creation of evenly spread localized damage. The long contact time also produces a global structure deformation with undetected internal damage at points far from the contact region [3].

In the aerospace industry, high-energy impacts consisting of low-velocity and high-mass are a subject of great interest due to the resulting invisible surface damage and severe sub-surface damage they cause, often referred to as BVID. BVID generated from blunt impact tends to be concentrated internally in the form of delamination of plies and matrix cracks that show very little visual evidence on the surface, and can severely effect on the performance and safety of composite structures [14]. BVID leads to significant reductions in the stiffness and strength of the structure by propagating under loading [5, 7, 15-16]. Keeping these facts in mind, BVID can go unnoticed during a routine inspection. This makes BVID a major reason for catastrophic damage and failures [3]. On the other hand, high-energy impacts due to high-velocity and low-mass usually lead to bending damage on the distal surface and an approximately circular internal delamination, followed by fiber splitting and perforation or shear failure [15]. Impact damage takes place in at least two phases [15]: 1) dynamic compaction of the composite plate which is being compressed ahead of the colliding object (projectile), and 2) delamination of plies in the region of the impact site. However, the exact nature of the damage will depend on the properties of the impacting object and of the structural 
material [15].

\subsection{Impact Failure Modes}

Impact failure modes vary significantly for anisotropic materials. The energy absorbed during the impact process is often very large. That energy is dissipated by a combination of failure modes, and lead to significant reductions in the load carrying capabilities of the structures [3]. Common failure modes are dependent on several parameters such as type of load applied, geometry, material system, lay-up, impact velocity and impact location [17-18]. Types of damage that can occur due to impact are fiber pullout and shear failure, matrix cracking, debonding, interlaminar damage, and delamination, of which delamination and debonding are the major failure modes. Delamination areas increases with the impactor mass, because with the increase of mass, flexural behaviour of the laminate becomes predominant, resulting in prolonged contact duration which gives delaminations more time to develop [4]. Delamination causes severe degradation of tensile and compressive properties [4, 19]. Delamination between plies occurs in the interlaminar (resin rich) regions where the axial and the bending stiffness differs mainly due to different fiber orientations [14]. The spread of delaminations over wide structural areas can also severely compromise the residual compressive strength, possibly even lower than the limit load for which the structure was initially designed [3]. Delamination can occur by matrix cracks in both opening and shear modes [15]. On the other hand, fiber debonding often occurs at the tip of a crack in the matrix material. This crack can propagate inside fiber material, but it can also propagate along the fiber-matrix interface causing fiber debonding [14].

The location of the impact site is another important criterion for understanding impact damage. A study conducted by Breen et al. [20] shows the damage formation and levels of strength reduction are different for central and edge impacts. Generally, an edge impact causes a greater reduction in compressive strength while a central impact causes more tensile strength reduction. Each impact may cause delaminations to occur at multiple interfaces through the thickness of the specimen. The size of the delaminated area can vary based on the location of the impact. Generally the density of fiber cracks is higher for a central impact than an edge impact, although the lengths of some individual cracks are larger for an edge impact [20]. Edge impact causes more deformation in the material and therefore, a greater delaminated area and a greater reduction in the stiffness. Thus, an edge impact leads to higher reduction in the compressive strength. The greater deformation also leads to larger individual cracks. Central cracks see higher density of fiber cracks because the deformation is not as high which limits the damage to a particular area. It is also observed that peak contact force in an impact event increases with the thickness of the CFRP as the contact time decreases [21]. 
Other factors of importance are the loading rate, the impact energy, orientation of the fibers and the stacking sequence. The loading rate is dependent on the input potential energy since a higher potential energy will lead to higher kinetic energy, leading to drop in the time of impact event [22]. The nature of the bond has been shown to depend on the loading rate, leading to a drop in the post-peak stiffness. In a study by Ghelli and Minka [23] on compression after impact tests on small and large specimens, in smaller specimens, compressive failure occurs at the impact zone and the pre-existing delaminations from impact reduce the residual compressive strength by up to $15 \%$. Depending on the impact energy the stacking sequence has little importance. In larger specimens, the orientations of the external fibers exhibit significant differences in compressive behaviour, including different buckling deformation shapes. Moreover, delaminations produced by impact can change the buckling mode and/or lower both the critical load and the ultimate strength (by up to 25\%), depending on the configuration [23]. Since smaller specimens have lower internal strain energy, certain impacts which may be considered to be insignificant for larger specimens become significant for the smaller specimens. The impact site becomes the critical location because it sees the significant amount of energy in a short duration. Therefore, in smaller specimens, the compressive failure occurs at the impact zone.

In the case of CFRPs, the modes of failure are heavily dependent on the properties, geometry, and the impact velocity of the projectile [24]. CFRP laminates subjected to low-velocity impact with sufficient energy can see various damage types such as matrix cracks, delaminations, fiber fracture, fiber-matrix debonding and fiber pull-out [21]. These damage forms cause reduction in structural stiffness and strength, leading to growth of the damage under further loading and eventually fracture. The projectile sharpness, the fiber reinforcement, and the initial contact all play major roles in determining the failure mode of CFRPs. Experimental studies have shown that a blunt impactor pushes the material inward and a sharp one pushes the material sideways resulting in different damage mechanisms [25]. As for the fiber reinforcement, it has been experimentally shown that at low-velocities, elastic deformation of the fibers dominates behaviour under impact [26]. Moreover, the damaged zone after low-velocity impact has been shown to vary with both the impact energy and the duration [27]. As a result, it is vital to know all of these lowvelocity impact conditions and duration when attempting to predict the damage caused to stiffened CFRP panels and the resulting property degradation.

\subsection{Impact Assessment}

CFRP structures are typically thin-walled and the expected loading direction is parallel or at a small angle to their axial direction [28]. Due to this, laminated CFRPs generally have poor out-of-plane impact responses. Generally, a CFRP's impact response is determined by the experimental behaviour during drop 
tests. The key parameters of impact damage are mass, velocity, and geometry of impact source [4]. In drop tests, damage that takes place in the matrix and fiber-matrix interface is a function of drop height and deflection level. If there is sufficient ductility and internal strain energy in the test sample to absorb the applied energy, some of its released elastic energy causes a rebound that is characterized by a reduction in deflection of the test sample [29]. Accordingly, the impact energy absorbed by the laminate is one of the most common indicators for impact assessment. A study showed low-energy impact had more significant influence on tensile strength for thinner than for thicker laminates [30]. Moreover, the energy required to penetrate the laminates was proportional to the thickness of the composites [30]. Similarly, the difference in geometry and support fixture produces different impact response and damage. It was found that smaller circular specimens get subjected to more extended delamination than larger rectangular specimens after impact with the same energy input. In the rectangular plates, both the impact response and the failure modes showed differences depending on the lay-up, which were attributed to the difference in the flexural stiffness due to orientation of the fibers in the external layers [23].

The speed of impact also plays an important factor in amount and the kind of damage. When comparing low-speed impact with high-speed impact for the same impact energy, it was found that [15]: 1) the energy absorbed during low-speed impact was about $40 \%$ lower than of the high-speed impact, 2) the low-speed impact damage area was observed to be 20-30\% smaller than the high-speed impact, and 3) the damage area increased as the mass decreased for high-speed impacts. In low-speed impacts, tow cracks seen on the impact surface propagate outwards from the outer rim of the dent suggesting that the dent formed first and that, once this had formed, subsequent damage in the form of tow splitting and inter-tow cracks developed at the edge of the dent. The dent is formed when the contact stresses from the impact cause matrix-dominated failure. A further increase in contact force can result in an increasing area of delamination damage around the dent rim, eventually leading to tow failures in the form of tow and fiber splitting [15].

Comparative impact studies conducted on low-speed and high-speed impacts of laminates show that CFRPs show good strength under low velocity impacts. However, they collapse unpredictably with both fiber cracks and separation from matrix as the impact conditions (mass or impact energy) are increased [31]. The study by Rhymer et al. [32] shows that wave dominated impacts typical of small mass (highspeed) behave differently than large mass (low-speed) quasi-static-like impacts, with a major difference being that the deflection and force history are out of phase for the small mass dynamic event.

\subsection{Impact Damage Control}

The damage resulting from low-velocity impacts can be controlled in numerous ways. Viable 
approaches include optimizing stiffness, lay-up orientation, and stacking sequence. The empirical relationship of the delamination area with absorbed energy and with maximum contact force measured during impact appears to be independent of the test configuration and stacking sequence [23]. However, at higher impact energies, the stacking sequence has a significant effect on the residual tensile strength. Initially, the tensile stiffness and the strength of angle-ply stacking sequence CFRP laminates are much lower than that in cross-ply stacking sequence laminates. However, after impact, the angle-ply stacking sequence used in CFRP laminate will preserve more tensile strength compared with that used with crossply stacking sequence [21]. Similar conclusions were made by Appleby-Thomas et al. [33] in their study of differing impact energies and CFRPs of different configurations. As the impact energy is increased delamination between fiber plies tend to occur (ex: Debonding/cracking within the matrix), before eventual fiber failure at elevated velocities. Differing threshold energies (energy below which no damage occurs) and rates of damage evolution are taken as an indication of the importance of fiber/matrix properties in determining impact resistance. The propagation of elastic waves in anisotropic material differs in many aspects from that in isotropic materials [34]. Woven fiber lay-ups are consistently found to resist damage from projectiles more effectively than unidirectional (UD) arrangements. This behaviour is attributed to the ability of the woven fibers to propagate stress away from the point of impact in a more even manner [33]. UD laminates are also less effective against impacts than woven laminates, both below and above the ballistic limit, because of the difference in flexural behaviour of its plies [35]. Studies by David-West et al. [36] conclude that symmetric laminates with multiple ply orientations have the best endurance against repeated low-energy impacts, and balanced symmetric CFRP has proven to be much safer in respect to impulse loading. Lastly, the effect of the boundary loading can be diminished by increasing the number of laminates [37]. 


\section{Numerical Model Generic Details}

In industries that require load-bearing structures, it is advised to conduct a numerical study prior to experimental test whenever possible. Physical testing of components can be both time and cost consuming, so the development of robust numerical modeling tool is essential [38-39]. Currently, the incomplete understanding of the effects of impact on the performance of composite structures result in overly conservative designs [5]. This provides a strong incentive to create a numerical impact model for FRPs. The finite element (FE) method allows for the development of such complex numerical models - to simulate impact on composite structures under realistic boundary conditions and loads. These models can replace real and expensive testing in laminated structures with some degree of approximation [3]. Additionally, the FE codes are usually of open-architecture which allows the modification of existing or creation of new numerical damage models for both intralaminar and interlaminar failure, and to accurately capture these damage mechanisms. The codes can be specialized to predict damage parameters in laminate aircraft structures at certain conditions [3]. The code can also be enhanced to accurately predict the initiation and propagation of damage in impacted composite structures [5]. Lastly, computational methods can also be utilized to reduce the certification and development costs by predicting the structural integrity of composite structures under impact [3].

The dynamic response of composite structures subjected to transient dynamics loading has been studied for many years using analytical, numerical and experimental techniques [3]. Impact damage might appear at micro, macro and meso levels, leading to significantly different approaches in their numerical prediction. The parameters playing significant role in the process are mechanical properties, type of matrix and fiber, the source of impact loading, the kinetic energy and geometry of impactor [4]. Traditionally, impact damage models rely on either analytical calculations or extensive experimental data. However, analytical predictions of the impact damage resistance and tolerance of composite laminates are overly simplified which sometimes make it unreliable [3]. The simplification is necessary because the anisotropic material properties in conjunction with the transient type of loading create a very complex mechanical response [40]. Moreover, composite components are often modified by structural elements, such as openings or stiffeners, which are mechanically critical [40]. These enhancements add further complexity in obtaining an analytical solution to the problem. On the other hand, testing each promising design is time consuming and costly. Low cost numerical testing by means of FE analyses can replace most of the actual impact testing of laminates. Once the dynamics of the impact phenomena and the damage mechanisms are correctly simulated, progressive failure analyses can be a valuable tool in the accurate prediction of impact damage resistance of composites [3].

The numerical simulations are performed using the nonlinear three-dimensional transient dynamic 
software LS-DYNA SMP D 971 R7. LS-DYNA is an accepted tool used in the aerospace industry [41].

In the studies, a simplified representation of the composite structures is modeled because only the macroscale modelling is applied. A relatively low amount of elements are needed to make the mesh for these simplified models, so it is relatively cheap to compute. However, microscopic information is lost [14]. Simulations performed on these macromechanical models presume the composite material to be homogeneous [14]. To make the studies as accurate as possible, several generic steps are taken to ensure the accuracy of the results. It is necessary to predict accurately where the damages will appear, how they will spread, and when they will eventually form a fracture and fail [3]. These steps are incorporated via the material modelling, contact modelling and the solution stability. These steps are incorporated in all the studies in the following sections.

\subsection{Material Modelling}

In all the studies, the ply elements are shell elements generated using LS-DYNA's '4N_Shell' option, and the impactor elements are generated using LS-DYNA's 'Sphere_Solid' option. The shell elements are fully integrated quadrilateral shell elements (Type 16), and the impactor elements were solid quadrilateral elements.

Among all the failure criteria available for composite materials, Tsai-Wu, Chang-Chang and Hashin are the most widely used to predict the level or degree of damage, fracture and failure of composite structures [3]. LS-DYNA's MAT_54 is used to model the plies. The material model is of interest for structural damage simulations because it is a relatively simple and requires minimal input parameters. MAT_54 uses Chang-Chang failure criterion, which is a modified version of the Hashin failure criterion. The Hashin failure criterion considers the failure of fiber and matrix in tension and compression separately. The Chang-Chang criterion expands on the Hashin failure criterion by including the non-linear shear-stress behaviour of laminas and defining the post-failure degradation rule so that the behaviour of the laminate can be analyzed after each successive lamina failure [42]. In other words, Chang-Chang criterion considers four types of damage and defines stress dependent damage variables that vary from 0 (no damage) to 1 (fully broken). When the damage variable equals one, the material loses its strength and hence some of the stress components are set to zero [35]. Chang-Chang has been widely employed to model the CFRP laminates in FE studies [35].

The governing equations for Chang-Chang failure criterion are as follows [43]:

(a) Tensile fiber failure mode $\left(\sigma_{a a}>0, \sigma_{\mathrm{aa}}>0\right.$,fiber rupture): 


$$
\left(\frac{\sigma_{a a}}{X_{t}}\right)^{2}+\beta\left(\frac{\tau_{a b}}{S_{c}}\right)^{2} \geq 1
$$

Upon failure, $E_{a}=E_{b}=G_{a b}=v_{a b}=v_{b a}=0$.

(b) Compressive fiber failure mode $\left(\sigma_{a a}<0\right.$, fiber buckling or kinking):

$$
\left(\frac{\sigma_{a a}}{X_{c}}\right)^{2} \geq 1
$$

Upon failure, $E_{a}=v_{a b}=v_{b a}=0$.

(c) Tensile matrix failure mode $\left(\sigma_{b b}<0\right.$, matrix cracking under transverse tension and in-plane shear):

$$
\left(\frac{\sigma_{b b}}{Y_{t}}\right)^{2}+\beta\left(\frac{\tau_{a b}}{S_{c}}\right)^{2} \geq 1
$$

Upon failure, $E_{b}=G_{a b}=v_{a b}=0$.

(d) Compressive matrix failure mode $\left(\sigma_{b b}>0\right.$, matrix cracking under transverse compression and in-plane shear):

$$
\left(\frac{\sigma_{b b}}{2 S_{c}}\right)^{2}+\left[\left(\frac{Y_{c}}{2 S_{c}}\right)^{2}-1\right]\left(\frac{\sigma_{b b}}{Y_{c}}\right)+\left(\frac{\tau_{a b}}{S_{c}}\right)^{2} \geq 1
$$

Upon failure, $E_{b}=G_{a b}=v_{a b}=v_{b a}=0$.

Material model MAT_20 is used to model the impactor. The input parameters for MAT_20 are the density, elastic modulus and Poisson's ratio. These input parameters are enough to generate basic material and mass properties for the impactor, which in turn generates the initial kinetic energy and the total energy of the system. The rigid body does not deform, hence, it does not generate any stresses and strains as it comes into contact with adjacent parts. This makes the application of MAT_20 very effective in terms of computation cost.

PART_COMPOSITE option card is used to model the different layers of the laminate. The ply thickness, material model and ply orientation are defined on this card. The total thickness of the composite shell is the sum of each individual ply thickness.

Under impact, certain material applications require strain rate to be considered such as in the impact of glass fiber composites. However, in the case of carbon or aramid fibers, strain rate is not that influential [4]. Therefore, in all the studies, strain rate effects are neglected because all studies employed carbon fibers. 


\subsection{Contact Modelling}

AUTOMATIC contacts are used to model the interlaminar behaviour. These contacts are preferred over the regular "non-automatic" contacts because they perform a two-way penetration check. 'AUTOMATIC' contacts check both the slave nodes and the master nodes for penetration making the results more reliable. However, the added check increases the computation cost by a factor of 2 [44].

\subsection{Solution Stability}

The orientation of the material coordinate system and thus the response of orthotropic shells can be very sensitive to in-plane shear deformation depending on how the element coordinate system is established. To minimize this sensitivity, objective stress update in combination with invariant node numbering for the local element coordinate system is defined on the CONTROL_ACCURACY card [45].

Classical lamination theory is used to define the material properties of the thin laminate from the material properties of the individual plies. The theory assumes the plies to have perfect bonding with one another, and the laminate normal direction to remains straight, unstretched, and normal to the neutral plane. Laminate shell theory is activated using LAMSHT parameter in the CONTROL_SHELL card to correct for the assumption of a uniform constant shear strain through the thickness of the shell [45]. NFAIL1 and NFAIL4 are also activated in CONTROL_SHELL to automatically delete the highly distorted shell elements. The highly distorted shell elements lead to instabilities in the solution [46].

It is vital to avoid any initial penetrations in the model in order to accurately capture the impact. ISLCHK is activated in CONTROL_CONTACT to conduct a complete check for any initial penetrations. FRCENG in CONTROL_CONTACT is also activated to account for frictional energy that occurs due to the numerous contacts defined in the model. Without accounting for the frictional energy, the energy balance would be incomplete.

Hourglass are non-physical modes of deformation that is can be regarded as forms of losses in the model. Hourglassing can be reduced by refining the mesh or by using appropriate element formulations [47]. HGEN in CONTROL_ENERGY is activated to include the hourglass energy in the energy balance. The non-physical hourglass energy must be small $(<10 \%)$ relative to the peak internal energy of all the individual parts to confirm the validity of the solution [47].

SLNTEN in CONTROL_ENERGY is also activated to account for the sliding interface energy dissipation in the model. 


\section{Numerical STUdies}

The physical phenomena involved in impact events are complex, limiting the applicability of closed form analytical solutions. The FE tools enable analysts and designers to simulate both the impact and the effects of impact on component or structural strength. The FE simulations help analysts to identify areas of the component that call for additional reinforcement or require design review [3]. LS-DYNA allows for the development of such complex numerical models, and to simulate impact on composite structures under realistic boundary conditions and loads.

To solve problems, LS-DYNA utilizes an explicit integration formulation which is computationally very expensive. For computation efficiency, shell elements are used to represent thin-walled structures. Shells can represent membrane stresses and out-of-plane deformations very well but are inadequate for modeling crush behaviour (because the latter is a bulk response problem) [28]. In shell elements, one also has the option of grouping the plies of the laminate into one single element to reduce computational effort, but this method does not capture the interlaminar behaviour such as delamination [48].

LS-DYNA uses various material cards to help itself select the solution methodology, which leads to small deviation from the true solution as one or more failure initiators get neglected. Embedded in these material cards are failure models based on continuum damage mechanics (CDM), which describes the gradual deterioration of the elastic properties of a material [28]. Failure in polymer matrix composites (PMCs) is initiated at the microscopic level, with length scales governed by fiber diameters. The length scale of aircraft is in meters and this poses severe challenges for FE analysis of composite structures. By using mesoscale models based on CDM, it is possible to define material models for FE codes at the structural macro level [3]. CDM has been applied to a variety of materials including metals and composites [28]. Most of the composite CDM models are developed based on experimental evidence of damage and damage evolution in laminated composites subjected to cyclic or long-term service load. Therefore, these models are only valid within a certain range and require extra caution when being extended beyond that range [28].

\subsection{Low-Velocity and High-Energy Blunt Impact Response of All-Composite Fuselage Section}

The main aim of this study is to develop and present a robust, reliable, yet computationally efficient preliminary design numerical tool; that can substitute or compliment experimental studies that are typically resorted to in order to understand the behaviour of stiffened aircraft fuselage sections under low-velocity, high-energy, blunt impacts. In particular, the tool is aimed to generate an adequate understanding of important design issues such as the damage and failure sequence, and the failure loads, locations and times, 
in order to ultimately help stress engineers and structural designers to develop optimal impact resistant designs.

The problem simulated in this numerical study is similar, in an overall sense, to the 'Frame01' experimental study investigated by Kim et al. [49] on low-velocity impacts on composite fuselage sections. Figure 4.1 and Figure 4.2 display the experimental setup of the Frame01 test.

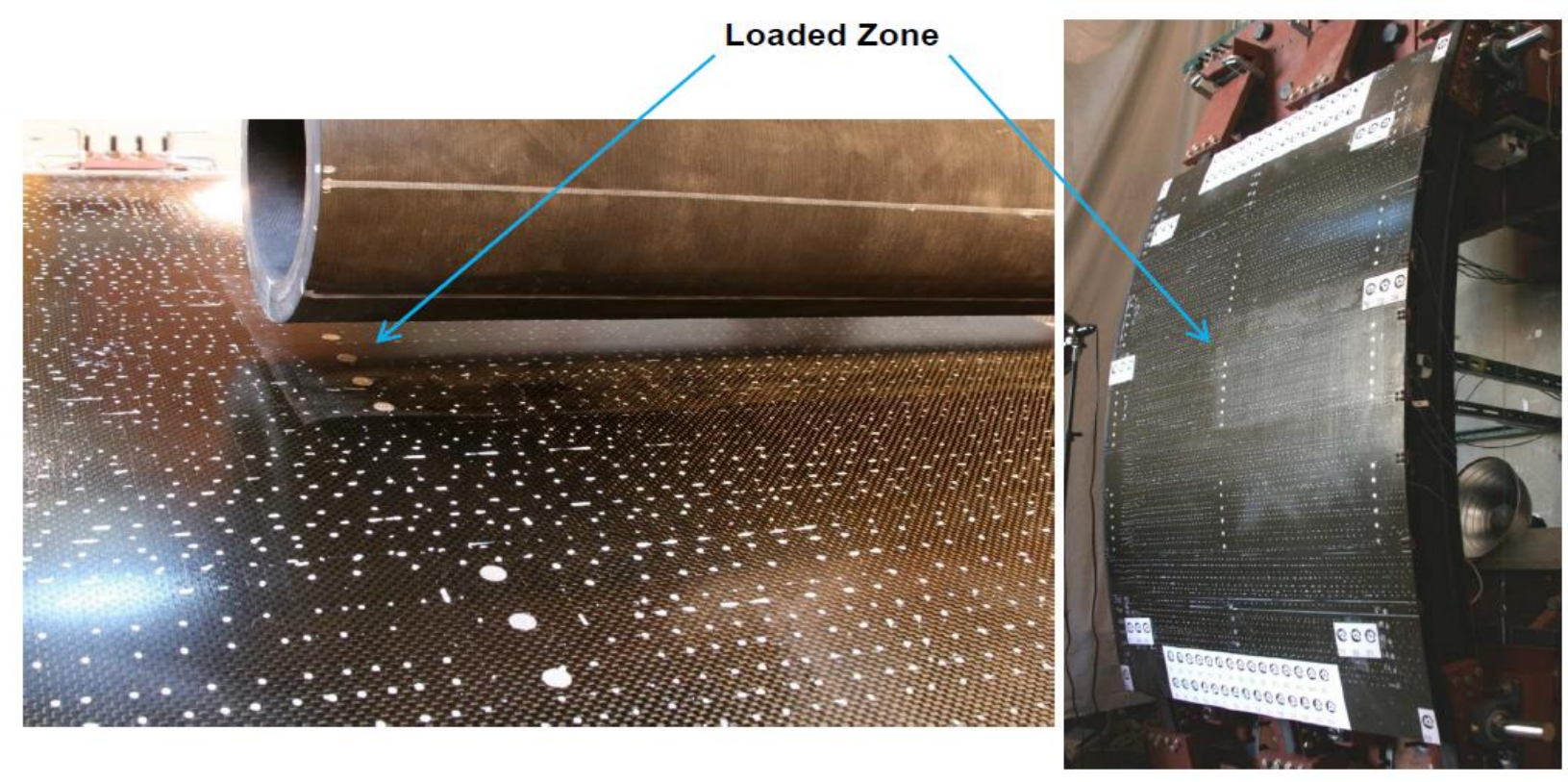

Figure 4.1: Experimental setup of the Frame01 test [49].

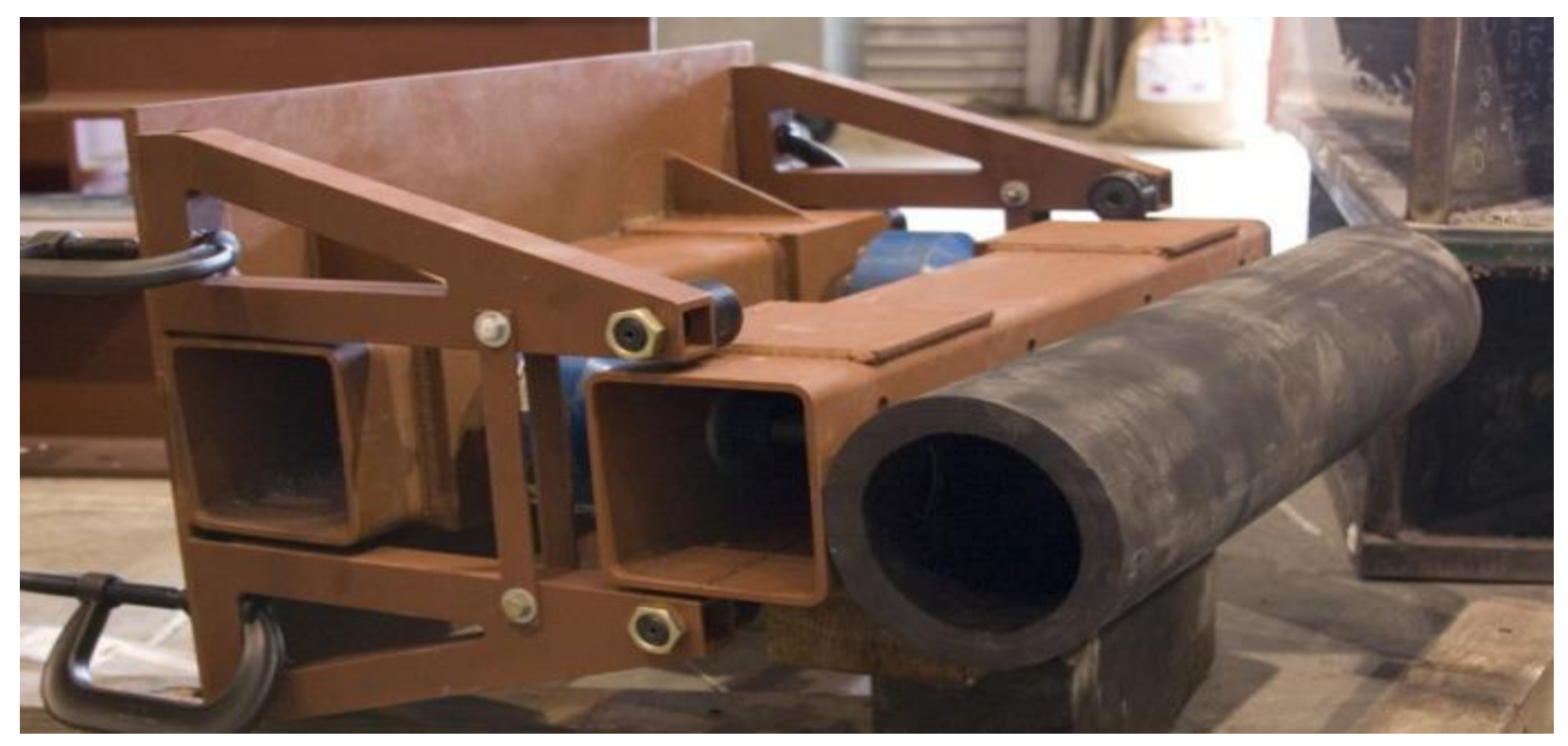

Figure 4.2: Frame01 impactor [50]. 
The following sections include the specific controls applied on top of the generic controls mentioned in 3 , to make the case study more accurate.

\subsubsection{Materials, Dimensions, and Meshing}

The model is of a stiffened fuselage section impacted by a low-velocity and high-mass impactor. The fuselage section consists of a skin, 4 stringers, 3 frames, and 15 shear ties. The impactor is a filled (solid) cylinder. The selected geometry and materials are similar to those adopted by Kim et al. [51] in a study on the impact damage formation on composite aircraft structures. The materials used for the current study are TORAY T700GC-12K-31E/\#2510 unidirectional (UD) Tape and TORAY T700SC-12K50C/\#2510 Plain Weave (PW) Fabric. The density of the UD tape is $1.54 \mathrm{~g} / \mathrm{cm}^{3}$ and $1.50 \mathrm{~g} / \mathrm{cm}^{3}$ for the PW fabric. The skin layup is $\left[0^{\circ} / 45^{\circ} / 90^{\circ} /-45^{\circ}\right]_{2 s}$ made up of UD tape with an additional $\left[0^{\circ}\right] \mathrm{PW}$ fabric on each side. The stringer layup is $\left[0^{\circ} / 45^{\circ} /-45^{\circ} / 90^{\circ} / 45^{\circ} /-45^{\circ} / 0^{\circ}\right]_{\mathrm{s}}$ of UD tape. The frame layup is $\left[ \pm 45^{\circ} / 0^{\circ} /-90^{\circ}\right]_{3 \mathrm{~s}}$ of PW fabric with an additional $\left[0^{\circ}\right]$ fabric on each side. The shear tie layup is the same as the frame layup, but without the $\left[0^{\circ}\right]$ fabric on the outer faces.

The thicknesses of the skin, stringers, frames and shear ties are $2.8210 \mathrm{~mm}, 2.0986 \mathrm{~mm}, 2.9582$ $\mathrm{mm}$ and $2.5356 \mathrm{~mm}$, respectively. The overall dimension of the fuselage section is $1.8288 \mathrm{~m}$ by $1.1684 \mathrm{~m}$. The skin dimensions are $1.7272 \mathrm{~m}$ by $1.1684 \mathrm{~m}$. The stringer dimensions are $0.2055 \mathrm{~m}$ by $1.1684 \mathrm{~m}$. The frame web is $0.1500 \mathrm{~m}$ and the frame flange is $0.0400 \mathrm{~m}$. The shear tie dimensions are $0.1250 \mathrm{~m}$ by 0.0600 $\mathrm{m}$. The radius of curvature of the skin and the top surface of the frames are $5.376 \mathrm{~m}$ and $5.167 \mathrm{~m}$. The length of the impactor is $1.1684 \mathrm{~m}$ and the diameter is $0.4000 \mathrm{~m}$. The meshed FE model is shown in Figure 4.3. The element sizes of the skin, stringers, frames and shear ties are $0.040 \mathrm{~m}, 0.020 \mathrm{~m}, 0.015 \mathrm{~m}$, and $0.010 \mathrm{~m}$. The element sizing is discussed in more details in the Solution Stability section. The fuselage elements are fully integrated quadrilateral shell elements (Type 16) generated using LS-DYNA's 'Auto Mesher' option. The impactor elements are generated using LS-DYNA's 'Shape Mesher' option, with 20 nodes across the cross-section that are placed at 5 equally spaced locations along the length of the cylinder, leading to differing element sizes in the radial direction. Mesh refinement is applied along the top-half edge of the impactor using the 'Split/Merge' option to distribute the mass more evenly during impact. All of the impactor elements were solid quadrilateral elements. The entire model consists of 14840 shell elements and 555 solid elements. 


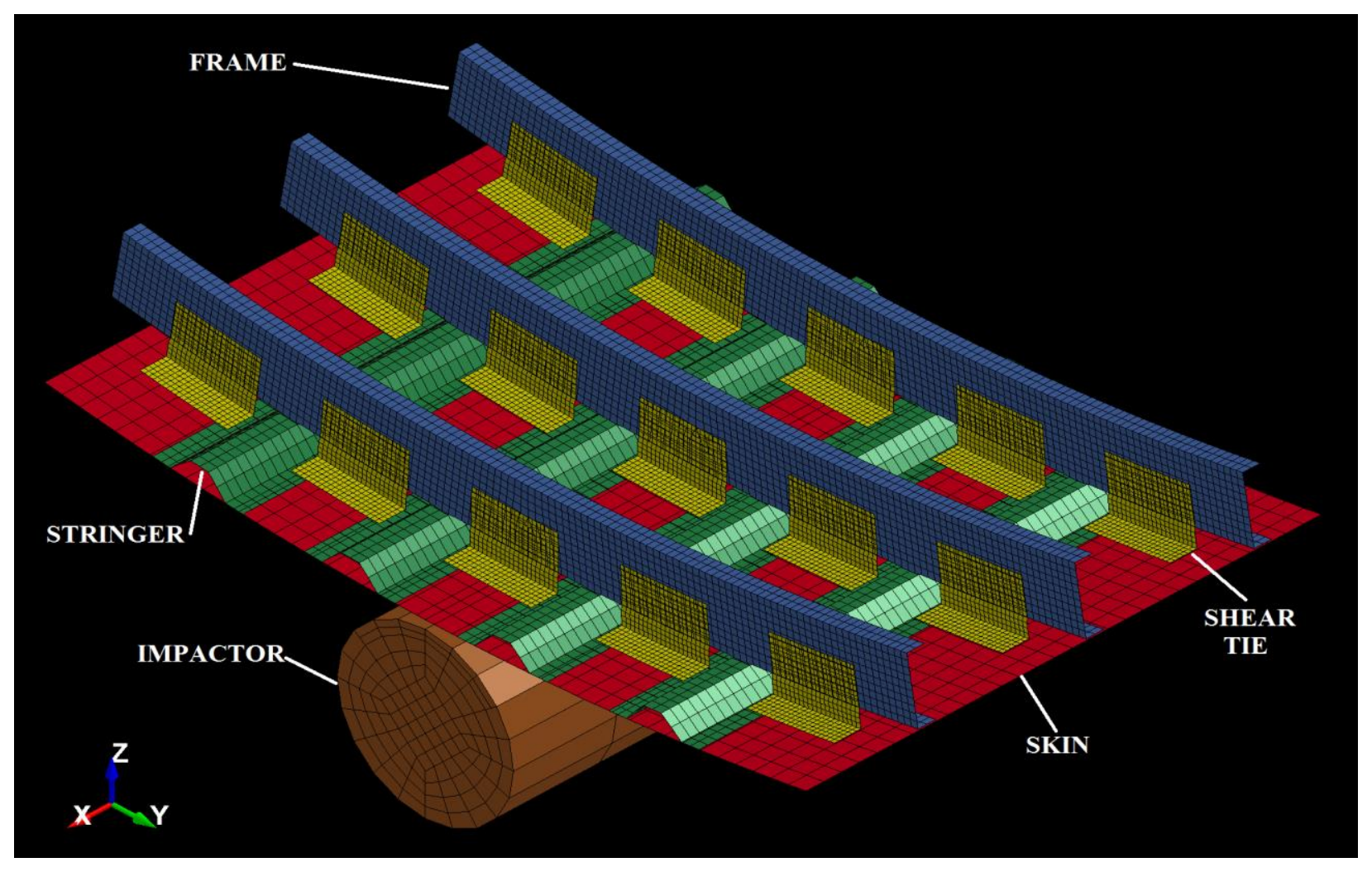

Figure 4.3: Mesh quality and component definition.

\subsubsection{Material Modelling}

LS-DYNA's MAT_54 material card is used to model the composite materials - skin, stringers, frames, and shear ties. The material properties of TORAY T700GC-12K-31E/\#2510 UD Tape and TORAY T700SC-12K-50C/\#2510 PW Fabric used in MAT_54 are provided in Table 4.1. Generally, the material constants provided by manufacturers are not accurate and need to be modified for numerical studies [34]. The values of the parameters in Table 4.2 account for these modifications and are based on the MAT_54 parametric study conducted by Wade et al. [48].

In Table 4.2, DFAILT is the axial tensile failure strain, DFAILC is the axial compressive failure strain, DFAILM is the transverse failure strain, DFAILS is the shear failure strain, EFS is the effective failure strain, TFAIL is the time step failure value, FBRT is the fiber tension damage factor after matrix failure, YCFAC is the fiber compression damage factor after matrix failure, SOFT is the crush-front damage parameter, ALPH is the factor for the non-linear term in shear stress, and BETA is the shear factor in fiber tension [48]. 
Table 4.1: Material properties for TORAY unidirectional (UD) and plain weave (PW) fabric [52-53].

\begin{tabular}{|c|c|c|c|c|c|c|c|c|c|}
\hline & \multicolumn{7}{|c|}{ MATERIAL PROPERTY VARIABLE } \\
\cline { 2 - 10 } & $\mathrm{E}_{1}$ & $\mathrm{E}_{2}$ & $\mathrm{G}_{12}$ & $\mathrm{v}_{21}$ & $\mathrm{X}_{\mathrm{t}}$ & $\mathrm{X}_{\mathrm{c}}$ & $\mathrm{Y}_{\mathrm{t}}$ & $\mathrm{Y}_{\mathrm{c}}$ & $\mathrm{S}_{\mathrm{c}}$ \\
& $(\mathrm{GPa})$ & $(\mathrm{GPa})$ & $(\mathrm{GPa})$ & & $(\mathrm{MPa})$ & $(\mathrm{MPa})$ & $(\mathrm{MPa})$ & $(\mathrm{MPa})$ & $(\mathrm{MPa})$ \\
\hline $\mathrm{UD}$ & 124.8 & 8.412 & 4.206 & $2.050 \times 10^{-2}$ & 2199 & 1448 & 48.88 & 198.6 & 154.4 \\
\hline PW & 55.92 & 54.40 & 4.199 & $4.300 \times 10^{-2}$ & 910.1 & 710.2 & 772.2 & 703.2 & 131.0 \\
\hline
\end{tabular}

Table 4.2: MAT_54 post failure material properties [48].

\begin{tabular}{|c|c|c|c|c|c|c|c|c|c|c|c|}
\hline & \multicolumn{11}{|c|}{ LS-DYNA MATERIAL PARAMETER } \\
\hline & $\begin{array}{c}\text { DFAILT } \\
{[\mathrm{mm} / \mathrm{mm}]}\end{array}$ & $\begin{array}{l}\text { DFAILC } \\
{[\mathrm{mm} / \mathrm{mm}]}\end{array}$ & $\begin{array}{l}\text { DFAILM } \\
{[\mathrm{mm} / \mathrm{mm}]}\end{array}$ & $\begin{array}{c}\text { DFAILS } \\
{[\mathrm{mm} / \mathrm{mm}]}\end{array}$ & $\begin{array}{c}\text { EFS } \\
{[\mathrm{mm} / \mathrm{mm}]}\end{array}$ & $\begin{array}{c}\text { TFAIL } \\
\text { (s) }\end{array}$ & FBRT & YCFAC & SOFT & $\mathrm{ALPH}$ & BETA \\
\hline UD & 0.0174 & -0.0116 & 0.024 & 0.03 & 0 & $\begin{array}{l}1.153 \\
\times 10^{-9}\end{array}$ & 0.5 & 1.2 & 0 & 0.1 & 0.5 \\
\hline PW & 0.0164 & -0.013 & 0.014 & 0.03 & 0 & $\begin{array}{l}1.153 \\
\times 10^{-9}\end{array}$ & 0.5 & 1.2 & 0 & 0.1 & 0.5 \\
\hline
\end{tabular}

LS-DYNA's MAT_20 material card is used to model the impactor. MAT_20 is used for creating rigid materials in order to avoid the calculation of stresses and strains. This increases the computation efficiency. The material properties of Titanium Carbide used in MAT_20 are provided in Table 4.3.

Table 4.3: Material properties for Titanium Carbide [54].

\begin{tabular}{|c|c|c|c|}
\hline \multirow{2}{*}{} & \multicolumn{3}{|c|}{ MATERIAL PROPERTY VARIABLE } \\
\cline { 2 - 4 } & $\rho$ & $\mathrm{E}$ & $\mathrm{PR}$ \\
& $\left(\mathrm{kg} / \mathrm{m}^{3}\right)$ & $(\mathrm{GPa})$ & \\
\hline $\mathrm{TiC}$ & $2.952 \times 10^{4}$ & 451.0 & 0.1900 \\
\hline
\end{tabular}




\subsubsection{Contact Modelling}

Numerous contacts are applied on the model to simulate the interaction of the impactor and fuselage skin, and the interaction of the fuselage components. Contacts are necessary for penetration checks upon impact [55]. Moreover, the type of contact must be selected carefully in order to capture the load transfer and failure propagation accurately.

The contacts used for modelling the interaction between the impactor and the fuselage skin, and the fuselage components consist of AUTOMATIC_NODES_TO_SURFACE, ERODING_SINGLE_SURFACE, and SPOTWELD. To capture the impactor/skin interaction, and the skin/shear tie interaction, AUTOMATIC_NODES_TO_SURFACE is used. Since these part bodies have a physical gap in the model, the contacts capture the impact from the nodes of the master segment colliding into the slave segment surface. ERODING_SINGLE_SURFACE is applied to account for the interaction between the shear ties and the skin, frames and stringers. Once the shear ties have eroded, the contact ensures the shear tie does not penetrate or pass through its own material, or that of the adjacent components. SPOTWELD is used to capture the interactions of the skin/stringers, stringers/frames, stringers/shear ties, and frames/shear ties. SPOTWELD is used to fix the motion of adjacent components together and the loads to transfer across. Upon impact, SPOTWELD allows for the generation of frictional loads and the transfer of adjacent component loads.

For all contacts, the coefficient of static friction is 0.2 , which is based on the experimental results of static frictions studies on carbon-fiber/carbon-fiber composites [56].

\subsubsection{Solution Stability}

In the model, the fuselage parts and the impactor utilized stiffness-based $(\mathrm{IHQ}=8$ and $\mathrm{IHQ}=4)$ hourglass controls to obtain the correct solution for warped shell elements and bulk viscosity necessary to propagate shock waves in solid elements. Stiffness-based hourglass controls are used to avoid hourglass modes, the non-physical modes of deformation, by generating hourglass forces that are proportional to the nodal displacement caused by the hourglass modes [57]. The hourglass forces are additional forces added to the model to correct any unrealistic nodal displacement and buckling of the elements, known as hourglass modes.

The element (mesh) sizing mentioned earlier is based on mesh sensitivity studies. The sensitivity studies shows further mesh refinement has no overall effect on the failure sequence and the energy balance of the system. The time step for outputting the history data in the study is $0.760 \mathrm{~ms}$. A separate study shows that further reducing the time step has no effect on the failure times and the energy balance curvatures. 
Hence, to reduce computational time, the element (mesh) size and the time step of the study are as listed above.

\subsubsection{Initial Impact Conditions}

The fuselage section is supported along its sides by the frames such that the translational motion about the global $\mathrm{x}, \mathrm{y}$, and $\mathrm{z}$ axes and the rotation about the $\mathrm{y}$ and $\mathrm{z}$ axes are constrained. The global axis system is shown in Figure 4.3. The rotational freedom about the $\mathrm{x}$-axis enable the nodes to locally rotate while the translational constraints allow for the appropriate stress reactions to generate on the local shell elements from the bending created by the impact. On the impactor, translational constraints are imposed in the $\mathrm{x}$ and $\mathrm{y}$ directions along with rotational constraints about the $\mathrm{x}, \mathrm{y}$ and $\mathrm{z}$ axes, for all nodes. The $\mathrm{z}$-axis translational motion allows for a straight path impact of the impactor with the skin while the rotational constraints prevent the impactor from rotating longitudinally or radially as it comes in contact and during the contact with the skin.

The initial velocity of the impactor is set to $1 \mathrm{~m} / \mathrm{s}$. The mass of the impactor is generated using the density and the volume of the solid elements. The volume of the impactor is $\sim 0.144 \mathrm{~m}^{3}$ as per LS-DYNA's measurements. The density of the impactor is entered as $29520 \mathrm{~kg} / \mathrm{m}^{3}$ to achieve a kinetic energy of 2.13 $\mathrm{kJ}$. The initial kinetic energy of the impactor represents the total input energy since the fuselage does not have any initial energy.

The time step for the study for outputting the history data is $0.760 \mathrm{~ms}$. The termination time is 0.190 s. This small value of the time step allows for a total of 250 increments from the initial state to the final state. Small increments are necessary to understand how the impact energy is transferring onto the fuselage components in the form of damage. Thus, having more increments allows for a more complete understanding of the damage accumulation and failure mechanisms. The termination time is carefully selected to capture the entire impact. The impact begins at $0.019 \mathrm{~s}\left(25^{\text {th }}\right.$ time step $)$ and ends at $0.190 \mathrm{~s}\left(250^{\text {th }}\right.$ time step).

\subsection{Condensation and Extraction of Super-Nodes}

The main aim of this study is to investigate the effectiveness of using supernodes in impact analysis rather than the original or the entire model. The first part of the study (Case B1) is focused on creating the supernodes, and the second part of the study (Case B2) is to extract them. The impact is in the form of a drop test using a spherical impactor. 
The study consists of 6 ply HTA/6376C carbon fiber/epoxy laminate and an impactor. The numerical study is performed at an impact energy of $15.4 \mathrm{~mJ}$. The material properties adopted in the numerical study are based on the experimental and numerical studies conducted by Faggiani and Falzon on stiffened composite panel damage under low velocity impacts [5].

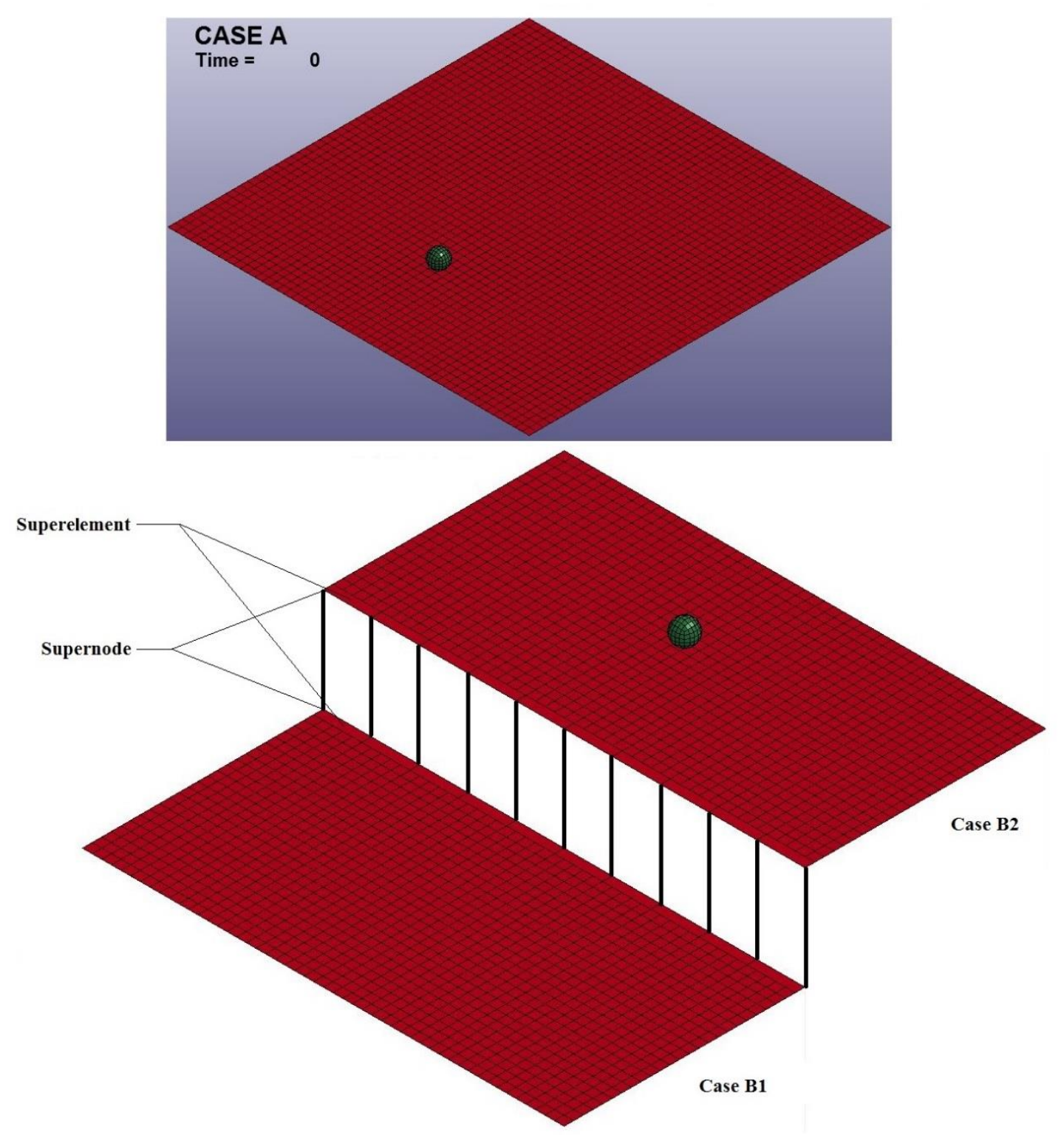

Figure 4.4: Model comparison for the two cases - original case (top) and supernode case (bottom).

Figure 4.4 displays the original and the supernode model. In Case B1, the entire model is condensed into the 11 supernodes that are shown. In Case B2, the supernodes are inputted to the remainder of the model where the impact is taking place. The results of Case B2 are then compared to that of the original (entire) model - Case A. 
The following sections include the specific controls applied on top of the generic controls mentioned in 3 to make the case study more accurate.

\subsubsection{Materials, Dimensions, and Meshing}

The carbon fiber/epoxy laminate used in the study is manufactured from Fibredux HTA/6376C. The density of HTA/6376C laminate is $1.59 \mathrm{~g} / \mathrm{cm}^{3}$ [5]. The laminate layup of the UD pre-impregnated carbon fiber is $\left[0^{\circ} / 90^{\circ} / 0^{\circ}\right]_{\mathrm{s}}$. The dimensions of the laminate are provided as $1 \times 1 \mathrm{~m}^{2}$. The ply thickness is given to be $0.125 \mathrm{~mm}$ [5]. The impactor is spherical, has a diameter of $5 \mathrm{~cm}$, and is made of Aluminum 7075-T6.

The elements used in the study have an edge length of $2 \mathrm{~cm}$, and the quality can be seen in Figure 4.4. The entire model consists of 2650 nodes. Of the 2650 nodes, 2500 nodes belong to the laminate, and the remaining 150 nodes to the impactor. The impactor is modelled as shell rigid elements.

\subsubsection{Material Modelling}

The material properties of HTA/6376C carbon fibers/epoxy are given in Table 4.4. The LS-DYNA post failure material properties are given in Table 4.5. The material properties of the Aluminum 7075-T6 impactor are provided in

Table 4.6.

Table 4.4: Material properties for HTA/6376C carbon fiber/epoxy [5].

\begin{tabular}{|c|c|c|c|c|c|c|c|c|}
\hline \multicolumn{10}{|c|}{ MATERIAL PROPERTY VARIABLE } \\
\hline $\begin{array}{c}\text { EA } \\
(\mathrm{Pa})\end{array}$ & $\begin{array}{c}\text { EB } \\
(\mathrm{Pa})\end{array}$ & $\begin{array}{c}\text { GAB } \\
(\mathrm{Pa})\end{array}$ & PRBA & $\begin{array}{c}\text { XT } \\
(\mathrm{Pa})\end{array}$ & $\begin{array}{c}\text { XC } \\
(\mathrm{Pa})\end{array}$ & $\begin{array}{c}\text { YT } \\
(\mathrm{Pa})\end{array}$ & $\begin{array}{c}\text { YC } \\
(\mathrm{Pa})\end{array}$ & $\begin{array}{c}\text { SC } \\
(\mathrm{Pa})\end{array}$ \\
\hline $1.450 \mathrm{E} 11$ & $1.030 \mathrm{E} 10$ & $5.300 \mathrm{E} 9$ & 0.0214 & $2.000 \mathrm{E} 9$ & $1.600 \mathrm{E} 9$ & $6.400 \mathrm{E} 7$ & $2.900 \mathrm{E} 8$ & $9.800 \mathrm{E} 7$ \\
\hline
\end{tabular}

Table 4.5: Post failure material properties [48].

\begin{tabular}{|c|c|c|c|c|c|c|c|c|c|c|}
\hline \multicolumn{10}{|c|}{ LS-DYNA MATERIAL PARAMETER } \\
\hline $\begin{array}{c}\text { DFAILT } \\
{[\mathrm{mm} / \mathrm{mm}]}\end{array}$ & $\begin{array}{c}\text { DFAILC } \\
{[\mathrm{mm} / \mathrm{mm}]}\end{array}$ & $\begin{array}{c}\text { DFAILM } \\
{[\mathrm{mm} / \mathrm{mm}]}\end{array}$ & $\begin{array}{c}\text { DFAILS } \\
{[\mathrm{mm} / \mathrm{mm}]}\end{array}$ & $\begin{array}{c}\text { EFS } \\
{[\mathrm{mm} / \mathrm{mm}]}\end{array}$ & $\begin{array}{c}\text { TFAIL } \\
(\mathrm{s})\end{array}$ & FBRT & YCFAC & SOFT & ALPH & BETA \\
\hline 0.0174 & -0.0116 & 0.024 & 0.03 & 0 & $\begin{array}{c}1.153 \mathrm{E}- \\
9\end{array}$ & 0.5 & 1.2 & 0 & 0.1 & 0.5 \\
\hline
\end{tabular}


Table 4.6: Material properties for Al 7075-T6 [58].

\begin{tabular}{|c|c|c|}
\hline \multicolumn{3}{|c|}{ MATERIAL PROPERTY VARIABLE } \\
\hline $\begin{array}{c}\mathrm{RO} \\
\left(\mathrm{kg} / \mathrm{m}^{3}\right)\end{array}$ & $\begin{array}{c}\mathrm{E} \\
(\mathrm{Pa})\end{array}$ & PR \\
\hline $2.810 \mathrm{E} 3$ & $7.170 \mathrm{E} 10$ & 0.330 \\
\hline
\end{tabular}

\subsubsection{Contact Modelling}

The AUTOMATIC_SURFACE_TO_SURFACE is applied to capture the interaction between the impactor and the laminate. Because of the physical gap, the contact captures the impact from the nodes of the master segment colliding into the slave segment surface making it the ideal choice for the penetration check.

For the contacts, the coefficient of static friction is 0.3 , as per the study of Faggiani and Falzon [5].

\subsubsection{Solution Stability}

In addition to the generic solution stability mentioned in the previous chapter, ISTUPD, SHLTHK, and THKCHG are also utilized.

ISTUPD is activated in the CONTROL_SHELL card account for the change in shell thickness [59]. While shell thinning is not an important consideration during impact as it may be in cases where the shell element is being stretched, it is still included in the analysis for slightly increasing the accuracy.

In the CONTROL_CONTACT, the SHLTHK and the THKCHG cards are activated. SHLTHK is activated to account for the shell thickness offsets for both the deformable and rigid nodes when they come under contact [60]. The THKCHG allows for constant thickness updates of the surface when in contact [61].

Since all of the elements are shell elements of Type 16 (fully integrated), IHQ $=8$ is activated as the hourglass control type because it activates the warping stiffness making the solutions more accurate.

\subsubsection{Node Condensation and Extraction}

Condensation and extraction of supernodes can only be performed under the implicit solver of LSDYNA. Condensation of supernodes is performed via CONTROL_IMPLICIT_MODES and can be extracted using ELEMENT_DIRECT_MATRIX_INPUT.Furthermore, since implicit solver is utilized, the 
implicit cards need to be activated in order to inform LS-DYNA as to which solution methodology to use. This is done via CONTROL_IMPLICIT_GENERAL and CONTROL_IMPLICIT_SOLVER.

In CONTROL_IMPLICIT_MODES, the set of nodes that are to be transformed into the supernodes are identified and SE_MASS, SE_DAMP, SE_STIFF, and SE_INERT are used to designate the mass matrix, the damping matrix, the stiffness matrix, and the inertia matrix of the supernodes. The SE_FILENAME is used to create the file where all the property matrices of the component are stored. The ELEMENT_DIRECT_MATRIX_INPUT is used in the extraction model to give the properties to the supernode in order to further proceed with the solution. The property matrices of the supernodes are inputted via the MASS, DAMP, STIFF, INERT, and the FILENAME options.

The implicit analysis for the model is activated using the IMFLAG card in the CONTROL_IMPLICIT_GENERAL option. A double precision linear equation solver is utilized to solve the implicit model and is activated using the LSOLVR card in the CONTROL_IMPLICIT_SOLVER.

\subsubsection{Initial Impact Conditions}

The plies are fixed in one end in the Case B1 model. The fixation enables the plate to act as a cantilever plate. All other nodes are free of constraints.

The numerical mass of the hollow spherical impactor is $2.700 \mathrm{~g}$. The mass is calculated via the density of Aluminum 7075-T6, equal to $2810 \mathrm{~kg} / \mathrm{m}^{3}$, surface area of $7.689 \times 10^{-3} \mathrm{~m}^{3}$, and shell thickness of $0.125 \mathrm{~mm}$. The impactor's initial velocity is set to $3.3774 \mathrm{~m} / \mathrm{s}$. This results in an impact energy of $15.4 \mathrm{~mJ}$.

The time step for outputting the history data is $0.300 \mathrm{~ms}$. The termination time is $22.5 \mathrm{~ms}$. This small value of the time step allows for a total of 75 data increments. The number of increments used in the study are sufficient to understand the effectiveness over supernodes over time, especially when the impactor is in contact with the laminate. The specified number of increments also helps to understand the capability of supernodes in determining the motion of the stress waves across the surface. The termination time is carefully selected to capture the entire impact. The impact begins at $0.750 \mathrm{~ms}\left(26^{\text {th }}\right.$ time step).

\subsection{Effect of Ply-Compaction and Mesh Refinement on Computation Time and Solution Accuracy}

The main aim of this study is to understand the effects of ply compaction (discretization of plies) and mesh refinement on computation time and solution accuracy. Moreover, the study is also focuses on understanding the material behaviour during impact and the interlaminar delamination locations and sequence. The impact is in the form of a drop test using a spherical impactor. The study consists of 24 ply CFRP laminate and an impactor. The first numerical study is performed at an impact energy of $4.61 \mathrm{~J}$ while 
the second one is at $6.24 \mathrm{~J}$. The numerical studies are based on the experimental studies conducted by Schoeppner and Abrate on delamination threshold loads on composite laminates during low velocity impacts [6].

The following sections include the specific controls applied on top of the generic controls mentioned in Chapter 3, to make the case study more accurate.

\subsubsection{Material and Dimensions}

The CFRP laminates are manufactured from Hexcel's AS4 carbon fibers and 3501-6 epoxy. The density of AS4/3501-6 laminate is $1.58 \mathrm{~g} / \mathrm{cm}^{3}$ [62]. The layup of the UD pre-impregnated carbon fiber laminate is $\left[90^{\circ} / 0^{\circ}\right]_{6 s}$. The dimensions of the laminate are provided to be $12.7 \times 12.7 \mathrm{~cm}^{2}$. The ply thickness is given to be $0.140 \mathrm{~mm}$ [6]. The impactor is spherical, has a diameter of $2.54 \mathrm{~cm}$, and is made of hardened steel [6]. 
4.3.2. Meshing and Ply Modelling

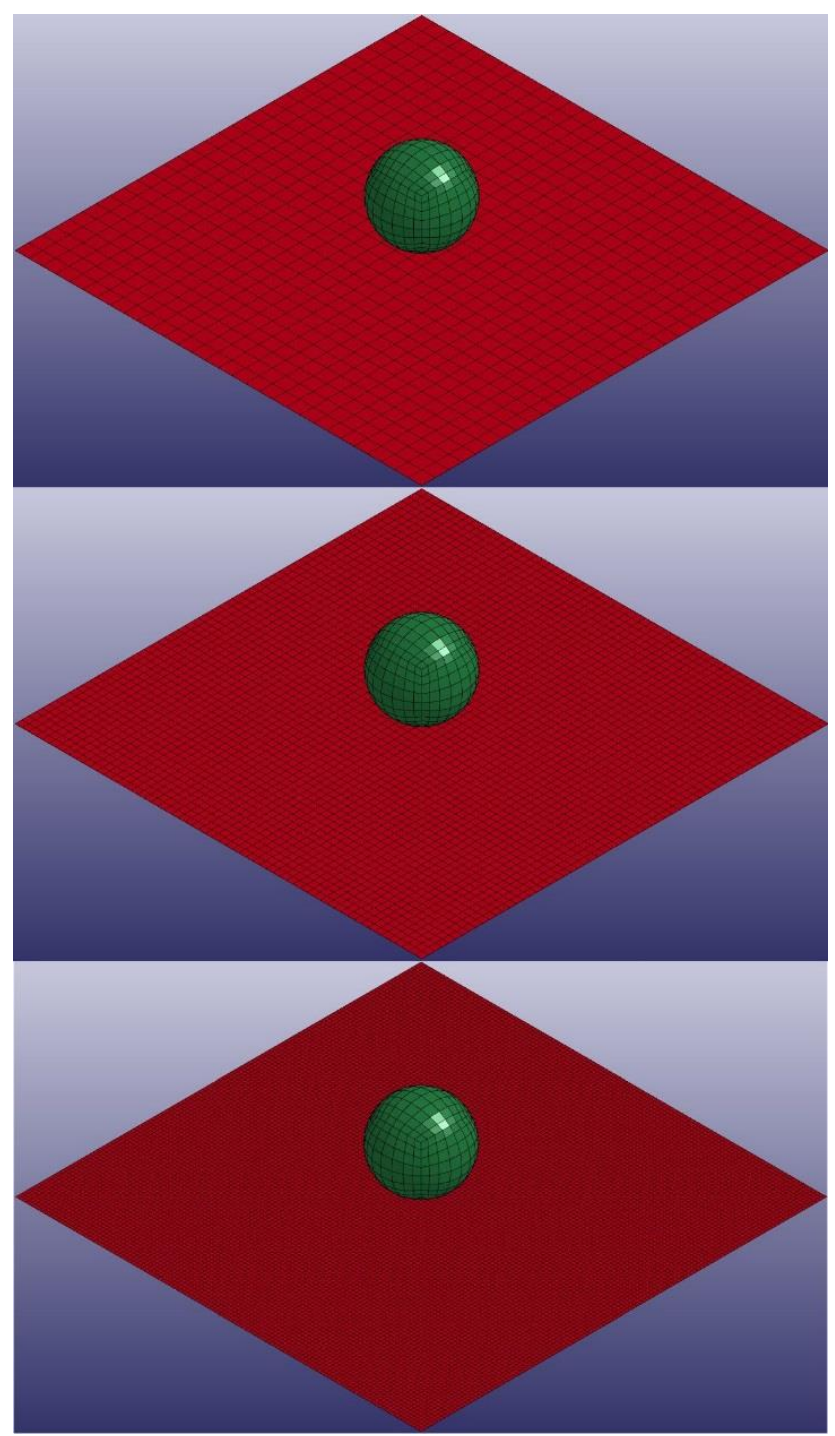

Figure 4.5: Mesh comparison of the different element sizes. From top to bottom: coarse mesh, moderate mesh and fine mesh. 


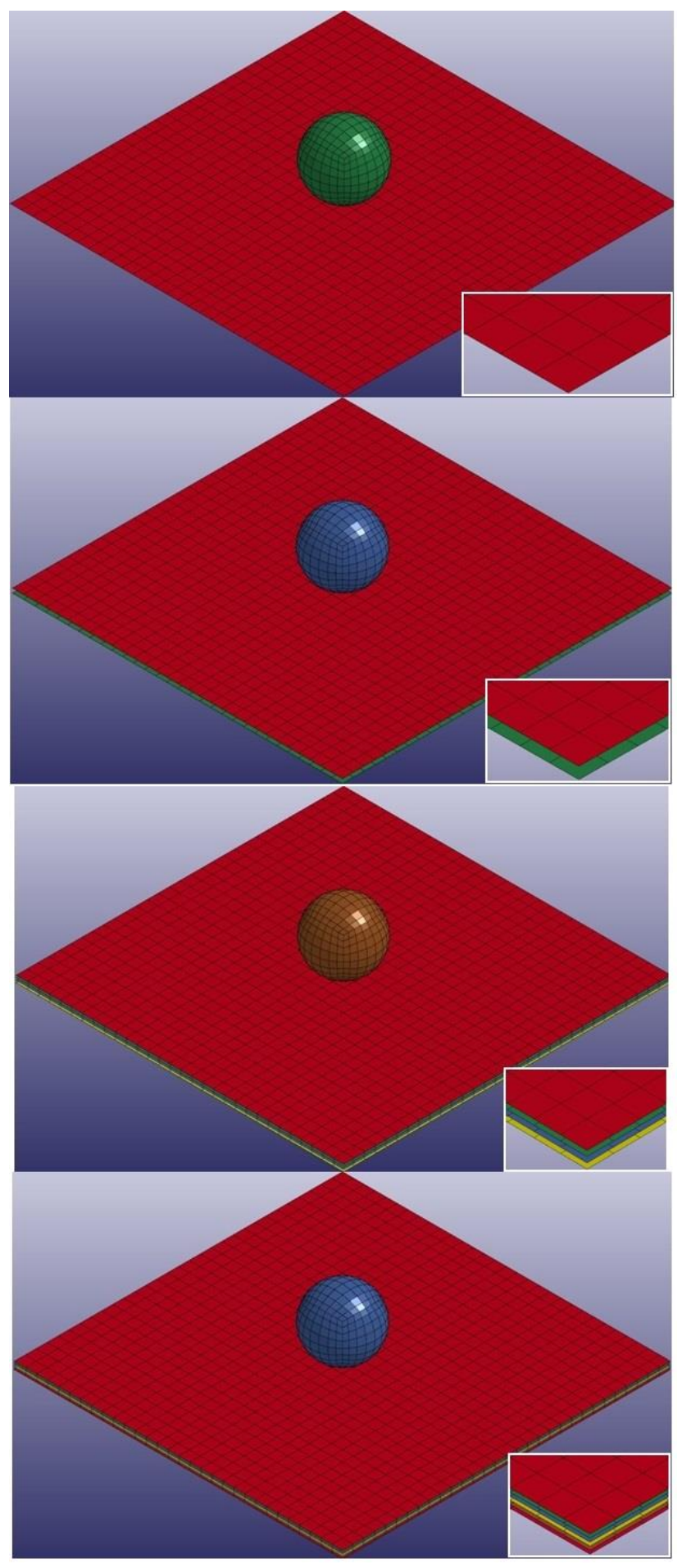

Figure 4.6: Illustration of different ply compactions. From top to bottom: first ply, second ply, third ply, and fourth ply compactions.

Three ply element sizes are explored to study the effects of mesh refinement on the computation time and the solution accuracy. The element sizes have an edge length of $4.233 \mathrm{~mm}$ (coarse mesh), 2.116 
$\mathrm{mm}$ (moderate mesh) and $1.058 \mathrm{~mm}$ (fine mesh), as can be seen in Figure 4.5. For each element size, four sets of 'ply compaction' are performed. In the first ply compaction, all 24 plies of the laminate are discretized and modelled as a single numerical ply. In the second ply compaction, the 24 plies are discretized and modelled as 2 numerical plies (each numerical ply being equivalent to 12 plies). In the third ply compaction, the 24 plies are discretized and modelled as 4 numerical plies (each numerical ply being equivalent to 6 plies). In the fourth ply compaction, the 24 plies are discretized and modelled as 6 numerical plies (each numerical ply being equivalent to 4 plies). Figure 4.6 illustrates the different ply compactions.

The base model is the single layer (first ply compaction) coarse mesh model. It consists of 900 shell elements and 3584 solid elements. The impactor is modelled as solid rigid elements. For the coarse mesh models, the second ply compaction consists of 1800 shell elements and 3584 solid elements, the third ply compaction consists of 3600 shell elements and 3584 solid elements, and the fourth ply compaction consists of 5400 shell elements and 3584 solid elements.

For the moderate mesh models, the first ply compaction consists of 3600 shell elements and 3584 solid elements, the second ply compaction consists of 7200 shell elements and 3584 solid elements, the third ply compaction consists of 14400 shell elements and 3584 solid elements, and the fourth ply compaction consists of 21600 shell elements and 3584 solid elements.

Lastly, for the fine mesh models, the first ply compaction consists of 14400 shell elements and 3584 solid elements, the second ply compaction consists of 28800 shell elements and 3584 solid elements, the third ply compaction consists of 57600 shell elements and 3584 solid elements, and the fourth ply compaction consists of 86400 shell elements and 3584 solid elements.

\subsubsection{Material Modelling}

The material properties of AS4/3501-6 UD pre-impregnated carbon fibers are given in Table 4.7. The LS-DYNA post failure material properties are given in Table 4.8. The material properties of the hardened steel impactor are provided in Table 4.9.

Table 4.7: Material properties for AS4/3501-6 carbon fiber/epoxy unidirectional prepreg [6, 62].

\begin{tabular}{|c|c|c|c|c|c|c|c|c|}
\hline \multicolumn{10}{|c|}{ MATERIAL PROPERTY VARIABLE } \\
\hline $\begin{array}{c}\text { EA } \\
(\mathrm{GPa})\end{array}$ & $\begin{array}{c}\text { EB } \\
(\mathrm{GPa})\end{array}$ & $\begin{array}{c}\text { GAB } \\
(\mathrm{GPa})\end{array}$ & PRBA & $\begin{array}{c}\text { XT } \\
(\mathrm{MPa})\end{array}$ & $\begin{array}{c}\text { XC } \\
(\mathrm{MPa})\end{array}$ & $\begin{array}{c}\text { YT } \\
(\mathrm{MPa})\end{array}$ & $\begin{array}{c}\text { YC } \\
(\mathrm{MPa})\end{array}$ & $\begin{array}{c}\text { SC } \\
(\mathrm{MPa})\end{array}$ \\
\hline 144.4 & 9.690 & 5.760 & 0.0201 & 2280 & 1440 & 57.00 & 228.0 & 71.00 \\
\hline
\end{tabular}


Table 4.8: Post failure material properties [48].

\begin{tabular}{|c|c|c|c|c|c|c|c|c|c|c|}
\hline \multicolumn{10}{|c|}{ LS-DYNA MATERIAL PARAMETER } \\
\hline DFAILT & DFAILC & DFAILM & DFAILS & EFS & $\begin{array}{c}\text { TFAIL } \\
(\mathrm{s})\end{array}$ & FBRT & YCFAC & SOFT & ALPH & BETA \\
\hline 0.0174 & -0.0116 & 0.024 & 0.03 & 0 & $1.153 \mathrm{E}-9$ & 0.5 & 1.2 & 0 & 0.1 & 0.5 \\
\hline
\end{tabular}

Table 4.9: Material properties for hardened steel [63].

\begin{tabular}{|c|c|c|}
\hline \multicolumn{3}{|c|}{ MATERIAL PROPERTY VARIABLE } \\
\hline $\begin{array}{c}\text { RO } \\
\left(\mathrm{kg} / \mathrm{m}^{3}\right)\end{array}$ & $\begin{array}{c}\mathrm{E} \\
(\mathrm{Pa})\end{array}$ & PR \\
\hline $3.682 \mathrm{E} 5$ & $2.050 \mathrm{E} 11$ & 0.290 \\
\hline
\end{tabular}

\subsubsection{Contact modelling}

The contacts for modelling the interaction between the impactor and the plies consist of AUTOMATIC_SURFACE_TO_SURFACE and ERODING_SURFACE_TO_SURFACE. In models involving more than one numerical ply, AUTOMATIC_SURFACE_TO_SURFACE_TIEBREAK is also applied to capture the interlaminar interaction.

The AUTOMATIC_SURFACE_TO_SURFACE is applied to capture the impactor and the individual ply interactions. Since the impactor and the laminate have a physical gap in the model, the contact captures the impact from the nodes of the master segment colliding into the slave segment surface, making it the ideal choice for the penetration check.

ERODING_SURFACE_TO_SURFACE is applied to account for the interaction between the impactor and different plies and within the plies themselves. The primary purpose of the ERODING_SURFACE_TO_SURFACE is to account for the interactions of the plies once they have eroded. Upon erosion, they can come into contact with themself and/or the adjacent plies, and lead to penetrations. The ERODING_SURFACE_TO_SURFACE ensures that once eroded, the plies do not penetrate or pass through their own or through the adjacent ply's material.

AUTOMATIC_SURFACE_TO_SURFACE_TIEBREAK is applied on models involving more than one numerical ply. The AUTOMATIC_SURFACE_TO_SURFACE_TIEBREAK is used to input and account for the normal and shear failure stresses between adjacent plies. The normal failure stress is $56 \mathrm{MPa}$ and the shear failure stress is $44 \mathrm{MPa}$, which is typical of epoxy adhesives [1]. During impact, the adjacent plies are tied together until one of the failure stresses is reached, upon which the ply separation occurs. 
For all contacts, the coefficient of static friction is 0.2 , which is based on the experimental results of static frictions studies on carbon/carbon composites [56].

\subsubsection{Solution Stability}

SHLTHK in CONTROL_CONTACT is activated to consider the thickness of both the deformable and rigid nodes because disjoints can occur between the slave and master nodes. THKCHG in CONTROL_CONTACT is activated to continually update thickness during contact.

In the model, the plies utilize stiffness-based $(\mathrm{IHQ}=8)$ hourglass control to obtain the correct solution for warped elements. The impactor used the Flanagan-Belytschko stiffness-based (IHQ=5) hourglass control.

\subsubsection{Initial Impact Conditions}

The plies are fixed on all edges. The fixation is applied to represent the experimental setup where an aluminum top plate and steel bottom plate were used to clamp and lock the laminates between them. Clamped boundary conditions are modelled as fixed boundary conditions in the numerical experiments [14]. All other nodes are free of constraints.

The experimental mass of the impactor is provided to be $3.10 \mathrm{~kg}$ [6]. The numerical mass of the impactor is assigned using the density and the volume of the solid elements. The volume of the impactor is approximately $8.4768 \mu \mathrm{m}^{3}$ as per LS-DYNA's measurements. Hence, the density of the impactor is adjusted to $368200 \mathrm{~kg} / \mathrm{m}^{3}$ in order to achieve matching mass between the experiment and numerical study. For 4.61 $\mathrm{J}$ impact numerical study, the initial velocity of the impactor is set to $1.7246 \mathrm{~m} / \mathrm{s}$, which is obtained through reverse calculations of the impactor mass and impact energy. Similarly, for $6.24 \mathrm{~J}$ impact numerical study, the initial velocity of the impactor is set to $2.0064 \mathrm{~m} / \mathrm{s}$.

The time step for outputting the history data is $11.6 \mu \mathrm{s}$. The termination time is $6.96 \mathrm{~ms}$. This small value of the time step allows for a total of 600 data increments. Increments are necessary to understand how the impact energy is transferring on to the individual plies in the form of damage. Thus, having more increments allows for a more complete understanding of the damage accumulation and failure mechanisms. The termination time is carefully selected to capture the entire impact. The impact begins at $0.150 \mathrm{~ms}\left(14^{\text {th }}\right.$ time step). 


\section{NUMERICAL RESULTS}

\subsection{Low-Velocity and High-Energy Blunt Impact Response of All-Composite Fuselage Section}

\subsubsection{Impact Characteristics}

Figure 5.1 shows the energy balance of the model. As can be seen, the total energy of the model stays constant at $2.13 \mathrm{~kJ}$ for the most part. The total energy is the summation of the kinetic energy, internal energy, hourglass energy, damping energy, and the sliding energy. As time progresses the energy form changes depending on the interaction that is occurring in the model. It is also important to note that the total energy slightly decreases with time as elements erode and get deleted. In other words, the amount of material at the initial state does not equate to the amount of material at the final state.

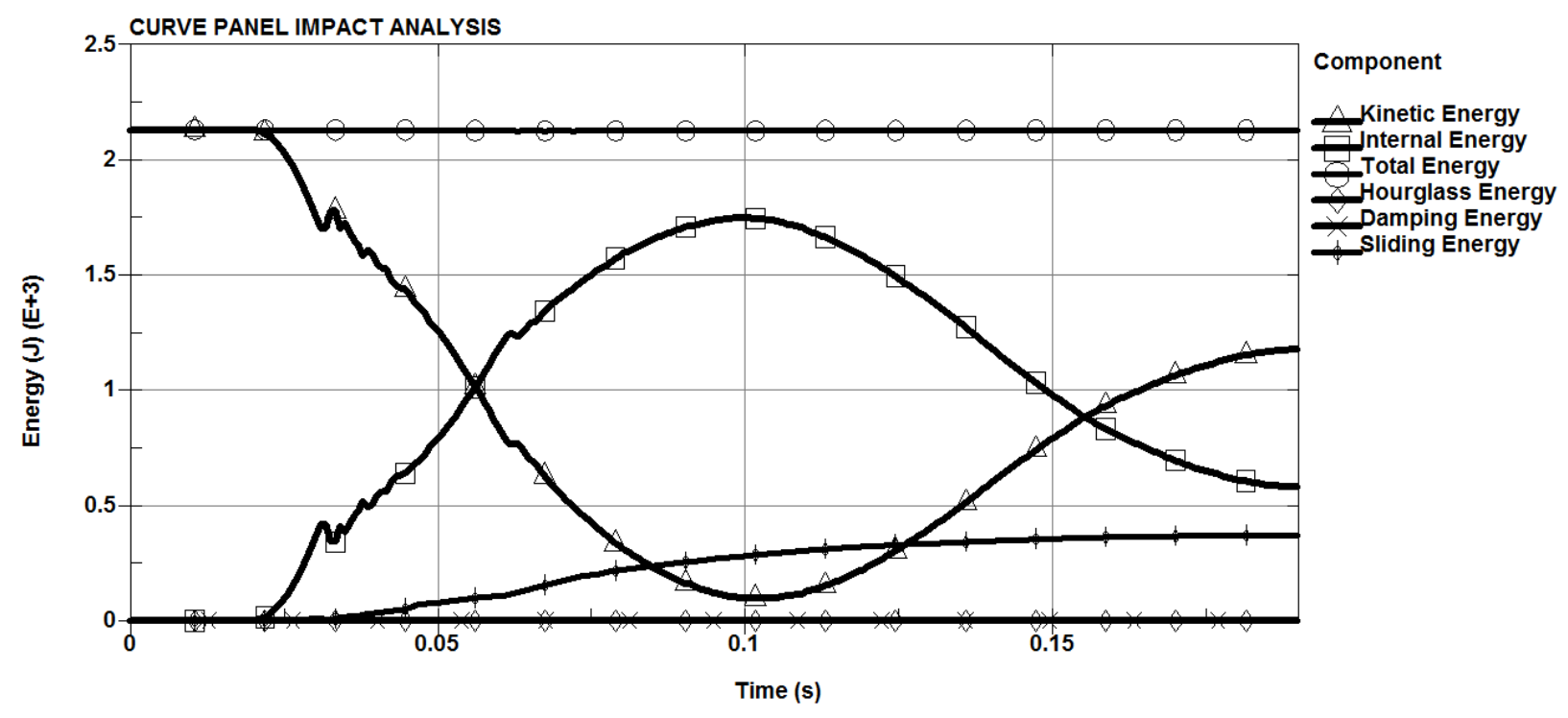

Figure 5.1: Energy balance.

The maximum kinetic energy of $2.13 \mathrm{~kJ}$ is solely due to the impactor's mass and velocity and occurs at the initial stages. As the impactor collides with the fuselage section at $0.019 \mathrm{~s}$, the kinetic energy of the system starts to convert into the internal, sliding, and the fuselage's kinetic energies. The internal energy is energy being absorbed by fuselage section in the form of damage. The sliding energy is due to friction being generated from the several contacts defined in the model. The fuselage's kinetic energy is due to the motion and vibration of the fuselage section upon impact. The minimum kinetic energy is $96.2 \mathrm{~J}$ at 0.101 s. At this point, the impactor momentarily stops, and the remaining $96.2 \mathrm{~J}$ kinetic energy is due to the motion and vibration of the fuselage section and the kinetic energy of the eroded elements. Due to the elasticity of the materials in the fuselage components, the elements start to return to their original configuration and thus pushing the impactor in the reverse direction. This motions results in net gain of the kinetic energy in the 
system. The kinetic energy is $1.18 \mathrm{~kJ}$ at termination time. The internal energy of the model sees an inverted pattern. The internal energy begins at $0 \mathrm{~J}$ at initial conditions due to the lack of any deformation and starts to grow to a maximum value of $1.75 \mathrm{~kJ}$ at $0.101 \mathrm{~s}$ as the impactor comes to a momentary stop. At this instant, the impactor has induced the maximum deformation in the fuselage. As the impactor starts to move away and regain its kinetic energy, the internal energy of the model starts to lower because the elements are returning to their original configuration. The internal energy is $581 \mathrm{~J}$ at termination time. The ridges in the kinetic energy and internal energy are due to element failures. As individual elements erode, the internal energy momentarily decreases while the kinetic energy increases, up until the next element with load bearing capabilities are encountered.

The hourglass energy and the damping energy of the model are equal to $0 \mathrm{~J}$ for the entire run. Hourglassing are non-physical modes of deformation and can be considered as losses in the model. In order to avoid hourglassing, appropriate control methods are applied and mesh refinements are conducted. Hence, hourglass energy of $0 \mathrm{~J}$ in the model means that none of the energy is being computationally lost. The damping energy of the model corresponds to the 'mass' damping energy which was ignored in this simulation. Finally, the sliding energy of the system is due to the friction being generated from the contacts defined. The initial sliding energy of the model is $0 \mathrm{~J}$ and it gradually starts to increase as impact occurs. The sliding energy starts to increase as the impactor slides against the skin, generating friction between the impactor and fuselage. As the impactor moves further into the fuselage section, the other components of the fuselage start to move and deform which creates additional friction. As the impactor comes to rest and begins to move away, the sliding energy continues to grow because of the friction that is continuously being generated by the vibratory motion introduced in the fuselage section. The final sliding energy is $372 \mathrm{~J}$ at the termination time. A similar sliding energy pattern was found in Gama and Gillespie's study on FE modelling of impact and penetration of thick-sections composites [64]. 


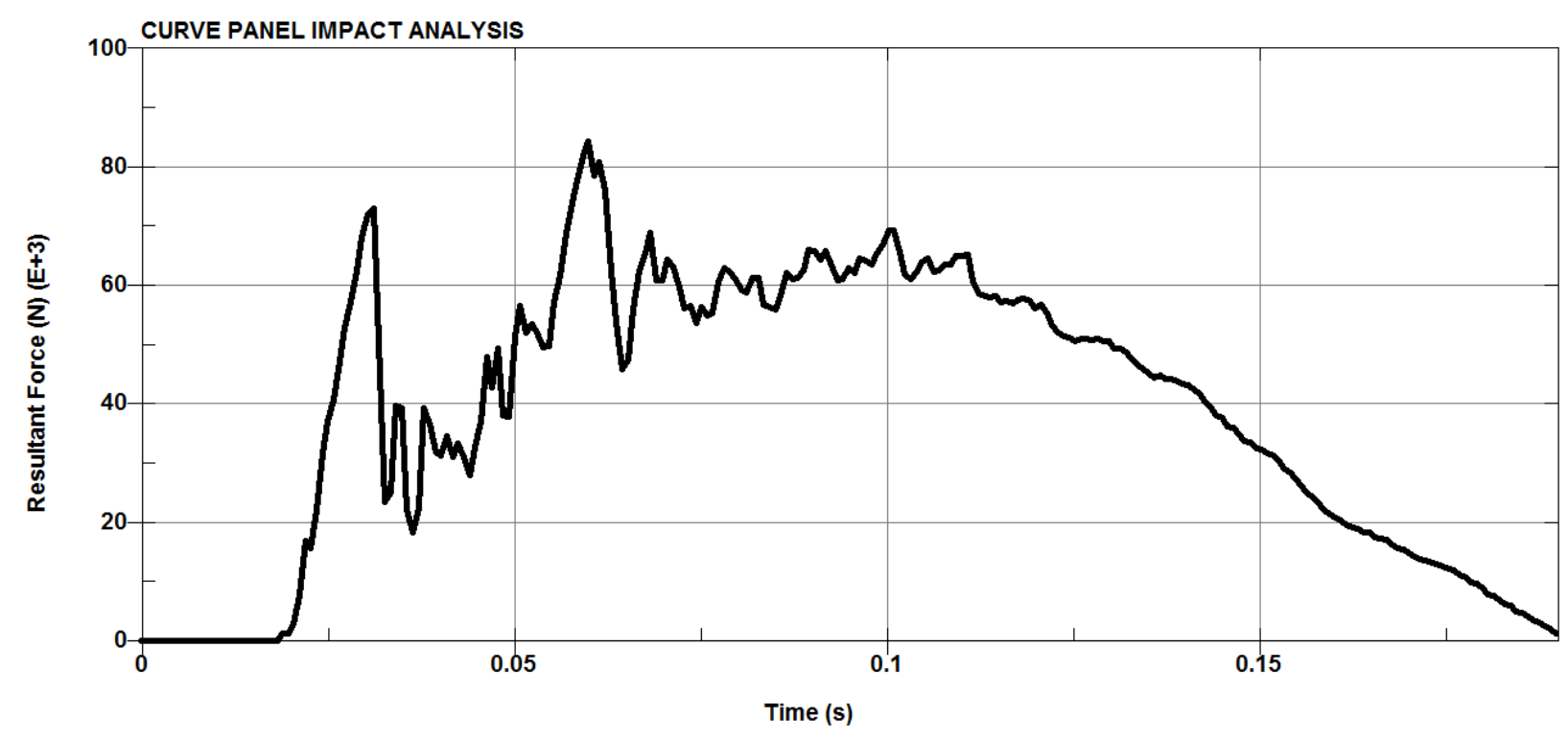

Figure 5.2: Force-time response for the skin-impactor contact.

In Figure 5.2, the skin resultant force during the skin/impactor interaction is displayed. As expected, the forces increase as the impactor impacts with the fuselage section and returns to $0 \mathrm{~N}$ as the impactor separates from the fuselage section. A drastic peak is noticed at the initial impact because of the high-energy being concentrated in a very small area, making the contact force significantly higher. As the impact occurs, the point of contact sees a lot of energy without enough time to react and the contact force increases drastically. The excessive contact force leads to a significant damage accumulation. This causes the material to erode from the model and get deleted, forcing a sharp decline in the contact force. As time progresses, the contact force is spread across the components via stress waves. Similar contact force-time pattern was found in the study conducted by Loikkanen et al. [65] on ballistic impacts on composite panels using cylindrical projectiles, and by Thatte et al. [66] on their study of behaviour of carbon and fiberglass epoxy composites subjected to low-velocity impacts.

\subsubsection{Damage Accumulation and Failure Sequence}

The failure of the fuselage section begins with the failure of the shear ties, and propagates onto the frames. The impactor first collides with the skin which exhibits a localized flexural bending. Upon bending, the skin collides with the shear ties and starts to transfer the localized load onto the shear ties. The shear ties see a longitudinal load due to their geometric orientation and are the first component to fail. As time progresses, the load transfers from the skin to the stringers, which transfers onto the frames. The frames also see longitudinal load and are next to fail. Figure 5.3 and Figure 5.4 display the principal stress distribution moments prior to the shear tie failure and at the maximum internal energy state. 


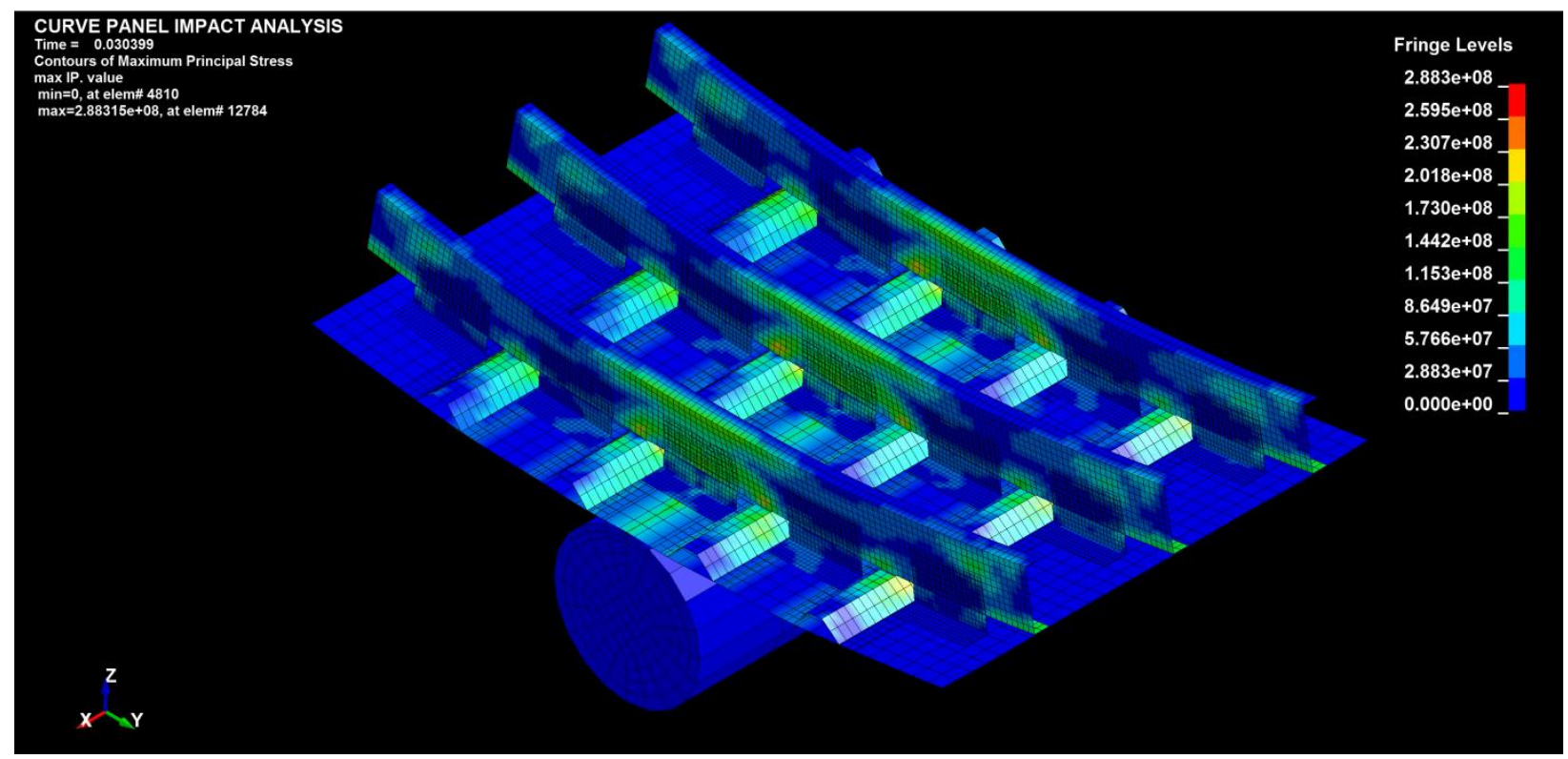

Figure 5.3: Principal stress $(\mathrm{Pa})$ distribution prior to shear tie failures.

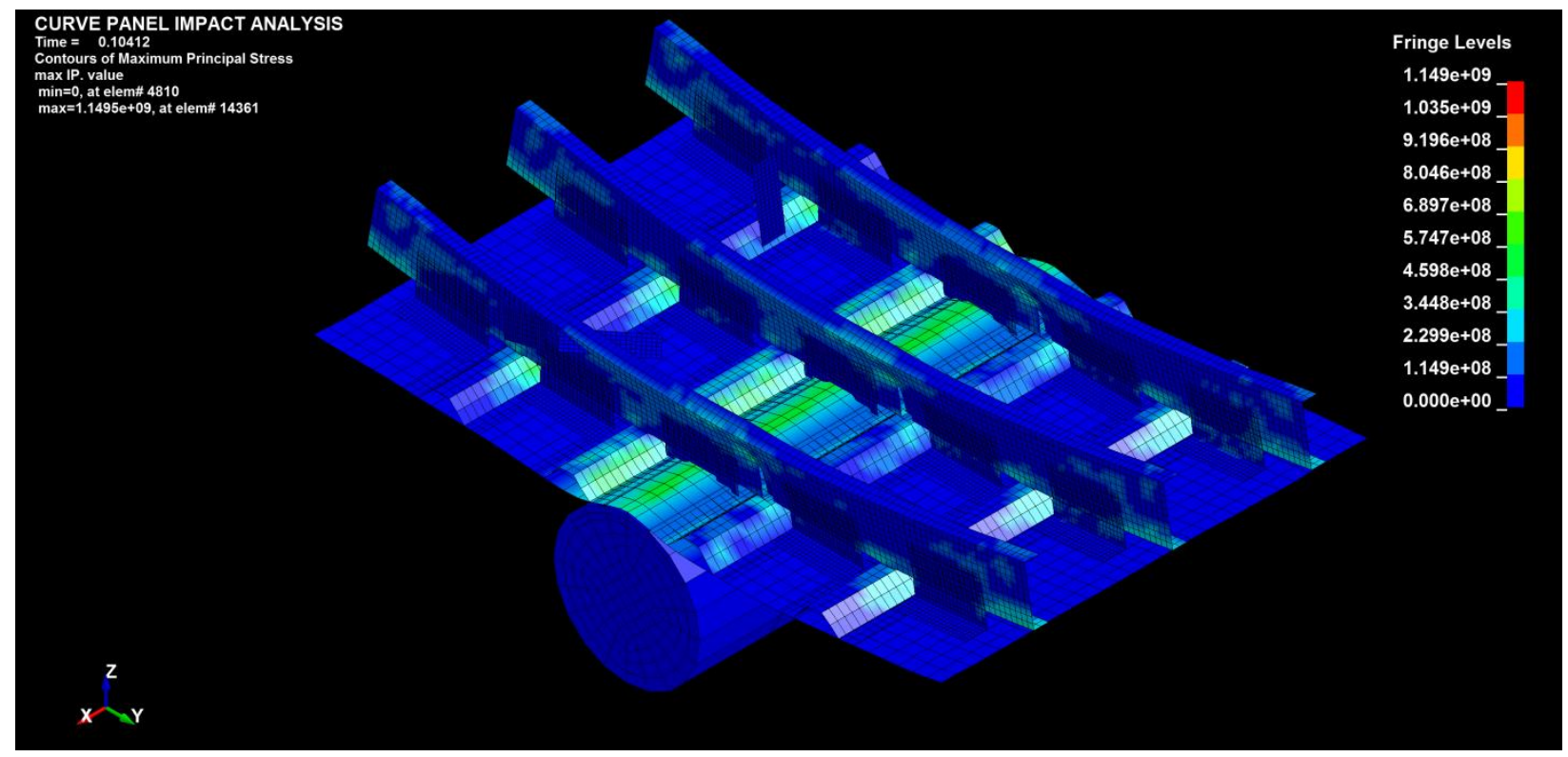

Figure 5.4: Principal stress $(\mathrm{Pa})$ distribution at maximum internal energy.

The shear ties in the middle section are the first to fail. The failure is due to the high contact force transmitted through the skin. Due to the quick chain of events, the shear ties do not have adequate time to successfully distribute the excessive load, and ultimately fails. The maximum principal stress that the shear ties are capable of sustaining is $288.3 \mathrm{MPa}$. From Figure 5.3, the location of the maximum principal stress is concentrated in the middle of the mid-section shear ties. This marks the location where the skin impacts with the shear ties. 
Figure 5.4 displays the damage and failure that occurs at the maximum internal energy. At this instant, significant failures of the shear ties and frames are evident. The failure sequence of the shear ties starts with deletion of the elements lying along the y-z plane and leading to the erosion of the elements in the $x-y$ plane. The deletion begins with the middle elements and propagates predominantly in the $y-$ direction, with relatively minor element deletion along the z-direction. This is because as time progresses, more surface area of the impactor comes in contact with the skin, which leads to contact with the shear ties. Again, the excessive contact force and the short duration of contact period leads to rapid deletion of elements. In the z-direction, damage occurs in the form of deformation of elements. The deformation occurs because the skin is pushing the non-deleted elements while lacking the energy required for completely eroding them.

The left-section and right-section shear ties do not experience the same failure as the mid-section shear ties. The loads experienced by the side shear ties is not due to a concentrated perpendicular force, thus, the damage accumulation is not as drastic. The loads experienced by the left and right shear ties are due to load transfer from adjacent components such as the stringers and frames, or through the stress wave via the skin.

The frames attached to the stringers closest to the impact site are the second to fail. Much like the shear ties, the failure is due to the excessive force from the impactor, which transfers onto the stringers via the skin. The frames fail momentarily after the shear ties because of the added time that it takes the load to transfer. Figure 5.4 also displays the frame failure and the highly localized buckling that follows shortly after. The maximum principal stress the frames are capable of bearing is $842.2 \mathrm{MPa}$. From Figure 5.4, the location of the maximum principal stress on the frames are concentrated near the mid-section stringers. Upon impact, the maximum load is generated at the impact site and starts to diminish as the distance increases. This results in the near mid-section stringers see a more enhanced effect of the impact compared to their far mid-section counterparts. The failure sequence of the frames starts with deletion of the elements located near the frame/stringer connection. This results in a severe component strength degradation. Since the mid-section shear ties have already failed, inadequate support for the frames along with the strength degradation leads to a highly localized buckling in the near mid-section region in the positive global x-axis. The deletion of the elements starts at the frame/stringer connection and propagates predominantly in the $\mathrm{z}$ direction and slightly in the y-direction. As per LS-DYNA's meshing capabilities, an offset in meshing is created about the central axis of the frame, which leads to non-symmetric failure at only one of the near mid-section frame-stringer attachment.

At maximum internal energy the damage to the components is at its peak. The impactor causes the maximum deformation onto the skin, which translates further to the adjacent components. Between the 
initial impact and the time of maximum internal energy, the fuselage components experience all the major failures. Nonetheless, minor failures may still result after the internal energy reduces due to the transient load transfers. However, no such failures were noticed in the numerical study.

\subsection{Condensation and Extraction of Super-Nodes}

\subsubsection{Energy Balance}

Figure 5.5 and Figure 5.6 display and compare the energy balance of the original and supernode impact model. The total energy stays constant at $15.4 \mathrm{~mJ}$. Like in the previous study, the energy balance consists of the kinetic, internal, hourglass, damping, sliding, and the total energy.

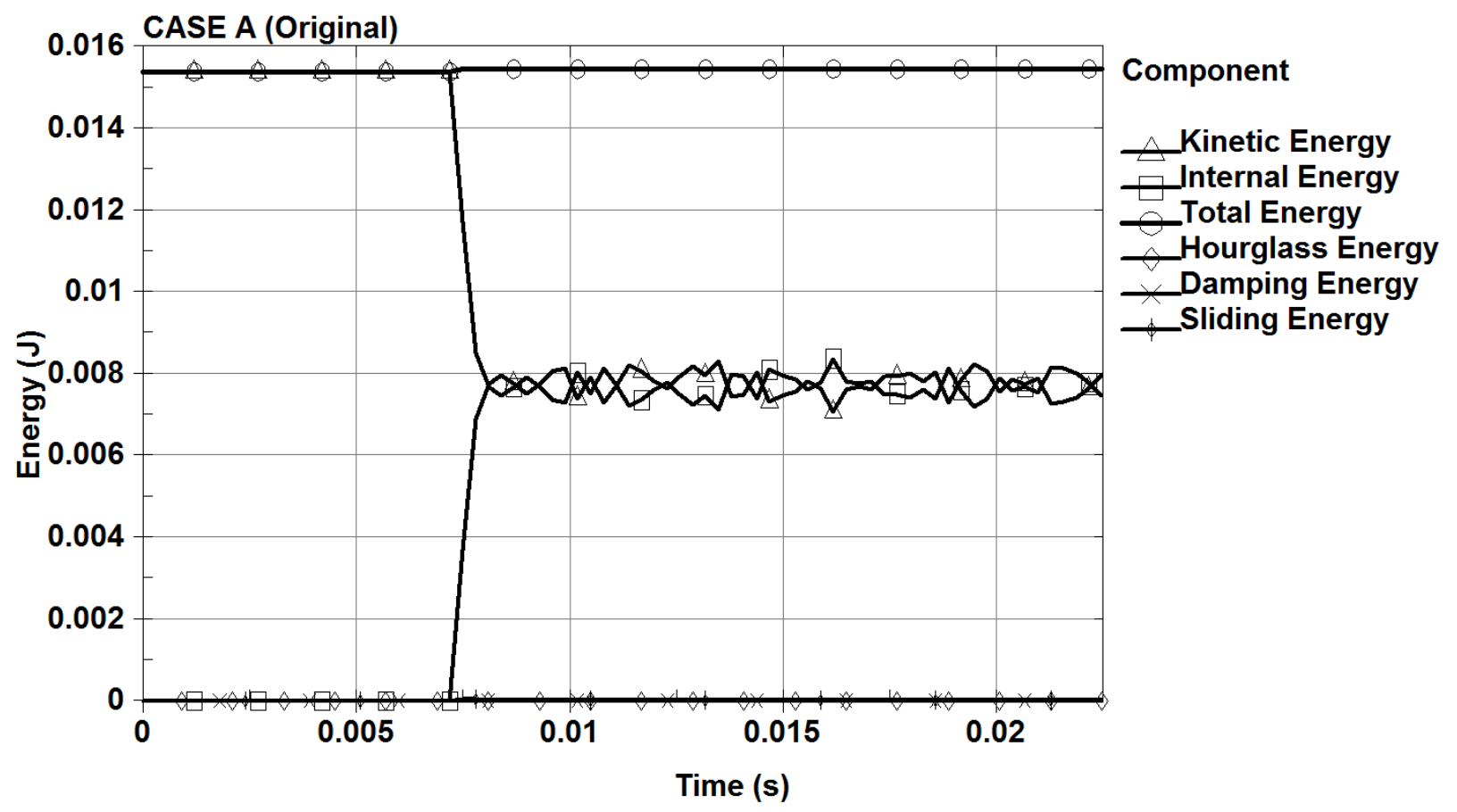

Figure 5.5: Energy balance of the original case. 


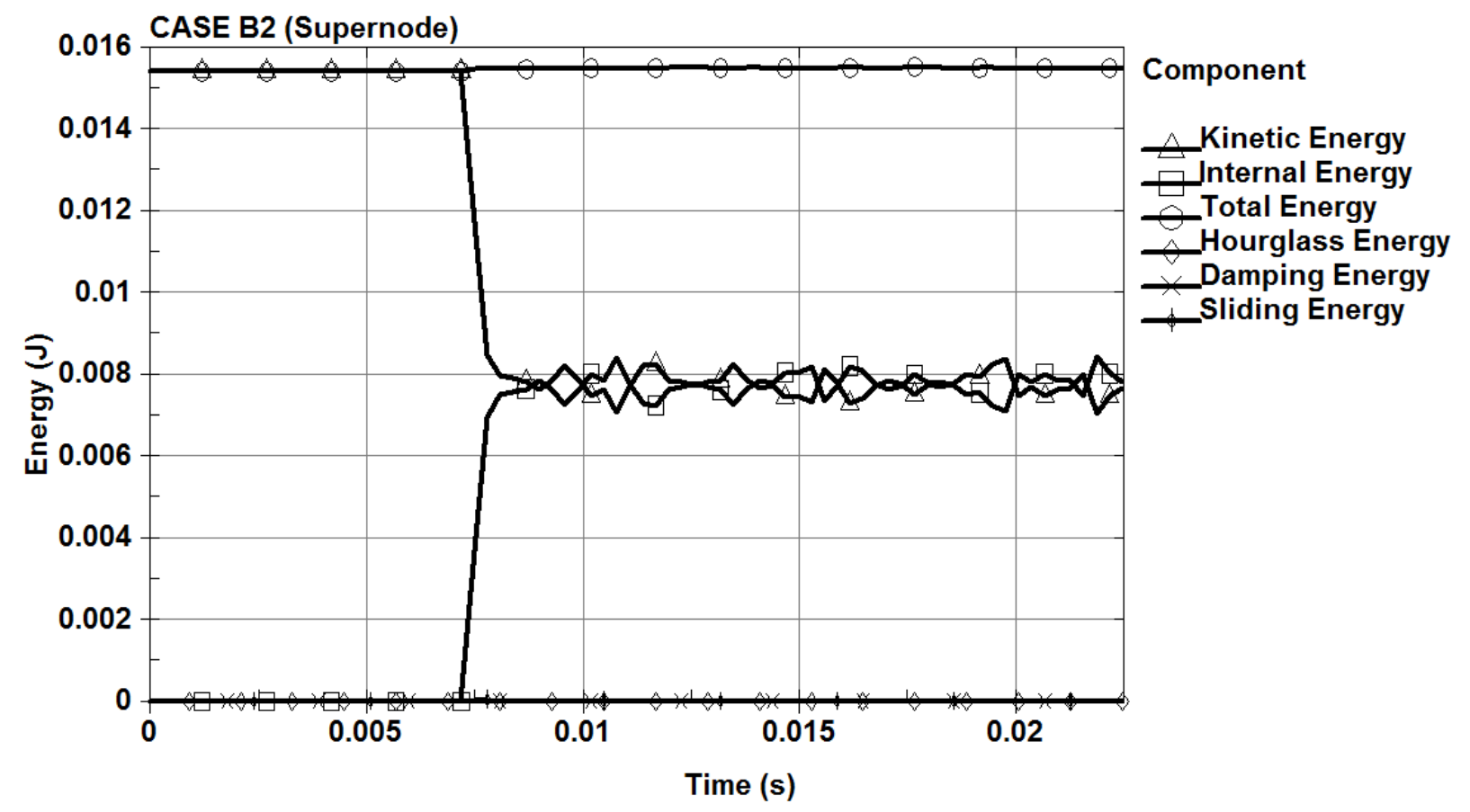

Figure 5.6: Energy balance of the supernode case.

The maximum kinetic energy is $15.4 \mathrm{~mJ}$, and occurs at the initial stages due to the impactor's motion. Upon contact at $7.20 \mathrm{~ms}$, the impactor's kinetic energy starts to covert into the internal energy, sliding energy and the laminate's kinetic energy. The minimum kinetic energy oscillates between $7.08 \mathrm{~mJ}$ and $8.31 \mathrm{~mJ}$ after the initial contact for the original case, and between $7.08 \mathrm{~mJ}$ and $8.36 \mathrm{~mJ}$ for the supernode case. This energy level marks the rebound kinetic energy of the impactor and the residual kinetic energy is due to the motion and vibration imparted on the laminate. The internal energy's time history is symmetric to that of the kinetic energy. The initial internal energy is $0 \mathrm{~J}$. Upon impact, the internal energy starts to grow and oscillate between $7.14 \mathrm{~mJ}$ and $8.38 \mathrm{~mJ}$ for the original case, and between $7.12 \mathrm{~mJ}$ and $8.40 \mathrm{~mJ}$ for the supernode case. The initial growth in the internal energy describes the amount of damage done on the laminate.

The hourglass and damping energies of the model are equal to $0 \mathrm{~J}$ for the entire run, for both the original and supernode cases. As mentioned before, hourglass energy of $0 \mathrm{~J}$ in the model means that none of the energy is being computationally lost, and since damping was not applied to reduce the vibratory behaviour of the model, the resulting damping energy is $0 \mathrm{~J}$ in the model.

The initial sliding energy of the model is $0 \mathrm{~J}$ at initiation and gradually starts to increase as the impact occurs. The sliding energy starts to lower as the impactor begins to move away from the laminate, and returns to $0 \mathrm{~J}$ as the impactor completely separates from the laminate. The maximum sliding energy is $39.4 \mu \mathrm{J}$ at $7.80 \mathrm{~ms}$, for both original and supernode cases. 


\subsubsection{Contact History}

Figure 5.7 and Figure 5.8 display the laminate resultant force during the laminate/impactor interaction. Upon contact, the forces increase as the impactor impacts with the laminate, and returns to $0 \mathrm{~N}$ as the impactor separates from the laminate. The spike at the initial impact is because the all of the energy from the impact is being concentrated in a very small area, making the contact force significantly higher. The maximum contact experienced by the laminate is $21.5 \mathrm{~N}$ at $7.50 \mathrm{~ms}$ for both the original and the supernode cases. The second peak or spike has a magnitude of $6.38 \mathrm{~N}$ at $8.10 \mathrm{~ms}$ for the original case, and $6.42 \mathrm{~N}$ at $8.10 \mathrm{~ms}$ for the supernode case. The second peak occurs because of the instantaneous elastic rebound of the laminate from the first contact.

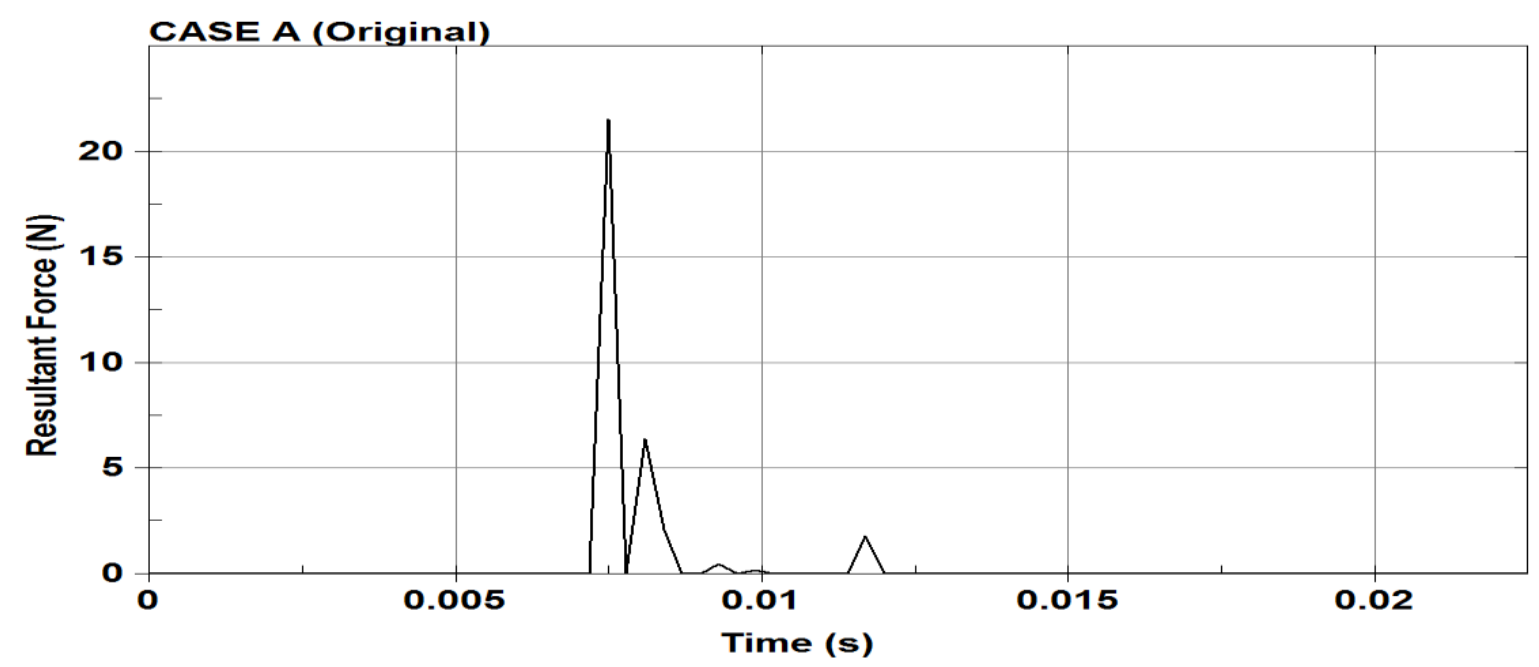

Figure 5.7: Contact force history for the original case.

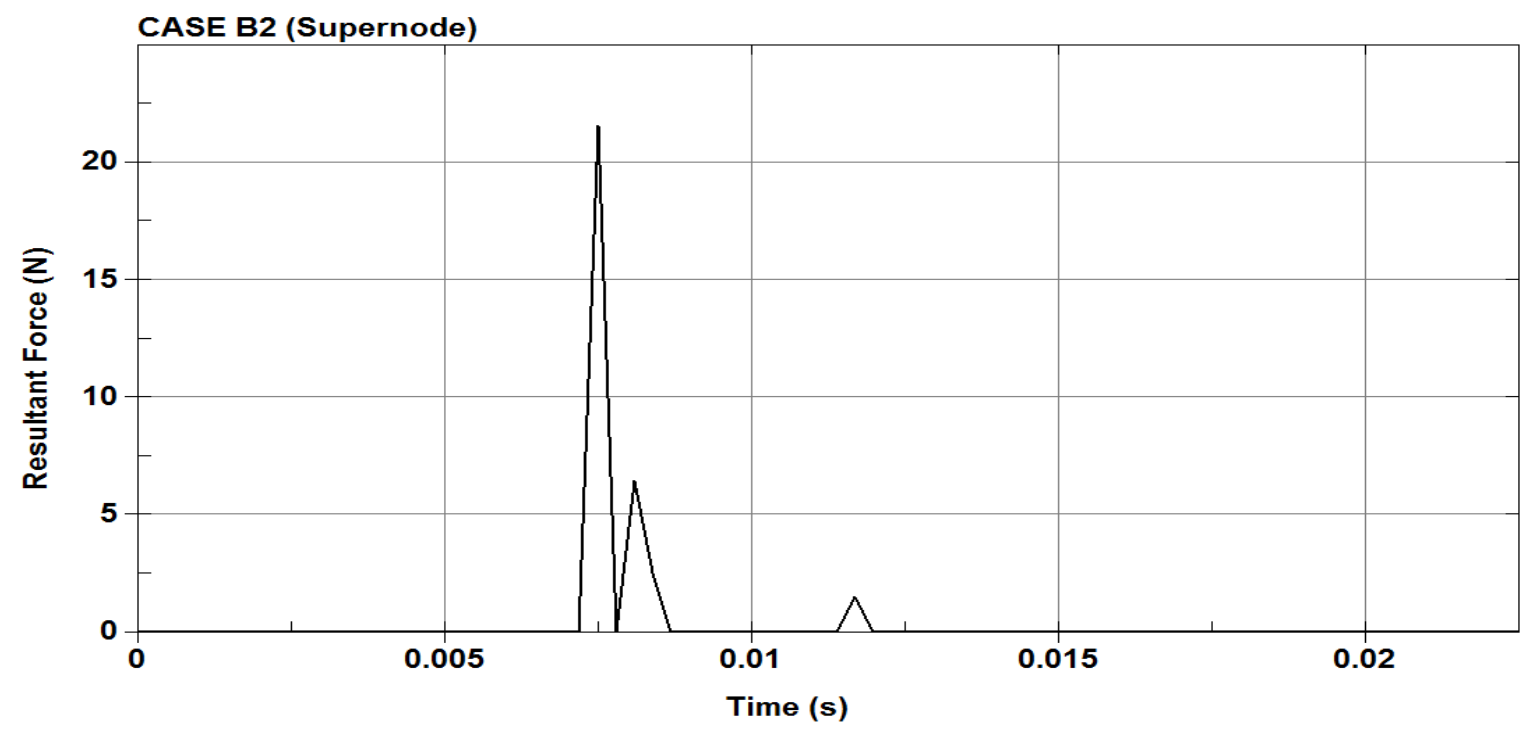

Figure 5.8: Contact force history for the supernode case. 
5.3. Effect of Ply-Compaction and Mesh Refinement on Computation Time and Solution Accuracy

\subsubsection{Energy Balance}

Figure 5.9 shows the energy balance of the $4.61 \mathrm{~J}$ base model. The total energy stays constant at 4.61 J. The energy balance consists of the kinetic (red), internal (green), hourglass (turquoise), damping (pink), sliding (orange) components, and their summation, the total (blue) energy. The energy level changes in form as time progresses depending on the interaction occurring.

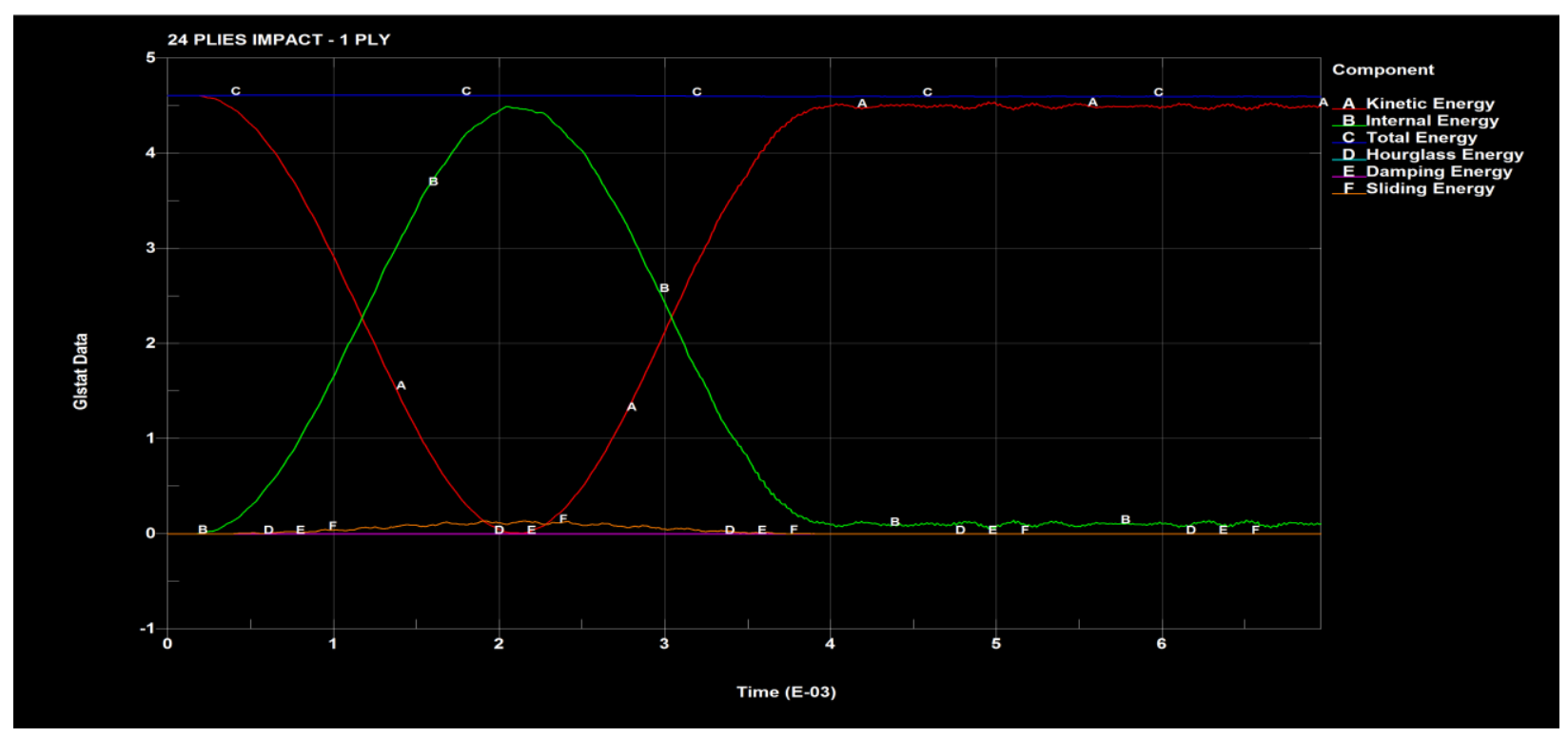

Figure 5.9: Energy (J) balance of the 4.61 J base model.

The maximum kinetic energy is $4.61 \mathrm{~J}$. The maximum kinetic energy occurs at the initial stages due to the impactor's motion. The mass and velocity of the impactor dictate the initial kinetic energy and the total energy of the system. Upon contact between the impactor and the laminate at $0.150 \mathrm{~ms}$, the impactor's kinetic energy starts to covert in the internal energy, sliding energy and the laminate's kinetic energy. The internal energy represents the energy absorbed by the laminate and the sliding energy is due to the friction being generated between the impactor-laminate and interlaminar contacts. The minimum kinetic energy is $8.65 \mathrm{~mJ}$ at $2.15 \mathrm{~ms}$. This time instant marks the instant when the impactor comes to a momentary rest prior to rebounding because of the elasticity of the laminate. The residual kinetic energy is due to the motion and vibration imparted on the laminate by the impactor. The kinetic energy then starts to increase as the impactor picks up speed and stabilizes at approximately $4.50 \mathrm{~J}$ at $3.99 \mathrm{~ms}$. The internal energy has the opposite pattern. The initial internal energy is $0 \mathrm{~J}$. Upon impact, the internal energy begins to rise until the impactor comes to a rest, and then begins to drop to specific value, which is dictated by the amount of damage done to the 
laminate. The maximum internal energy is $4.49 \mathrm{~J}$ at $2.05 \mathrm{~ms}$. The internal energy stabilizes at $0.102 \mathrm{~J}$ at 4.12 ms.

The hourglass and the damping energies of the model are equal to $0 \mathrm{~J}$ for the entire run. Hourglassing are non-physical modes of deformation and can be considered as losses. To avoid hourglassing, appropriate control methods and mesh refinements are applied. The hourglass energy displays the non-physical losses and must be kept to a bare minimum. Hence, hourglass energy of $0 \mathrm{~J}$ in the model means that none of the energy is being computationally lost. The damping energy of the model is the 'mass' damping energy. The mass damping energy is energy of any mass that works against harmonic motions by reducing the amplitudes of mechanical vibrations. In the model, damping was not applied to reduce the vibratory behaviour of the model, resulting in the damping energy of $0 \mathrm{~J}$ for the entire run.

The sliding energy of the system is due to the friction being generated from the contacts defined. The initial sliding energy of the model is $0 \mathrm{~J}$ at initiation and gradually starts to increase as the impact occurs. The sliding energy starts to lower as the impactor begins to move away from the laminate, and returns to $0 \mathrm{~J}$ as the impactor completely separates from the laminate. The maximum sliding energy is $0.136 \mathrm{~J}$ at $2.15 \mathrm{~ms}$. In models with multiple plies, the sliding energy does not return to $0 \mathrm{~J}$ because the interlaminar contacts continue to generate friction initiated from the vibratory response of the laminate from the impact.

\subsubsection{Contact History}

Figure 5.10 displays the force-time response of the moderate-mesh fourth ply compaction of the 4.61 J model. In the figure, 'Sl 1' (red) is the first ply in the impactor/first-ply interaction; 'S1 7' (green) is the second ply in the first-ply/second-ply interlaminar interaction; 'Sl 8' (blue) is the third ply in the secondply/third-ply interlaminar interaction; 'Sl 9' (turquoise) is the fourth ply in the third-ply/fourth-ply interlaminar interaction; 'S1 10' (pink) is the fifth ply in the fourth-ply/fifth-ply interlaminar interaction; and 'Sl 11' (orange) is the sixth ply in the fifth-ply/sixth-ply interlaminar interaction. 


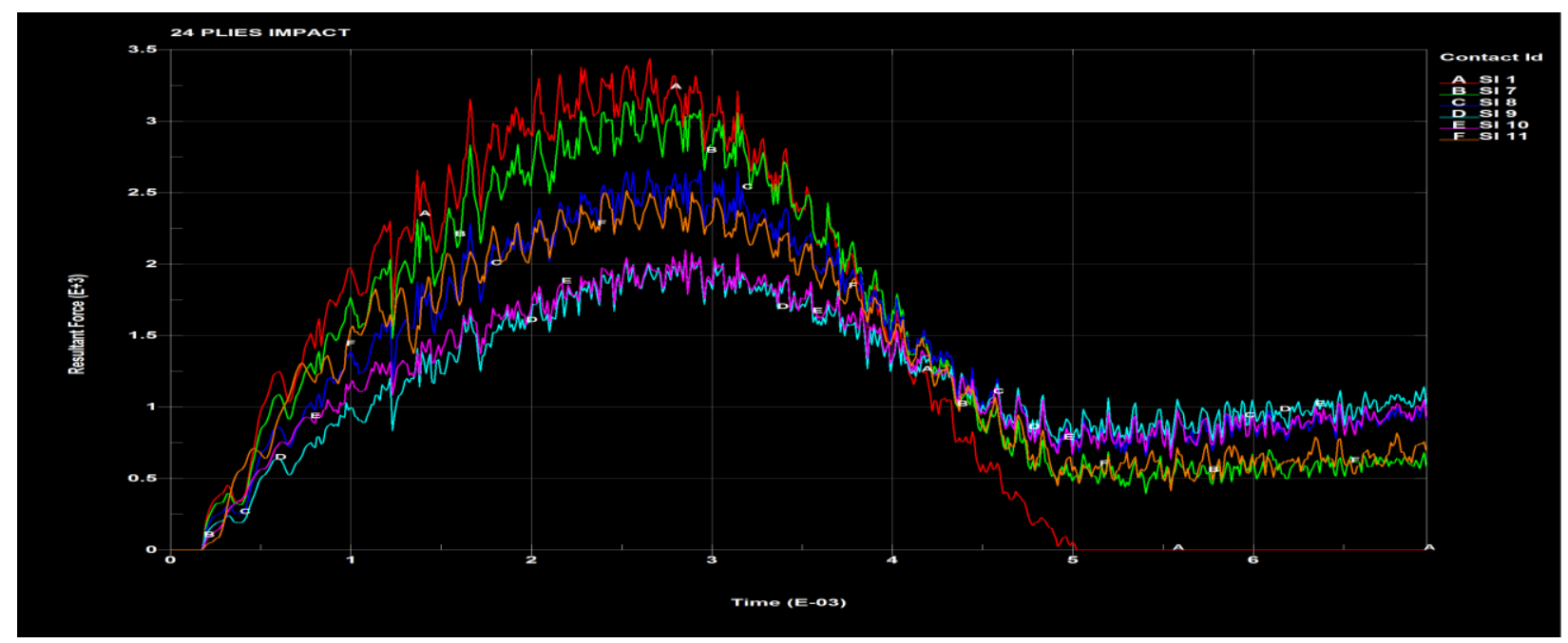

Figure 5.10: Force (N) vs. Time (s) response of the $4.61 \mathrm{~J}$ fourth ply moderate mesh compaction.

The contact forces increase as the impactor collides with the laminate and pushes it inward, and decrease as the impactor starts to move away from the laminate causing it to return to its original shape. The contact force starts to increase at $1.62 \mathrm{~ms}$ for all contacts, reaches the maximum at approximately $2.47 \mathrm{~ms}$, and then begins to lower. For ' $\mathrm{S} 1$ 1' contact, the contact force returns to $0 \mathrm{~N}$ at $4.88 \mathrm{~ms}$ marking complete separation of the impactor and first ply. Other contacts do not return to $0 \mathrm{~N}$ because interlaminar vibratory motion induced by the impact. 


\section{OVERAll Discussion AND SUMmary}

\subsection{Low-Velocity and High-Energy Blunt Impact Response of All-Composite Fuselage Section}

As stated earlier, the problem simulated in this numerical study is similar, in an overall qualitative sense, to the 'Frame 01 ' experimental study investigated by Kim et al. on low-velocity impacts on composite fuselage sections [49].
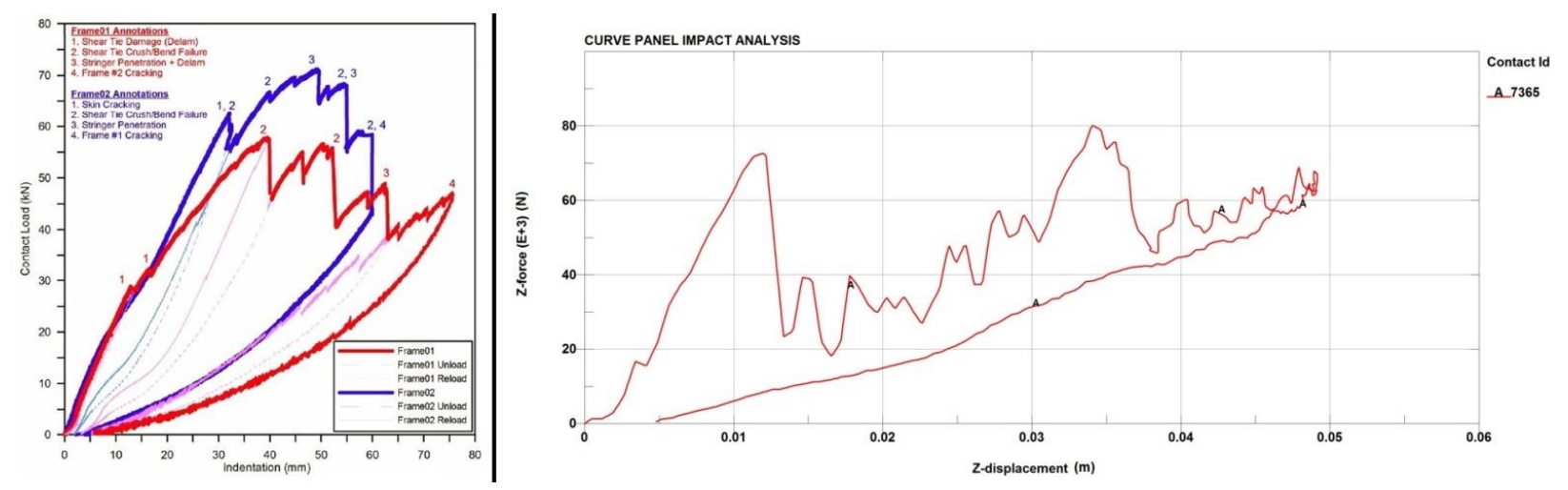

Figure 6.1: Experimental force-displacement results of Frame01 test (left) and numerical study (right) [49].

Figure 6.1 compares the contact force and impactor indentation of the experimental results with the results of this numerical study. The maximum load for Frame01 was measured to be $57.4 \mathrm{kN}$ at the indentation of approximately $40 \mathrm{~mm}$. The maximum displacement is measured to be $75.5 \mathrm{~mm}$ at the contact load of approximately $48 \mathrm{kN}$ [49]. The several peaks mark the failure points of the components. In the numerical study, the maximum load is $80.2 \mathrm{kN}$ at indentation of $34.1 \mathrm{~mm}$, and the maximum displacement is $49.2 \mathrm{~mm}$ at contact load of approximately $66 \mathrm{kN}$. The difference between the experimental and numerical maximum loads is $28.4 \%$ and $34.8 \%$ between the maximum displacements. 


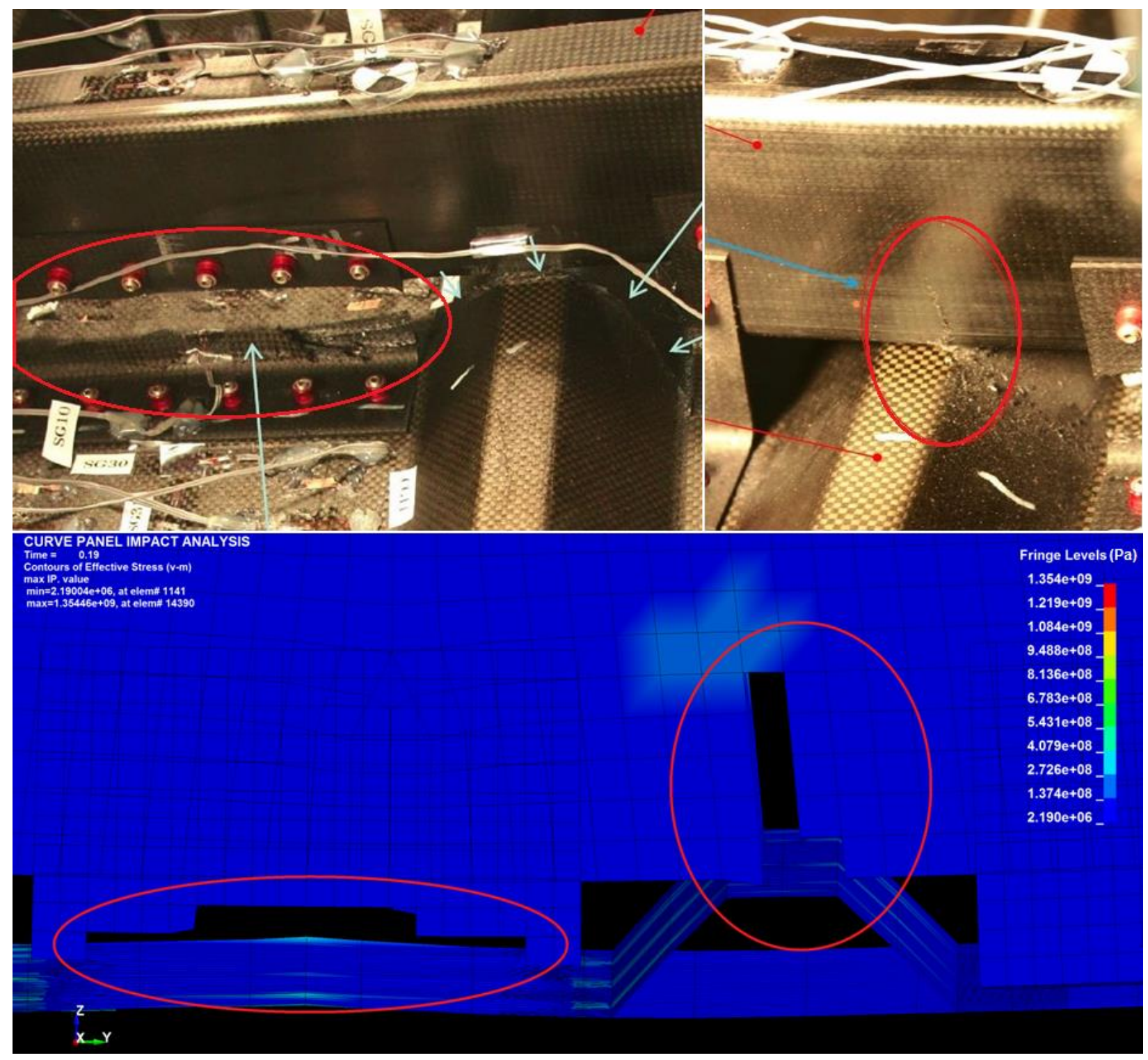

Figure 6.2: Failures of shear-ties (top-left) and frames (top-right) in the Frame01 test, compared with end result in the numerical study (bottom) [49].

Figure 6.2 displays the failures in the experimental results by Kim et al. [49] and numerical results. In the experiments, the shear ties are the first to fail. The failure is in the form of the crack running across the shear ties, leading to the component's separation into two. The stringers are the second component to fail due to delamination. The delamination is not shown in Figure 6.2. The frames are the last component to fail as can be seen from the crack. In the numerical study, the shear ties are also the first to fail in a similar manner as the experimental study. The failure is due to a crack formation across the shear ties, and leads to the component's separation in two. Since the lower portion of the shear ties are not 'fastened' to the skin in the numerical model, they bounce off from the skin. The frames are the second and final component 
to fail in the numerical study. The numerical study does not capture the delamination due to the utilization of single-layered shell element for computation efficiency, hence the stringer failure which was governed by delamination is not captured in our study.

The deviations from the experimental test results could be attributed to factors such as loading rate and impact energy levels, impactor geometrical differences, fuselage curvature differences, deviations in material properties, shell element capabilities, lack of stress concentrated regions created by the fasteners, and differences in the boundary conditions. Nonetheless, the overall failure mechanism and damage sequence are the same for the experimental and numerical studies despite the simplifying assumptions. The failure crack location and direction, and the order and modes of failure are other important events that match closely in both studies.

\subsection{Condensation and Extraction of Super-Nodes}

Figure 6.3 compares the principal stress and the deflection in the two cases at instant the impact occurs. As it can be seen, the magnitude and its distribution across the surface is the same for the two cases. This gives insight that during the initial stages, the supernode model is capable of exhibiting the same results as the original or the entire model. As time progresses, the accuracy of solution starts to deviate because of the stress and deflection waves that are rebounding from the edges. The plots below provide and graphical display of the deviation.

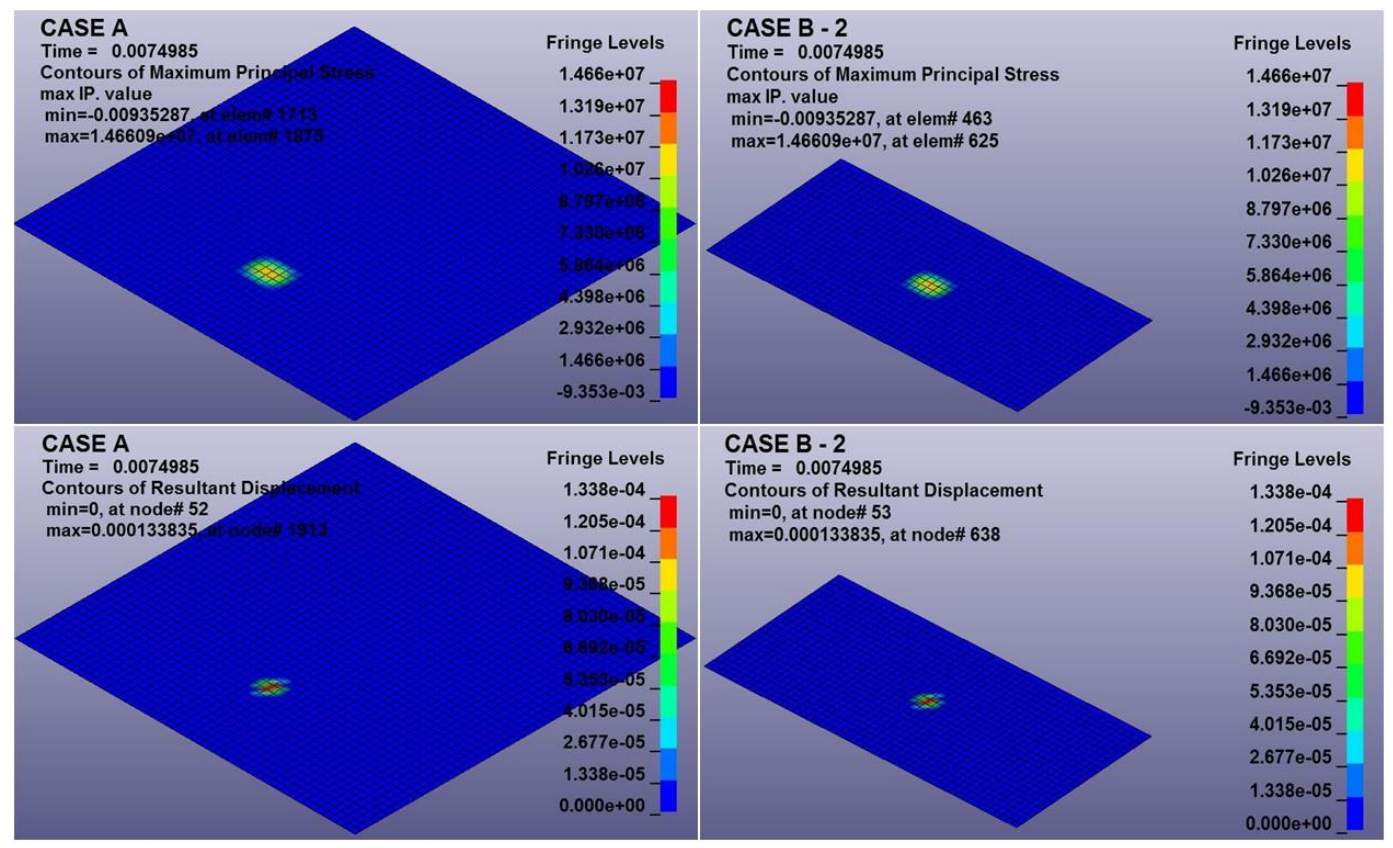

Figure 6.3: Principal stress (top) and deflection (bottom) comparison of the original (left) and supernode (right) cases. 


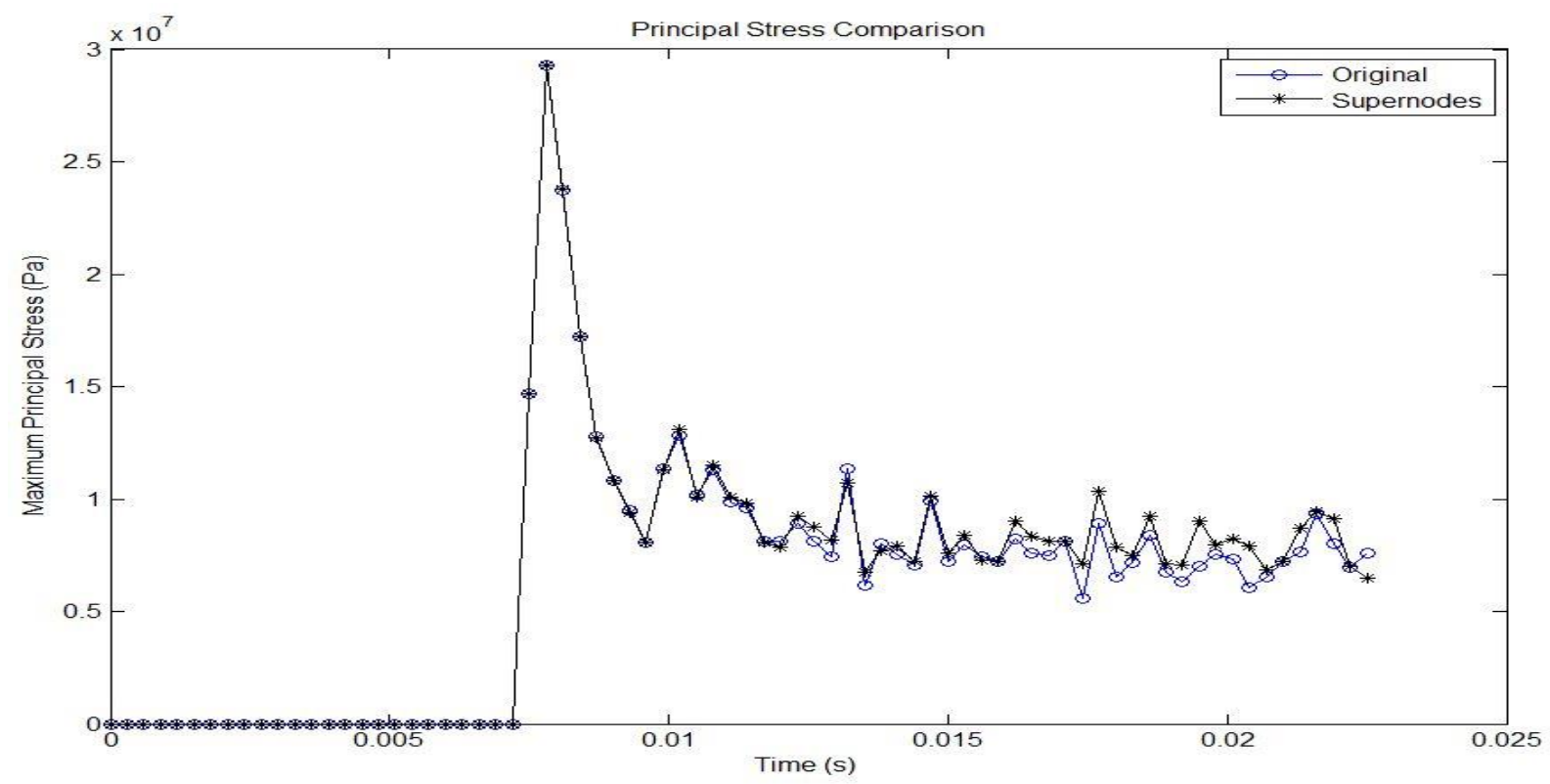

Figure 6.4: Principal stress comparison of the original and the supernode cases.

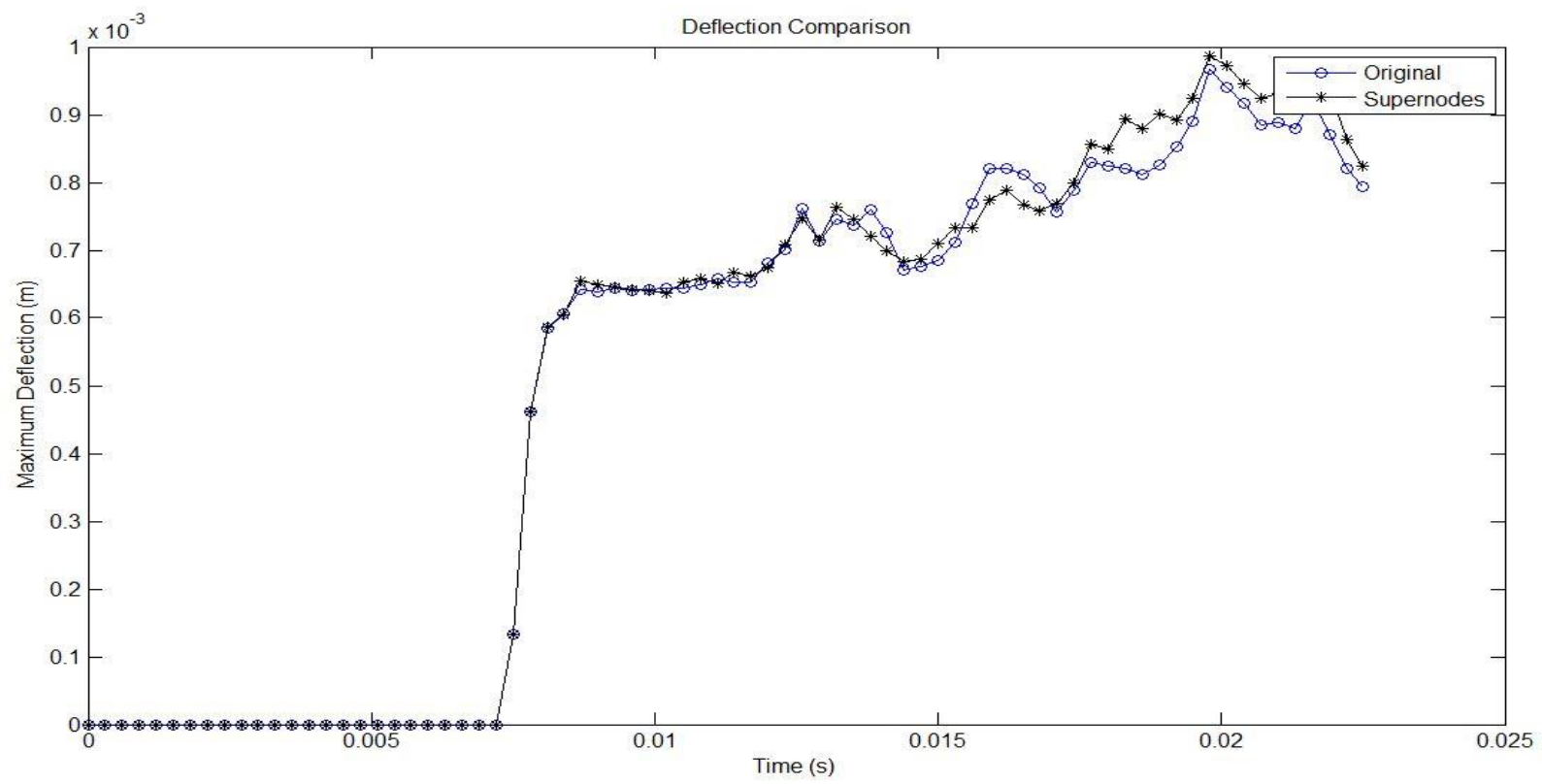

Figure 6.5: Deflection comparison of the original and the supernode cases. 
Table 6.1: Deviation in results between the original and supernode cases during impact.

\begin{tabular}{|c|c|c|}
\hline \multirow{2}{*}{ Time (s) } & \multicolumn{2}{|c|}{ Percent Deviation (\%) } \\
\cline { 2 - 3 } & $\begin{array}{c}\text { Maximum } \\
\text { Principal } \\
\text { Stress }\end{array}$ & $\begin{array}{c}\text { Maximum } \\
\text { Deflection }\end{array}$ \\
\hline 0.0072 & 0.00 & 0.00 \\
\hline 0.0075 & 0.00 & 0.00 \\
\hline 0.0078 & 0.17 & 0.02 \\
\hline 0.0081 & 0.06 & 0.17 \\
\hline 0.0084 & 0.16 & 0.31 \\
\hline 0.0087 & 0.28 & 1.79 \\
\hline 0.0090 & 1.23 & 1.69 \\
\hline 0.0093 & 0.20 & 0.14 \\
\hline 0.0096 & 0.44 & 0.23 \\
\hline 0.0099 & 1.87 & 0.40 \\
\hline 0.0102 & 1.28 & 1.09 \\
\hline 0.0105 & 2.22 & 1.45 \\
\hline 0.0108 & 2.47 & 1.20 \\
\hline 0.0111 & 2.28 & 1.19 \\
\hline 0.0114 & 1.01 & 2.16 \\
\hline 0.0117 & 3.06 & 1.21 \\
\hline 0.0120 & 3.48 & 1.04 \\
\hline 0.0123 & 8.20 & 0.91 \\
\hline 0.0126 & 9.95 & 1.67 \\
\hline 0.0129 & 5.72 & 0.27 \\
\hline
\end{tabular}

From Figure 6.4, Figure 6.5, and Table 6.1, it is graphically and tabularly observable that the deviation in the maximum principal stress and the deflection is very small for the two cases. At the initial stages, there is no deviation between the two, but starts to grow as the impactor further indents the laminate. For the entire impact, the maximum deflection is within $3 \%$ for the two cases, and within $10 \%$ for the maximum principal stress for the two cases. From the plots, it can be noted that the pattern is the same for the two cases. That is, the increase and decrease in the magnitudes happens together, while the magnitudes differ.

The maximum principal stress for both the original model and the supernode model is $29.3 \mathrm{MPa}$ and occurs at $7.50 \mathrm{~ms}$. The maximum deflection for the original model is $0.966 \mathrm{~mm}$ at $19.8 \mathrm{~ms}$. The maximum deflection for the supernode model is $0.987 \mathrm{~mm}$ at $19.8 \mathrm{~ms}$. The deviation in the two models is $2.17 \%$ for maximum deflection. The impactor rebounds away from the laminate at $7.20 \mathrm{~ms}$ and completely separates at $12.9 \mathrm{~ms}$. The noticeable deviation on the plots starts after the separation. This means for 
practical purposes, the supernodes can effectively and efficiently replace the original models during the impact stage.

\subsection{Effect of Ply-Compaction and Mesh Refinement on Computation Time and Solution Accuracy}

The numerical study is based on the results of G. A. Schoeppner's and S. Abate's experiments on delamination threshold load at low velocity impacts [6]. The numerical study is specifically meant to depict specimens H28's and H29's experimental data. Specimens H28 and H29 consist of 24 ply AS4/3501-6 carbon fiber/epoxy laminate fixed between two plates and impacted by a hardened steel impactor.

Table 6.2: Experimental Results of $4.61 \mathrm{~J}$ and $6.24 \mathrm{~J}$ impact studies.

\begin{tabular}{|c|c|c|c|}
\hline $\begin{array}{c}\text { Impact Energy } \\
(\mathbf{J})\end{array}$ & $\begin{array}{c}\text { Impact Time } \\
(\mathbf{m s})\end{array}$ & $\begin{array}{c}\text { Maximum Load } \\
(\mathbf{k N})\end{array}$ & $\begin{array}{c}\text { Maximum } \\
\text { Displacement } \\
(\mathbf{m m})\end{array}$ \\
\hline $\mathbf{4 . 6 1}$ & 4.65 & 3.28 & 2.5 \\
\hline $\mathbf{6 . 2 4}$ & $\mathrm{n} / \mathrm{a}$ & 3.92 & 3.2 \\
\hline
\end{tabular}

Table 6.3: Numerical results for $4.61 \mathrm{~J}$ impact energy.

\begin{tabular}{|c|c|c|c|c|}
\hline $\begin{array}{c}\text { Ply } \\
\text { Compaction }\end{array}$ & $\begin{array}{c}\text { Mesh } \\
\text { Quality }\end{array}$ & $\begin{array}{c}\text { Impact } \\
\text { Time } \\
(\mathbf{m s})\end{array}$ & $\begin{array}{c}\text { Maximum } \\
\text { Load } \\
(\mathbf{k N})\end{array}$ & $\begin{array}{c}\text { Maximum } \\
\text { Displacement } \\
(\mathbf{m m})\end{array}$ \\
\hline \multirow{3}{*}{$\begin{array}{c}\text { First ply } \\
\text { compaction }\end{array}$} & Coarse Mesh & 3.82 & 4.79 & 2.09 \\
\cline { 2 - 5 } & Moderate Mesh & 4.08 & 4.64 & 2.12 \\
\cline { 2 - 5 } & Fine Mesh & 4.09 & 4.66 & 2.11 \\
\hline \multirow{2}{*}{$\begin{array}{c}\text { Second ply } \\
\text { compaction }\end{array}$} & Coarse Mesh & 4.24 & 4.05 & 2.20 \\
\cline { 2 - 5 } & Moderate Mesh & $\mathrm{n} / \mathrm{a}$ & $\mathrm{n} / \mathrm{a}$ & $\mathrm{n} / \mathrm{a}$ \\
\cline { 2 - 5 } $\begin{array}{c}\text { Third ply } \\
\text { compaction }\end{array}$ & Fine Mesh & $\mathrm{n} / \mathrm{a}$ & $\mathrm{n} / \mathrm{a}$ & $\mathrm{n} / \mathrm{a}$ \\
\cline { 2 - 5 } & Coarse Mesh & 4.60 & 3.08 & 2.37 \\
\cline { 2 - 5 } & Moderate Mesh & 4.84 & $\mathrm{n} / \mathrm{a}$ & $\mathrm{n} / \mathrm{a}$ \\
\hline \multirow{2}{*}{$\begin{array}{c}\text { Fourth ply } \\
\text { compaction }\end{array}$} & Fine Mesh & $\mathrm{n} / \mathrm{a}$ & 4.56 & 2.51 \\
\cline { 2 - 5 } & Moderate Mesh & 4.72 & 3.44 & $\mathrm{n} / \mathrm{a}$ \\
\cline { 2 - 5 } & Fine Mesh & $\mathrm{n} / \mathrm{a}$ & $\mathrm{n} / \mathrm{a}$ \\
\hline
\end{tabular}


Table 6.4: Numerical results for 6.24 J impact energy.

\begin{tabular}{|c|c|c|c|}
\hline \multirow{4}{*}{$\begin{array}{c}\text { Ply } \\
\text { Compaction }\end{array}$} & $\begin{array}{c}\text { Mesh } \\
\text { Quality }\end{array}$ & $\begin{array}{c}\text { Maximum } \\
\text { Load } \\
(\mathbf{k N})\end{array}$ & $\begin{array}{c}\text { Maximum } \\
\text { Displacement } \\
(\mathbf{m m})\end{array}$ \\
\hline \multirow{3}{*}{$\begin{array}{c}\text { First ply } \\
\text { compaction }\end{array}$} & Coarse Mesh & 5.72 & 2.41 \\
\cline { 2 - 4 } & Moderate Mesh & 5.28 & 2.68 \\
\cline { 2 - 4 } Second ply compaction & Fine Mesh & $\mathrm{n} / \mathrm{a}$ & $\mathrm{n} / \mathrm{a}$ \\
\cline { 2 - 4 } & Coarse Mesh & 4.28 & 2.64 \\
\cline { 2 - 4 } & Moderate Mesh & 3.02 & 3.53 \\
\hline \multirow{3}{*}{ Third ply compaction } & Fine Mesh & $\mathrm{n} / \mathrm{a}$ & $\mathrm{n} / \mathrm{a}$ \\
\cline { 2 - 4 } & Coarse Mesh & 4.94 & $\mathrm{n} / \mathrm{a}$ \\
\cline { 2 - 4 } & Moderate Mesh & $\mathrm{n} / \mathrm{a}$ & $\mathrm{n} / \mathrm{a}$ \\
\hline \multirow{3}{*}{ Fourth ply compaction } & Fine Mesh & 5.05 & 2.88 \\
\cline { 2 - 4 } & Coarse Mesh & $\mathrm{n} / \mathrm{a}$ & $\mathrm{n} / \mathrm{a}$ \\
\cline { 2 - 4 } & Moderate Mesh & $\mathrm{n} / \mathrm{a}$ & $\mathrm{n} / \mathrm{a}$ \\
\hline
\end{tabular}

Table 6.2 presents the experimental results of the H28 (4.61 J) and the H29 (6.24 J) specimens. Table 6.3 presents the numerical results of the $4.61 \mathrm{~J}$ impact, and Table 6.4 displays the numerical results the 6.24 $\mathrm{J}$ impact. The " $\mathrm{n} / \mathrm{a}$ " are tests that are not performed because to insufficient memory, caused by the numerous contacts that generated as the number of nodes (from increasing the plies and refining the mesh) are increased. The several numerical studies performed are used to determine the overall effect of the mesh refinement and the ply compaction on the solution accuracy.
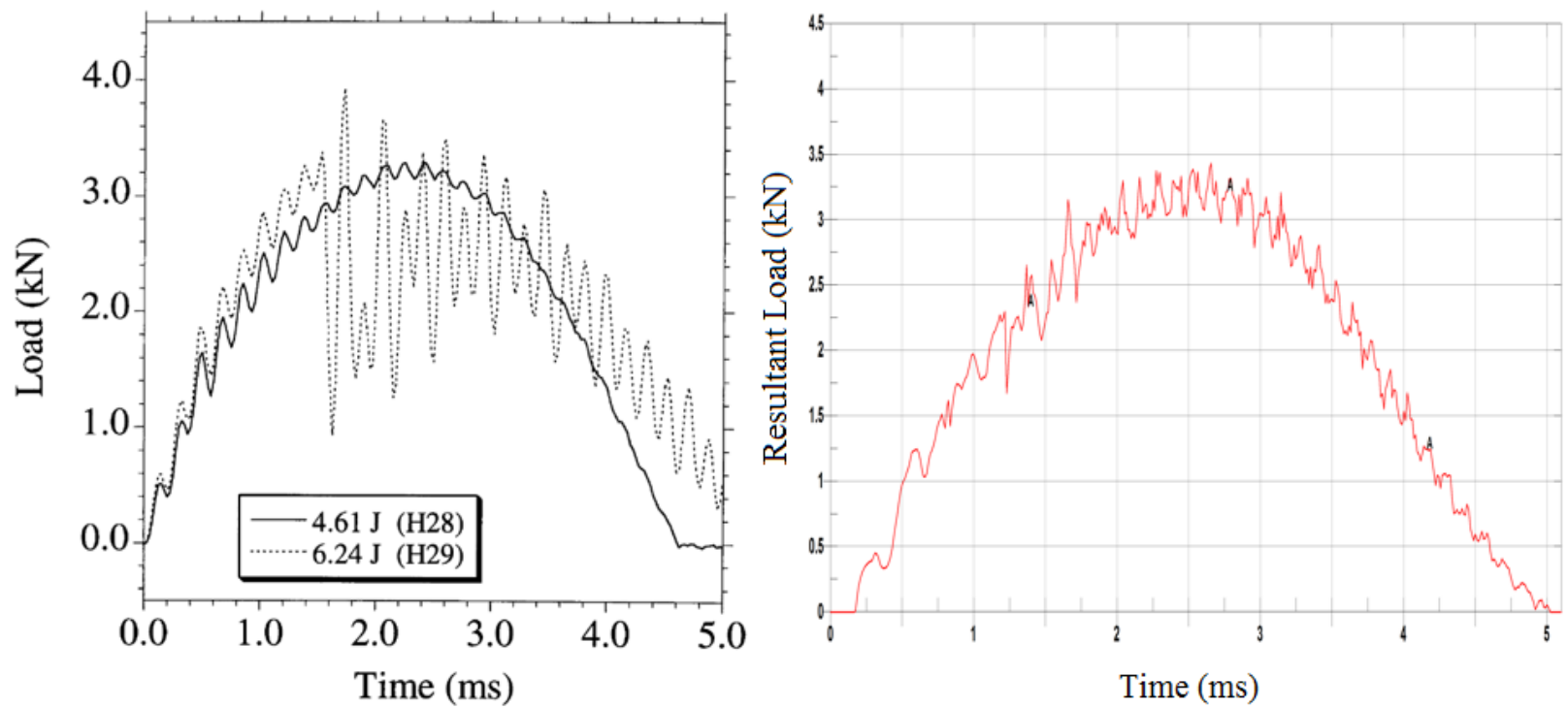

Figure 6.6: Load history response of the impactor-laminate. From left to right: experimental data and 4.61 $\mathrm{J}$ impact numerical response [6]. 
Figure 6.6 displays the force-time response of the H28 and H29 experimental studies compared with the $4.61 \mathrm{~J}$ impact model. For the comparison of the $4.61 \mathrm{~J}$ impact response, the fourth ply compaction and moderate mesh result is presented because it yields the most accurate results. The contact load history resembles very closely with the experimental data. The experimental data yield an impact duration of 4.65 $\mathrm{ms}$ and maximum load of $3.28 \mathrm{kN}$. The numerical model results in an impact duration of $4.87 \mathrm{~ms}$ and maximum load of $3.44 \mathrm{kN}$, which is equivalent to $4.69 \%$ and $4.75 \%$ deviations. The computation time for this study was $6596 \mathrm{~s}(1 \mathrm{hr} 49 \mathrm{~min} 56 \mathrm{~s})$.

It is also noted that for low impact energy the numerical code provides acceptable solutions but as the impact energy increases the solution starts to deviate. The reason for such deviation is due to element deletion that occurs in the high impact energy models. The deviation will be discussed in more details in the following section.
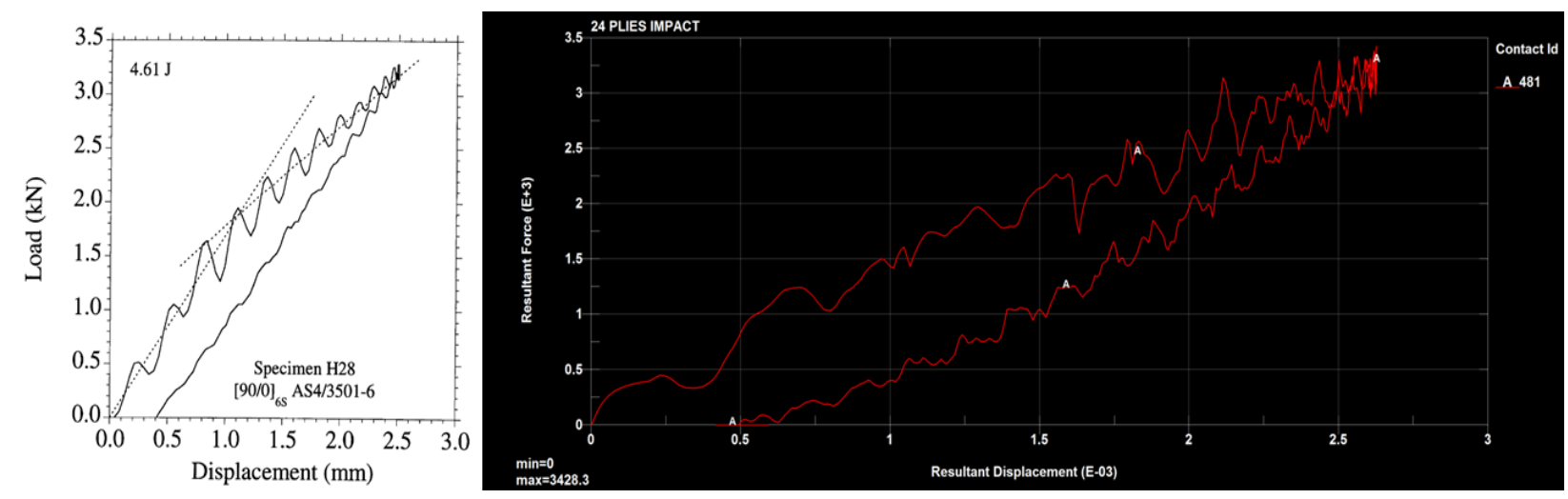

Figure 6.7: Force vs. Displacement response of the impactor-laminate of the experimental data and the

4.61 J impact response [6]. The numerical results are in ' $\mathrm{N}$ ' for load and ' $\mathrm{m}$ ' for displacement.

Figure 6.7 compares the contact force and impactor indentation of the experimental results and the same numerical model. At the maximum load value mentioned earlier, the experimental data yields a maximum displacement of $2.5 \mathrm{~mm}$, and the numerical model results in a maximum displacement of 2.63 $\mathrm{mm}$. This is equivalent to $5.09 \%$ deviation.

Similar pattern was found for the $6.24 \mathrm{~J}$ impact model, with differing energy magnitudes. Few differences in the experimental and numerical studies lead to such divergence in the results, and are discussed later. The computation time for this study was $3116 \mathrm{~s}$ (51 min $56 \mathrm{~s})$. 


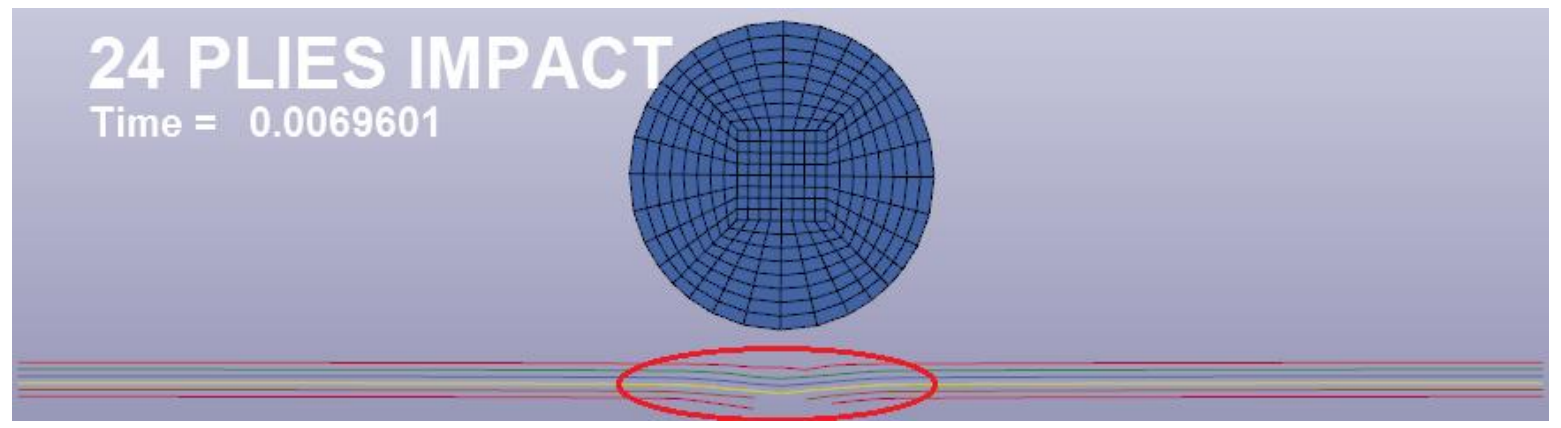

Figure 6.8: Delamination and ply failure in multi-layered laminates.

The numerical model can also detect delamination in the model. Figure 6.8 displays the delamination between the top two plies, as well as ply failure in the bottom two plies. The delamination is dictated by adhesive normal failure and shear failure stresses. The delamination detected in the model are useful for gaining preliminary understanding of the delamination location, sequence and damage area. For a better understanding of the delamination occurring in the numerical model, solid elements should be employed since they are capable of capturing the through thickness stresses.

The purpose of the numerical study is to study the effect of ply compaction and mesh refinement on the computation time and solution accuracy. To do so, several ply compactions and mesh element sizes are generated and their effect on the computational time and accuracy are compared. Table 6.5 and Table 6.6 present the results of ply compaction and mesh refinement on computation time and solution accuracy. The bolded column marks the best case.

Table 6.5: Computational time and solution accuracy deviation comparison for $4.61 \mathrm{~J}$ impact energy.

\begin{tabular}{|c|c|c|c|c|c|}
\hline \multirow{2}{*}{$\begin{array}{c}\text { Ply } \\
\text { Compaction }\end{array}$} & \multirow{2}{*}{$\begin{array}{c}\text { Mesh } \\
\text { Quality }\end{array}$} & \multirow{2}{*}{$\begin{array}{c}\text { Computation } \\
\text { Time } \\
\text { (s) }\end{array}$} & \multicolumn{3}{|c|}{ Solution Deviation (\%) } \\
\hline & & & $\begin{array}{c}\text { Impact } \\
\text { Time }\end{array}$ & $\begin{array}{c}\text { Maximum } \\
\text { Load }\end{array}$ & $\begin{array}{c}\text { Maximum } \\
\text { Displacement }\end{array}$ \\
\hline \multirow{3}{*}{$\begin{array}{c}\text { First ply } \\
\text { compaction }\end{array}$} & Coarse Mesh & 263 & 17.9 & 46.1 & 16.2 \\
\hline & Moderate Mesh & 1148 & 12.3 & 41.4 & 15.3 \\
\hline & Fine Mesh & 8064 & 12.1 & 42.1 & 15.6 \\
\hline \multirow{3}{*}{$\begin{array}{l}\text { Second ply } \\
\text { compaction }\end{array}$} & Coarse Mesh & 455 & 8.90 & 23.4 & 11.9 \\
\hline & Moderate Mesh & $\mathrm{n} / \mathrm{a}$ & $\mathrm{n} / \mathrm{a}$ & $\mathrm{n} / \mathrm{a}$ & $\mathrm{n} / \mathrm{a}$ \\
\hline & Fine Mesh & $\mathrm{n} / \mathrm{a}$ & $\mathrm{n} / \mathrm{a}$ & $\mathrm{n} / \mathrm{a}$ & $\mathrm{n} / \mathrm{a}$ \\
\hline \multirow{3}{*}{$\begin{array}{l}\text { Third ply } \\
\text { compaction }\end{array}$} & Coarse Mesh & 693 & 1.12 & 24.3 & 5.14 \\
\hline & Moderate Mesh & 3711 & 4.04 & 6.22 & 4.47 \\
\hline & Fine Mesh & $\mathrm{n} / \mathrm{a}$ & $\mathrm{n} / \mathrm{a}$ & $\mathrm{n} / \mathrm{a}$ & $\mathrm{n} / \mathrm{a}$ \\
\hline \multirow{3}{*}{$\begin{array}{l}\text { Fourth ply } \\
\text { compaction }\end{array}$} & Coarse Mesh & 2041 & 1.46 & 39.0 & 0.48 \\
\hline & Moderate Mesh & 6596 & 4.69 & 4.75 & 5.09 \\
\hline & Fine Mesh & $\mathrm{n} / \mathrm{a}$ & $\mathrm{n} / \mathrm{a}$ & $\mathrm{n} / \mathrm{a}$ & $\mathrm{n} / \mathrm{a}$ \\
\hline
\end{tabular}


Table 6.6: Computational time and solution accuracy deviation comparison for $6.24 \mathrm{~J}$ impact energy.

\begin{tabular}{|c|c|c|c|c|}
\hline \multirow{2}{*}{$\begin{array}{c}\text { Ply } \\
\text { Compaction }\end{array}$} & \multirow{2}{*}{$\begin{array}{c}\text { Mesh } \\
\text { Quality }\end{array}$} & \multirow{2}{*}{$\begin{array}{l}\text { Computation } \\
\text { Time } \\
\text { (s) }\end{array}$} & \multicolumn{2}{|c|}{ Solution Deviation (\%) } \\
\hline & & & $\begin{array}{c}\text { Maximum } \\
\text { Load }\end{array}$ & $\begin{array}{c}\text { Maximum } \\
\text { Displacement }\end{array}$ \\
\hline \multirow{3}{*}{$\begin{array}{c}\text { First ply } \\
\text { compaction }\end{array}$} & Coarse Mesh & 761 & 45.8 & 24.6 \\
\hline & Moderate Mesh & 1274 & 34.6 & 16.1 \\
\hline & Fine Mesh & $\mathrm{n} / \mathrm{a}$ & $\mathrm{n} / \mathrm{a}$ & $\mathrm{n} / \mathrm{a}$ \\
\hline \multirow{3}{*}{$\begin{array}{l}\text { Second ply } \\
\text { compaction }\end{array}$} & Coarse Mesh & 1588 & 9.17 & 17.5 \\
\hline & Moderate Mesh & 1462 & 22.9 & 10.2 \\
\hline & Fine Mesh & $\mathrm{n} / \mathrm{a}$ & $\mathrm{n} / \mathrm{a}$ & $\mathrm{n} / \mathrm{a}$ \\
\hline \multirow{3}{*}{$\begin{array}{l}\text { Third ply } \\
\text { compaction }\end{array}$} & Coarse Mesh & 2312 & 26.1 & 12.8 \\
\hline & Moderate Mesh & $\mathrm{n} / \mathrm{a}$ & $\mathrm{n} / \mathrm{a}$ & $\mathrm{n} / \mathrm{a}$ \\
\hline & Fine Mesh & $\mathrm{n} / \mathrm{a}$ & $\mathrm{n} / \mathrm{a}$ & $\mathrm{n} / \mathrm{a}$ \\
\hline \multirow{3}{*}{$\begin{array}{l}\text { Fourth ply } \\
\text { compaction }\end{array}$} & Coarse Mesh & 3116 & 28.8 & $\mathbf{1 0 . 0}$ \\
\hline & Moderate Mesh & $\mathrm{n} / \mathrm{a}$ & $\mathrm{n} / \mathrm{a}$ & $\mathrm{n} / \mathrm{a}$ \\
\hline & Fine Mesh & $\mathrm{n} / \mathrm{a}$ & $\mathrm{n} / \mathrm{a}$ & $\mathrm{n} / \mathrm{a}$ \\
\hline
\end{tabular}

From Table 6.5 and Table 6.6, the general trend shows that mesh refinement does not have as much of an effect in reaching the most accurate solution as done by increasing the number of plies, while also considering the computation time. Moreover, highly refined meshes lead to instabilities in the numerical model due to extensive number of contacts being generated for each individual elements.

For the $4.61 \mathrm{~J}$ numerical study, the third ply compaction and fourth ply compaction for all meshing quality give the best results. All values are within $10 \%$ of the true solution. For the $6.24 \mathrm{~J}$ impact energy numerical study, none of the meshing and ply compaction combinations led to all values being within $10 \%$ of the true solution.

The deviation in the experimental data and numerical results can be associated with the material properties, fixation modelling, and element sizing in the critical areas. While some material properties are provided in the experimental study, the missing properties are obtained via alternate source. In the experiment, the laminate is held in place via an aluminum top plate and steel bottom plate. In the numerical study, the edge nodes are modelled as fixed nodes. Lastly, the differences in higher impact energy models may be due to mesh sizing in critical failure locations. The element deletion removes load-bearing material from the numerical model and in effect altering its load capabilities, which is not representative of experiments. In experiments, even though cracks may occur, the same amount of material is not removed and the load-bearing capabilities of the laminate is higher. The mesh should be refined further to reduce the effect of element deletion on solution accuracy, but this also increases the computation time. 


\section{Additional Considerations}

The numerical code can be improved by incorporating the effects of fasteners and other stress concentrators that lead to early failure, and by predicting the post-failure repairs. To do so, one must first understand the nature of these phenomena. A brief literature review has been conducted on these topics and presented below.

\subsection{Effect of Fasteners on Stress Concentration}

Fasteners are among the most common joining methods used in the aerospace industry. Fasteners offer numerous benefits over the alternative joining methods such as welding, brazing, or adhesives. The most important benefits are joint strength, reversibility (for most types), cost-efficiency, and wide range of size availability [67]. Unfortunately, they also have a negative contribution towards the performance of the overall structures - the creation of stress concentrated regions.

FE modelling of fastener load transfer is the most common approach since no other techniques provides with the same flexibility in terms of modelling complex geometries and considering the various physical mechanisms [68]. The increased capability of FE analysis comes at the expense of increased computation cost. To reduce the cost, most analyses utilize 2D continuum elements to study the behaviour of fasteners [68]. The effect of fasteners are critical in the modelling of impact damage of multi-components sections, like the fuselage section, because they can have significant contribution towards early elemental failure.

\subsubsection{Considerations}

The most commonly used fasteners in aviation are rivets. Tens of thousands of rivets are used in a typical aircraft and have a significant influence on the fatigue performance - a major concern for the service life [69]. Different types of rivets serve different purposes, for example, countersunk rivets are mainly used for external surfaces of aircraft in order to reduce the aerodynamic resistance [69]. When using fasteners in designs, several considerations should be taken into account like the geometric, material, structural and the manufacturing properties.

In stressed components, changes to the cross section forces the load path to change accordingly. Modifications to components like holes, notches, variation in cross-sectional area, sharp corners, and thread to shank transition, all have stress riser effects on the design and ignoring any of these can result in catastrophic failure of the design [70]. In fastener joints, crack usually initiates at the joints because of high stress concentration in the region [69]. In joints with several rows of fasteners, the longitudinal stress are different over the cross section due to the variation of fastener reaction load and bypass load [68]. Moreover, 
fasteners with threads add discontinuities to the load path which commonly results in tensile failure within the first 3 threads in cases of thread run-outs [70].

A common design practice to reduce stress concentration in fastener region is by ensuring that the minimum elongation of the fastener material is not less than below 10\% [70]. Material elongation (ductility) goes down as the strength goes up which makes the material to become more brittle. Brittleness of materials make it sensitive to discontinuities, resulting in increased stress concentration factors. Furthermore, additional considerations are required when utilizing fasteners to join anisotropic materials. The mechanical, physical and thermal properties of anisotropic materials, such as CFRPs, are directiondependent, and complicates the stress analysis in the neighbourhood of holes [71].

The load carrying capacity and fatigue resistance of riveted joints depends on many structural and manufacturing factors. The structural factors include connection type, size, rivet pitch and spacing, sheet thickness, diameter of rivet shank and rivet type [69]. The manufacturing factors are mainly the method and quality of riveting, such as the hole drilling, edge finish, hole concentricity of joining sheets, and rivet squeezing [69].

\subsection{2. $\quad$ Stress Concentration Factor}

Stress concentration factor gives an indication of where the stress is concentrated in the design and in effect identifies the critical locations. In plates with circular straight-shank holes subjected to remote tension, the stress concentration factor is at its maximum at the mid-thickness of the isotropic plate and drops near the free surface [71]. This creates localized stress in the fastener at mid-thickness because of the load that are being transferred from the plate. In fastener designs, steps can be taken to lower the stress concentration factor and evenly distribute the loads. Darwish, Tashtoush and Gharaibeh [71] in their study of stress concentration analysis for countersunk rivet holes in orthotropic plates subjected to tensile loading deduced that: 1) maximum theoretical stress concentration factor occurs at the countersunk edge, and 2) the theoretical stress concentration factor monotonically increases with the countersink radius to plate width ratio, plate thickness to countersink radius ratio, countersink depth to plate thickness ratio, and with the countersink angle. Similarly, in threaded components, the threaded portion's minor diameter should be greater than the diameter of the unthreaded portion. This eliminates the stress concentration factor as long as the transition radius between the two sections is generous [70].

\subsubsection{Performance Improvement}

Fasteners can be highly effective when interference fit fasteners are used. Interference fit fastener contains cylindrical part having a diameter larger than that of the hole where it is fitted and the two parts are locked together by the tightening load, and the combined effect of friction and radial pressure that is 
caused by the interference in size and their interface diameter. This process makes the fastener hole less susceptible from crack propagation, and increases the fatigue life of structures [72]. In $90 \%$ of cases on the fatigue life prediction of interference fit fastener, the crack initiation takes place between the bore and edge of the joining plate instead of the circumference of the hole [72].

Another method of improving load transfer is by adjusting the sizing and the positioning. Ekh and Schon [68] in their FE study of load transfer in multi-fastener joints showed that: 1) stiffness mismatch between the adjacent plates shifts the load over to the fastener located closest to the clamped end of the thinner plate, which could be significant for certain joint configurations, 2) using larger bolts for the inner positions has the potential to create an even load distribution for some joint configurations, and 3) row spacing affects the load distribution, such as moving the inner fasteners closer to the outer ones or reducing the length of the overlap region, causes the load distribution to become more even.

Lastly, riveting processes can be used to increase the service life because they are known to create a residual stress state in the joint, which despite exceeding the yield strength, has a profitable influence of the fatigue performance [69].

\subsection{Repair}

Repairs are essential for performing life extensions of structures that may have reached their service life or may have been damaged prematurely. Bonded composite patch repair methodologies are seen as the most viable method for repair because the fiber reinforced layers of the repair patch can be optimized to handle any magnitude and direction of loads that are seen during service [73].

Bonded composite patches are often used as an economical repair strategy to restore the strength of heavily loaded aerospace structures after non-catastrophic damage. Component repair over replacement leads to significant cost savings [74]. Bonded repairs offer a wide range of advantages such as ease of application without any damage to the underlying structure, they offer high stiffness to weight ratio, and such repairs can be readily formed into various complex shapes [75]. On the other hand, issues in bonded repair include the inability to predict the fatigue growth of cracks under the bonded patch as well as the effect of disbond of the patch on the effectiveness of the repairs [75].

Important considerations for bonded repair include asymmetry of the fracture surface, residual thermal stresses, and local debonding of the adhesive layer [76]. These considerations need to be accounted for in order to avoid the development of nonlinear distributions of stress intensity factor through the plate thickness. Secondary bending is another common issue for bonded repairs. There are three main individual effects which are important for the design of a bonded repair without a secondary bending [77]: (1) residual 
thermal stresses, (2) patch aspect ratio, and (3) tapering ratio. Consequently, a two-sided bonded repair has no secondary bending due to a symmetric lay-up of the patch-plate combination [77].

\subsubsection{Composite Repair Techniques}

The main objective of any repair is to return the damaged component or structure back to its original state in the most economical approach possible. The economic factors vary for every repair and can range from time consumption to material costs or from labor costs to the economic loss endured by an airline while the aircraft is taken out of service. Structural resistance, quick and easy setting are the first objectives for repair efficiency [78].

Whenever a repair is being conducted, the actual damages should always be assumed to be more extensive than the visible damage present. This is mainly because the subsurface damage propagates drastically as one move into the thickness of the laminate. In more scientific terms, due to the high modulus of fibers, during damage the laminate usually springs back and leaves residual subsurface damage in the form of broken fibers, ply separations, crushed cores, and disbonded face sheets for sandwich panels [79]. Combining this with the earlier discussion, impact damage is a major issue in the design of laminated composite structures as it may reduce strength and stiffness significantly without any visible damage to the surface [21]. The accumulated damages are hidden under the exposed surface of the composite structure. The criticality of impact damage becomes highly severe in the case of low-velocity and high-mass projectile impacts. In critical impact locations (for example, the under-skin of the wing being exposed to rocks and other particles on the ground during taxing, takeoff and landing) the reinforcement of composites with Kevlar fibers can significantly increase the impact damage tolerance if used in place of or in conjunction with carbon fibers. Once the failure of the brittle layers (carbon fibers) is reached in an interlaminar hybrid, the load can be transferred to the ductile layers (Kevlar) if bonding between the laminates is sufficient [80]. Also, the addition of Kevlar and hybrid to the facesheets actually reduces the overall weight of the composite compared to the entirely carbon fiber samples due to the lower areal densities of Kevlar and hybrid fabrics compared to the carbon fiber [80]. Repairs are also known to improve the capacity of the structure to take compressive loads. The repaired structure is much thicker locally and reduces the damage to the parent laminate underneath, and possibly raise the load at which buckling in the damaged region of the parent structure will occur [81]. As for the tensile loads, the most influential parameter is the bonding strength since it is the bond that transfers the tensile load across the repair in the form of shear load.

The extent of structural strength recovery depends on energy of impact and eventually the size of repaired damage. Cheung et al. [82] concluded that average repair quality systematically degrades as repair size increases, which also reduced the reliability of structure if the damages grow. The underlying reason 
for the finding is that repair techniques (based on the repairs available when the corresponding inspection is carried out) do not always take into account the different materials, differences in methods of repair, the original manufacturing standards and the limited quality control. This leads to an imperfect strength recovery and degradation in the repair quality. Moreover, the effects of imperfect strength recovery become more pronounced as the damage size increases. Since load exceedance is distributed approximately exponentially, a bad repair will have a much larger negative impact on reliability than the positive impact an above average repair would bring. This also leads to the fact that, from a reliability standpoint, a repair technique with high scatter in strength recovery is equivalent to a technique with a lower strength recovery capability [82]. Statistically, a high degree of variation in the data leads to uncertainty in the results. In order to be safe one should take the lower end of the results spectrum and deem it as the final result or collect more data till the results stabilize. The latter is can be very time-consuming and cost-consuming, and it is generally acceptable to take lower strength recovery values as a safe approach.

The most common approach for composite repair is through bonded doubler or scarf repairs. Sometimes they can be used in conjunction with one another to form scarf-doubler repairs. A doubler or patch repair is a set of filler plies that are bonded onto the surface of the damaged section. A scarf repair is performed by sanding a set of plies in a tapered fashion to match the profile of the damage and placing the sanded plies in to the damaged section [83]. A scarf-doubler repair is simply the combination of the two where a scarf repair is used to fill the damaged section and the doubler is bonded on top of it to cover the damaged section. In studies performed by Harman and Rider [81], scarf-doubler repairs where thickness of the doubler matched the thickness to the parent structure offered the maximum capacity available to achieve strength targets as close to the undamaged strength of the parent laminate. The presence of the scarf-doubler repair also improved the capacity of the structure to retain compression strength following an impact. The compression strength was shown to be insensitive to delamination damage at the bondline and the adjacent adherends caused by the impact, but sensitive to the extent of internal damage caused to the parent laminate, with the failure shown to progress through the thickness of the parent laminate adjacent to the location of the impact [81].

Doubler and scarf repairs can also be applied to the sandwich panel composites. Sandwich composites are very suitable for lightweight structures requiring high in-plane and flexural stiffness and are extensively used in engineering designs. A vital element of the sandwich construction is the effective bond between the facesheet and the core material. The joint must be stiff and strong, as well as tough in order to allow the sandwich structure to sustain high loads over a long service life [80]. The doubler and scarf repair are applied to the sandwich in the same manner as a regular laminate. For both the doubler and scarf repairs, the damaged facesheets are replaced with filler plies, the only difference being in the method of replacement, as mentioned above. Another type of repair that is can be applied to composite repairs is the 
step sanded repair. However, this technique has found very limited use since it is extremely difficult to cut each layer of the filler plies to the correct dimension in order to form the step-like geometry [83]. Therefore, the review will only focus on doubler and scarf repairs because of their widespread applications in the aerospace industry.

\subsubsection{Scarf Repair}

A scarf repair is essentially a set of plies that are sanded in a tapered fashion to match the profile of the damage. The sanded plies are then placed in to the damaged section to fill and cover the damaged area.

The quality of scarf repair is heavily dependent on the bonding between the filler plies and the parent material. Experimental tests performed on scarf repairs have shown that fracture surface tend to propagate at the adhesive-composite interface [84]. This clearly indicates the importance of good bonding adhesion and the bonding geometry between the filler plies and the parent material. Additional test data also indicate that a bond line angle of less than $60^{\circ}$ with respect to the load direction would restore the strength nearly to that of an undamaged composite strength [73]. This adds to the validity to the importance of the bonding geometry. A bond line angle of less than $60^{\circ}$ essentially means a shallow angle. The shallow angles lead to greater contact area between the filler plies and the parent material. Intuitively, one can imagine that as the contact area increases, the bonding area, leading to bonding strength, will also increase.

To have a better understanding of repair quality, one must also look into the effects of adhesive disbond, that is, small voids between the filler plies and the parent material. An adhesive disbond is equivalent to air voids trapped within laminates as a result of poor manufacturing. The study by Li et al. [74] showed that the presence of a disbond had a significant effect on the surface strain distribution due to the severed load path. The surface strain distribution is highly localized around the disbond region. If disbonds appear in the plies, the integrity of the scarf repair is threatened. It is also possible for a disbond in the scarf repair to occur with no damage to the over plies. The presence of a disbond considerably alters the strain profile. Within the disbonded region, a large reduction in strain is observed indicating significant load shedding. The disbond is an empty space within the bonding and therefore as the material deforms due to excessive loading, the lack of material or the discontinuity of the material leads to zero strain since no material is being elongated. The effect is highly localized, with the far field strain remaining undistributed by the presence of the damage because of the uniformity in the material.

Scarf repairs has been shown to have several advantages over other repair methods, including [73, 81, 83-84]: (1) scarf-repair in moisture conditioned state show an increase in the shear strength as the testing 
temperature decreases, (2) scarf repairs do not add high amounts of resin meaning it does not modify the percentage relation between fiber and matrix, (3) scarf joints experience lower peel stress compared to other joint configurations, (5) existence of a small delamination under the surface layer of the patch does not affect the performance of scarf-repaired panel under static tensile load, (6) the repairs are only marginally thicker than the parent material, (7) each repair ply overlaps the ply that it is repairing resulting in a straighter and stronger load path, (8) scarf repairs minimize the secondary effects of bending and, (9) scarf repairs offer a flush finish and have the ability to repair thick structures. The disadvantages of scarf repair are as follows [79, 83-84]: (1) scarf repairs are more difficult to apply, (2) scarf repair techniques induces small resin-rich regions in the laminate which can contribute to strength reduction of the composite, (3) scarf repairs are very time consuming, and (4) resin heterogeneity and the discontinuity of the reinforcement in the repaired areas leads to differences in strength and fatigue resistance of original and scarf-repaired composites.

Additional considerations surrounding scarf repairs limit its application such as the boundary conditions and the complexity of the repair geometry. Although in other instances, scarf repair is the only viable method because of the nature of the repair, such as applications requiring for surface flushness due to aerodynamic considerations are ideal scarf repairs [74].

\subsubsection{Doubler Repair}

Doubler repairs are patched repairs using a set of filler plies that are bonded onto the surface of the damaged section to cover the damaged area. The repair does not fill the damaged area with filler plies.

To determine the effectiveness of the bonded repair, two important quantities of interest are [77]: 1) the crack-tip stress intensity factor, and 2) the stress concentration (load attraction) in the skin near the edge of the patch. Stress intensity factors help predicts the stresses near the tip of the crack caused from remote loads or residual stresses. Applied to bonded repairs, the stress intensity factor is an indicator of the crack growth rate underneath the patch since the higher the stress intensity factor value is, the higher the stresses will be leading to quicker growth of the crack. Equally important is the stress concentration because it helps with the assessment of damage initiation in the parent material adjacent to the patch. The bonding length seems to be the most significant parameter for the repair efficiency. Increasing bonding length allows the stress flux from the parent material towards the repairing patch to be higher [78]. The stress in the parent material decreases as the bonded length increases. However, the global strength of the repaired specimen will always be lower than the parent material. In order to achieve the same strength as the parent material requires the patch to be the same size as the parent material, in which case the parent material is simply being replaced rather than being repaired. Bonding length has no influence on shear stresses in the adhesive 
joint near the damage, but has a large influence on shear stresses in the adhesive joint at the end of the last repairing ply [78]. As one moves away (in the thickness direction) from the location of the damage, the shear stresses tend to increase within the filler plies. The filler ply farthest from damage experiences the greatest stresses in tension or compression because it is the longest and covers all other filler plies. The high stresses leads to early separation between the farthest filler ply and adjoining filler plies. The overlapping length is the difference in half-length of the overlapping filler ply layers. It has been shown that the overlapping length increase has a minor influence on the direct stress in the laminated plate, but it increases the filler plies' contribution to cause a large reduction of the shear stress in the adhesive joint [78]. An overlapping length increase leads to a gradual increase in the thickness of the patch. The gradual increase causes a more even distribution in the shear stresses within the filler plies. Intuitively, one can image that if the overlapping length was zero, that is, a prismatic patch, the shear stresses will see a discontinuity as they move closer to the edges of the patch. The overlapping avoids this and leads to uniform distribution in the shear stress as one moves closer to the patch edges. Moreover, the secondary bending effects caused by the introduction of filler plies can be reduced by lowering the number of repairing plies. This causes the assembly neutral plane to be nearer to the center of the plate.

Repair efficiency of doubler is highly dependent on the fiber orientation, loading conditions and the location of disbonds. Chue et al. [85] showed that in cases of bi-axial loads, the fiber orientation should coincide with the maximum tensile load direction in double-sided patching and be perpendicular to the crack in single-sided patching for maximum effectiveness. Additionally, Chow and Atluri [75] showed the effectiveness of the composite patch is more sensitive to disbonds in the filler plies located at the center of the crack rather than disbonds located at the crack tips. The considerations listed above are essential for improving the quality of doubler repairs.

The advantages attributed to the doubler repairs are [83-84]: (1) the joint strength of the adhesive increases proportionally with the doubler stiffness in hot and wet surrounding conditions, (2) quick and simple to perform, and (3) minimum preparation required to conduct. The disadvantages of doubler repairs are [83-84]: (1) the strength of the doubler may be compromised by the geometric non-linear bending since it increases the stress concentration adjacent to the damage cut-out region, (2) geometrically uneven patching will lead to bending due to the shift in the neutral plane, (3) the repaired component is thicker and thus heavier than the original part, and (4) a very careful surface preparation is required for good adhesion.

Doubler repairs are commonly used for structural repairs of components where aerodynamic consideration is not the greatest or if the repair requires a relatively smaller patch. The doubler induces additional thickness onto the structure causing a disturbance in the airflow around it. If the repair is to be done on a critical aerodynamic component such as the wing, it is important to first understand the geometry 
of the damage. If the geometry of the damage is relatively smaller than the doubler can be used without causing much disturbance to the airflow around it. If the damage geometry is large than scarf repairs would generally be the better repair choice. Internal components that do not see airflow are ideal for doubler repairs because of its benefits over scarf repairs.

\subsubsection{Additional Considerations}

\subsubsection{Surface Preparation}

Surface preparation is perhaps the most important processing step to govern the quality of an adhesive bond. A good surface preparation provides a clean bond surface and also fresh cleaning that avoids adsorption of gases [86]. Inert gases are sometimes used for the surface preparation process in order to prevent any unwanted chemical reactions that may degrade the quality of the bonding. Surface preparation is essential in increasing the bond strength in a number of ways including [87]: (1) increasing surface tension, (2) increasing surface roughness, or (3) changing surface chemistry.

The basic steps for adequate surface preparation are [88]: (1) the surfaces being joined must be free of contamination by removing surface contamination through degreasing, (2) the parent material and the repairing plies must be a sufficiently fresh and chemically active to enable formation of chemical bonds between the adhesive and the surfaces, typically by chemical etching or surface abrasion, and (3) the surfaces should be chemically modified (especially by hydration) to produce an interface that is resistant to environmental deterioration in service. Degreasing is commonly used approach for removing oil, grease, dirt, loose particles or any other contaminants from the surface of the parent material. In composite repairs, degreasing is generally a prequel for future steps such as surface abrasion. The abrasion of composite surface with alumina sandpapers help to remove the loose carbon fibers and resin flakes from the matrix. The loosely bound fibers and matrix lead to reduction in the bond strength [84]. Hydration allows for an enhanced intermolecular attraction between the adhesive and the surfaces of the repairing plies and the parent material by attraction and association of the molecules.

Numerous studies have been conducted on the quality of surface preparation as it relates to more than just repair such as in the case of simple tensile and fatigue tests where the bond between the composite and the end tabs is critical. In regards to composite repair, void formation and wettability of adhesion are of high importance. Studies on vacuum pressurizations have found that voids can be reduced if the vacuum was released at the adhesive flow temperature and a small positive differential pressure was maintained during cure [84]. The small positive differential pressure enables any trapped air pockets in the vacuum to be removed. The magnitude of the pressure difference determines the speed of the air exiting. A greater 
speed may cause spillage of the adhesive and therefore affecting the quality. Another way of reducing voids is by adhesive staging [84]. Adhesive staging is a process that utilizes heat to remove volatile components that can produce voiding during high temperature cure. Similarly, wettability of an adhesive can also be enhanced. Plasma treatment increases the oxygen content of the surface and thus the wettability, corresponding to an increase in the surface energy of the composite [84]. The plasma treatment alters the surface chemistry and enables the water to spread out which is equivalent to oxygen being spread out. Oxygen allows for better contact between the surfaces and the adhesive, leading to an improved adhesion. Complete wetting (i.e., for a contact angle equal to zero) can also be theoretically achieved if the surface energy of the adhesive is lower than the surface energy of the surfaces of the composite and the filler plies [87]. Therefore, the primary objective of surface treatment is to increase the surface energy of the surfaces as much as possible.

\subsubsection{Adhesion}

The purpose of a good adhesion is to transfer the axial loads across the crack in the form of shear loading. It is very important for an adhesion to not fail under such loads otherwise the material will fracture further. In order to perform its job, the adhesive material must have sufficient toughness to dissipate energy from cracking, and sufficient strength and stiffness to transfer stresses between the parent and repair materials [89]. When the adhesion is strong enough to prevent any cracking within the adhesive, debonding cracks will primarily propagate within the parent material and repair filler plies and cohesive failure will occur. Over the years adhesive bonding has proven to be very effective method of joining dissimilar materials, and the most suitable method of joining for metallic and non-metallic structures where strength, stiffness and fatigue life must be maximized at minimum weight $[87,90]$. An additional benefit that comes with polymeric adhesive/polymer interface is the decreased likeliness of failure due to environmentalinduced stress because of the nature of bond formed [87]. Under exposure to hot/humid environmental conditions, a polymeric adhesive/polymer interface is much more stable than the equivalent polymeric adhesive/metal interface. Overall mechanical strength of adhesive-bonded joint is, in its majority, dependent on the adhesive properties (strength and ductility), but joint configuration also plays an important role. If the adhesive shear stresses distribution in an overlap-bonded joint is uneven, the edges will experience the loading peak values, while the central regions will be less affected [91-92]. The effectiveness of the adhesive bonding is dependent upon many variables including [93]: (1) the polymeric composition of the adhesive, (2) surface preparation materials and method of surface pretreatment, (3) adhesive lay-up procedure, (4) tooling, and (5) curing process. 
Adhesive bonding offers many advantages over other forms of joint. The major benefits of adhesive bonding are [93]: (1) the ability to join dissimilar materials, (2) exhibit higher stiffness, (3) more uniform load distribution, (4) cleaner lines for aerodynamic benefits, (5) not requiring holes to be drilled on the surfaces leading to elimination of extra stress concentrations, (6) generally less labor cost, (7) high resistance to fatigue, and as a consequence (8) reduced life-cycle maintenance costs. The primary drawback of polymeric adhesives is the service temperature limitation. Organic polymers maintain their mechanical integrity only at relatively low temperatures, and strength decreases rapidly with increasing temperature [87]. The joint strength of the adhesion significantly reduces as the glass transition temperature falls below the test temperature [84].

The effect of temperature and moisture can be drastic on the performance of repairs. At high temperatures, the effect of moisture on the adhesion and composite may be significant because the strength of the adhesive and the matrix are related to the glass transition temperature, which depends on the cure temperature and moisture state. The adhesive strength lowers as the temperature increases in the dry condition [84]. In a study by Harman and Rider [81], more adhesive failures are observed in the elevated temperature with wet environment than in room temperature with dry environment. Upon impact, the fracture path of damaged specimens in room temperature with dry conditions passes into the first ply of the parent laminate but for the elevated temperature with wet conditions the fracture path continues through the adhesive. From above, temperature and moisture conditions are equally important for adhesion strength. Temperature and moisture influences the physical and mechanical properties of the adhesion and can either deteriorate or improve the performance. The effect of disbonds also plays a major role in thermal deterioration especially when the repair patch differs from the parent material. Specimens with repair materials differing from parent material that undergo a thermal-mechanical-fatigue cycle are more sensitive to disbonds in the adhesive layer than similar specimens that undergo mechanical fatigue loading at a constant loading [75].

Adhesives generally poses poor wetting characteristics because of their high viscosity state during bonding. Primers are normally used to pretreat high surface energy substrates prior to adhesive bonding. This can improve the performance of the bonded component. Furthermore, primers offer improvements in such aspects as thermal stability and environmental resistance, establishing strong and moisture-resistant interfacial bonds and protecting surface regions of the substrate from hydration and corrosion [89]. Applying primers as a coupling agent on the composite surface can significantly help to improve the bonding strength, especially for poorly treated surfaces. 


\subsubsection{High Temperature Applications}

Repairs of components or structure that are exposed to high temperatures are still of a major challenge. A common example is the carbon fiber based composites with bismaelemide (BMI) resin. These composites have become increasingly popular in the design of modern aircraft due to their exceptional performance properties and high operating temperature range. However, a major drawback of this material, particularly from ease of repair point of view, is that it requires a post-cure of $227^{\circ} \mathrm{C}$ [81]. CFRPs are by far the most commonly used composites in the aerospace industry. Hence repair methodologies that require for high temperature curing need to be better addressed. Problems also arise in the cases of composites of different filler ply and parent material. Thermal residual stresses will occur due to differences in the thermal expansion coefficient upon cooling the fully cured repair from elevated curing temperature to the ambient temperature $[75,77]$. During the curing, either material will contract much more than the other during the cooling from the cure to room temperature. As a result, the crack surfaces will be opened by the residual stress generated resulting in high stress concentrations at the crack tips. Moreover, repairs undergoing a thermal cycle would be more affected by partial disbonds than the specimen loaded at constant temperature [75]. The thermal cycle will result in an expansion/contraction cycle for the material which can be thought of as a fatigue cycle. The disbonds will consequently turn into initial crack propagation points. The disbonds will significantly reduce the life as the number of cycles leading to first crack has been eliminated. Hence, early failure is imminent. 


\section{Conclusions}

In recent years, the usage of CFRPs in the aviation industry has increased significantly. While numerous advancements have been made in the field of testing and analysis of advanced composites, improvements can still be made in terms of time and cost. This thesis focused on nonlinear 3D transient dynamic impact behaviour and numerical techniques of reducing computational and time costs while maintaining the accuracy of results.

The first study on low-velocity and high-energy impact on a stiffened composite fuselage section via a cylindrical impactor allowed for a better understanding of the critical damage locations, the failure sequence, the failure loads, and the failure times. The critical location is at the impact site. The impact generates a highly localized stress region and due to the short duration of the event, the material is unable to successfully dissipate the load leading to failure. The failure sequence begins with the failure in the shear ties and extends to the frames as time progresses. The bend in the shear ties makes it geometrically prone to failure. The load from the skin impacting onto the shear ties at the bend leads to its inevitable failure. Moments later, the frames fail at the stringer/frame connection. The loads are transferred onto the frames via the stringers which are directly connected to the skin. The bent edges in the frames also make them geometrically prone to failure. Lastly, all of the failures occur before the maximum internal energy is reached. This is important because one does not need to wait until the impactor has completely separated from the fuselage section to call a solution valid. One can save computation time by stopping the iterations as soon as the maximum internal energy is reached because all of the primary failures have already occurred.

Comparisons between the numerical results and those of an experimental study of a similar problem have shown that the overall failure mechanism and sequence, crack location, and its direction match closely. In both instances, the failure sequence began with the shear ties through the formation of a crack across the width that separates the shear ties and ended with the crack formation in the frames on the frame/stringer contact. The direction and the length of the crack in the components matched closely for both the experimental and numerical studies. However, deviation in the load and indentation is observed. The factors possibly leading to such deviations were briefly discussed. Nonetheless, it is concluded that for preliminary design purposes, the ability to identify the critical areas of the structure upon impact in a computationally efficient manner outweighs the desire for a high level of precision which often comes at a prohibitive computational cost.

The second study is on impact of a HTA/6376C carbon fiber/epoxy cantilever plate using an Aluminum 7075-T6 impactor. This helped to understand the effectiveness of using supernodes in analyses rather than a complete model. Based on the study, it can be seen that supernodes can effectively and 
efficiently replace entire models for the impact duration. However, moments after the laminate and impactor separation during the rebound stage, the results of the supernode models start to deviate from that of the complete model. This deviation is below $3 \%$ for the maximum deflection and below $10 \%$ for the maximum principal stress experienced by the laminate. The deviation continues to grow after the impactor and laminate separate because the supernode model is unable to capture the reflecting deflection and stress waves from the boundaries. Nonetheless, it should be noted that in cases where the post-impact time history of the load, deflection, or any other variables, are not as important as those at the initial impact stages, the supernode model should be utilized in order to reduce model complexity and to save computation time.

Lastly, the third study on impact of AS4/3501-6 laminate via a hardened steel impactor provided an understanding of ply compaction and mesh refinement on LS-DYNA's computation time and solution accuracy. The study also allowed for understanding the material behaviour during impact and gave a preliminary insight of the interlaminar delamination locations and sequence. The general trend observed in the study is that the number of plies in the model has a more significant effect on the solution accuracy than the mesh sizing, while also considering the computation time. Increasing the number of plies will increase the solution accuracy. On the other hand, element deletion (material failure) in the solution starts to increase the deviation because mass and volume are being removed from the numerical model which is not representative of experiments. One way to reduce the effect of element reduction is through mesh refinement which in turn leads to additional computational time.

To validate the findings, the numerical results were compared with the experimental results of G. A. Schoeppner's and S. Abate's experiment on delamination threshold load at low velocity impact. The study represents $4.61 \mathrm{~J}$ and $6.24 \mathrm{~J}$ impact energy drop tests on a 24-ply AS4/3501-6 laminate. The comparison yielded deviations of less $6 \%$ for the impact duration, maximum load, and maximum displacement for the $4.61 \mathrm{~J}$ study; and deviations of upto $30 \%$ for the maximum load and maximum displacement for the $6.24 \mathrm{~J}$ study. 


\section{FUTURE WORK}

The numerical code can be further enhanced by accounting for the recommendations listed in Chapter 7.

In addition to the recommendation listed in Chapter 7, the numerical can be impeoved by accounting for post-impact damage propagation and failure. In cases where impact does not lead to immediate failure, a model for post-impact damage growth should be considered to see the alterations to the load path, and how much residual load the structure can withstand before failure. The following points summarize the recommendations for future work:

- $\quad$ Consider the effects of ground and air static loads that are experienced by the aircraft during flight. Some examples of the ground static loads are taxiing, towing, and landing loads. Air static loads include the loads common during manoeuvre and gust loads. Cabin pressurization loads should also be considered.

- $\quad$ Fatigue loads resulting from the various ground-air-ground cycles that are seen by the aircraft over its life should be accounted for. Fatigue loads can cause serious damage to aerostructures if not analysed proeperly and can lead to early failure of the structure. 


\section{APPENDICES}

NOTE: The node and element numbering are not shown for any of the source codes.

Source Code 1: Low-Velocity and High-Energy Blunt Impact

*KEYWORD MEMORY=40000000 NCPU $=4$

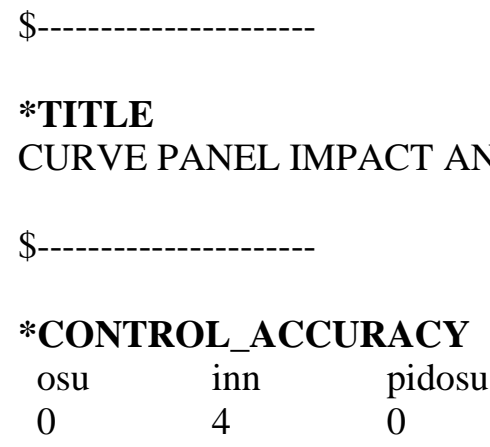

$\begin{array}{llllllll}\text { *CONTROL_CONTACT } & & & & & \\ \text { slsfac } & \text { rwpnal } & \text { islchk } & \text { shlthk } & \text { penopt } & \text { thkchg } & \text { orien } & \text { enmass } \\ 0.1 & 0 & 2 & 0 & 0 & 0 & 1 & 2 \\ \text { usrstr } & \text { usrfrc } & \text { nsbcs } & \text { interm } & \text { xpene } & \text { ssthk } & \text { ecdt } & \text { tiedprj } \\ 0 & 0 & 0 & 0 & 4 & 0 & 0 & 0 \\ \text { sfric } & \text { dfric } & \text { edc } & \text { vfc } & \text { th } & \text { th } & \text { _sf } & \text { pen_sf } \\ 0 & 0 & 0 & 0 & 0 & 0 & 0 & 0 \\ \text { ignore } & \text { frceng } & \text { skiprwg } & \text { outseg } & \text { spotstp } & \text { spotdel } & \text { spothin } & \\ 0 & 1 & 0 & 0 & 0 & 0 & 0 & \\ \text { isym } & \text { nserod } & \text { rwgaps } & \text { rwgdth } & \text { rwksf } & \text { icov } & \text { swradf } & \text { ithoff } \\ 0 & 0 & 0 & 0 & 1 & 0 & 0 & 0 \\ \text { shledg } & \text { pstiff } & \text { ithcnt } & \text { tdcnof } & \text { ftall } & \text { unused } & \text { shltrw } & \\ 0 & 0 & 0 & 0 & 0 & 0 & 0 & \end{array}$

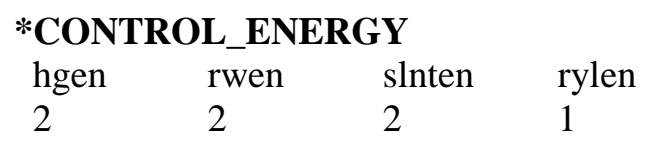

$\begin{array}{llllllll}\text { *CONTROL_SHELL } & & & & & \\ \text { wrpang } & \text { esort } & \text { irnxx } & \text { istupd } & \text { theory } & \text { bwc } & \text { miter } & \text { proj } \\ 20 & 0 & -1 & 0 & 2 & 2 & 1 & 0 \\ \text { rotascl } & \text { intgrd } & \text { lamsht } & \text { cstyp6 } & \text { tshell } & & & \\ 1 & 0 & 1 & 1 & 0 & & & \\ \text { psstupd } & \text { sidt4tu } & \text { cntco } & \text { itsflg } & \text { irquad } & & & \\ 0 & 0 & 0 & 0 & 2 & & & \\ \text { nfail1 } & \text { nfail4 } & \text { psnfail } & \text { keepcs } & \text { delfr } & \text { drcpsid } & \text { drcprm } & \\ 1 & 1 & 0 & 0 & 0 & 0 & 1 & \end{array}$

\section{*CONTROL_TERMINATION \\ endtim endcyc dtmin endeng endmas}



0.19
0
0
0
0

$\$$

*DATABASE_GLSTAT

$\begin{array}{llll}\mathrm{dt} & \text { binary } & \text { lcur } & \text { ioopt } \\ 7.6 \mathrm{E}-4 & 1 & 0 & 1\end{array}$

*DATABASE_RCFORC

$\begin{array}{llll}\mathrm{dt} & \text { binary } & \text { lcur } & \text { ioopt } \\ 7.6 \mathrm{E}-4 & 1 & 0 & 1\end{array}$

*DATABASE_SLEOUT

$\mathrm{dt}$ binary lcur ioopt

$\begin{array}{llll}7.6 \mathrm{E}-4 & 1 & 0 & 1\end{array}$

\section{*DATABASE_BINARY_D3PLOT}

$\begin{array}{lllll}\mathrm{dt} & \text { lcdt } & \text { beam } & \text { npltc } & \text { psetid } \\ 7.6 \mathrm{E}-4 & 0 & 0 & 0 & 0\end{array}$

ioopt

0

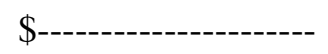

*BOUNDARY_SPC_SET_ID

id heading

0 IMPACTOR TWISTING CONSTRAINT

$\begin{array}{lllllll}\text { nsid cid dofx dofy dofz } & \text { dofrx dofry }\end{array}$

$\begin{array}{llllllll}1 & 0 & 1 & 1 & 0 & 1 & 1 & 1\end{array}$

*BOUNDARY_SPC_SET_ID

id heading

$0 \quad$ FIX END

nsid cid dofx dofy dofz dofrx dofry dofrz

$\begin{array}{llllllll}2 & 0 & 1 & 1 & 1 & 0 & 1 & 1\end{array}$

\$-----------------------

*CONTACT_SPOTWELD_ID

cid title

1 SKIN-STRINGER

ssid msid sstyp mstyp sboxid mboxid spr mpr

21

fs $\quad$ fd

$0.2 \quad 0$

sfs $\quad$ sfm

$1 \quad 1$

soft sofscl

$1 \quad 0.1$

3

$\mathrm{dc}$

0

sst

0

lcidab

0

3

0

$0 \quad 0$

0

vc vdc

0

$\mathrm{vdc}$

penchk bt

$0 \quad 0$

mst sfst sfmt fsf

$1 \quad 1$

0

maxpar sbopt depth bsort

$1.025 \quad 2$

2

0

$\mathrm{dt}$

$1 \mathrm{E}+20$

vsf

1

frcfrq

1

*CONTACT_SPOTWELD_ID 


\begin{tabular}{|c|c|c|c|c|c|c|c|}
\hline cid & title & & & & & & \\
\hline 2 & STRIN & FRAME & & & & & \\
\hline ssid & msid & sstyp & mstyp & sboxid & mboxid & spr & $\mathrm{mpr}$ \\
\hline 3 & 2 & 3 & 3 & 0 & 0 & 0 & 0 \\
\hline fs & $\mathrm{fd}$ & $\mathrm{dc}$ & $\mathrm{vc}$ & $\mathrm{vdc}$ & penchk & bt & $\mathrm{dt}$ \\
\hline 0.2 & 0 & 0 & 0 & 0 & 0 & 0 & $1 \mathrm{E}+20$ \\
\hline sfs & $\mathrm{sfm}$ & sst & mst & sfst & sfmt & fsf & vsf \\
\hline 1 & 1 & 0 & 0 & 1 & 1 & 1 & 1 \\
\hline soft & sofscl & lcidab & maxpar & sbopt & depth & bsort & frcfrq \\
\hline 1 & 0.1 & 0 & 1.025 & 2 & 2 & 0 & 1 \\
\hline
\end{tabular}

\begin{tabular}{llllllll}
\multicolumn{7}{l}{$\begin{array}{l}\text { *CONTACT_SPOTWELD_ID } \\
\text { cid }\end{array}$} & title \\
3 & SHEAR TIE-STRINGER & & & & & \\
ssid & msid & sstyp & mstyp & sboxid & mboxid & spr & mpr \\
4 & 2 & 3 & 3 & 0 & 0 & 0 & 0 \\
fs & fd & dc & vc & vdc & penchk & bt & dt \\
0.2 & 0 & 0 & 0 & 0 & 0 & 0 & $1 \mathrm{E}+20$ \\
sfs & sfm & sst & mst & sfst & sfmt & fsf & vsf \\
1 & 1 & 0 & 0 & 1 & 1 & 1 & 1 \\
soft & sofscl & lcidab & maxpar & sbopt & depth & bsort & frcfrq \\
1 & 0.1 & 0 & 1.025 & 2 & 2 & 0 & 1
\end{tabular}

\begin{tabular}{|c|c|c|c|c|c|c|c|}
\hline \multicolumn{8}{|c|}{ *CONTACT_SPOTWELD_ID } \\
\hline cid & title & & & & & & \\
\hline 4 & SHE $A$ & FRAME & & & & & \\
\hline ssid & msid & sstyp & mstyp & sboxid & mboxid & spr & $\mathrm{mpr}$ \\
\hline 4 & 3 & 3 & 3 & 0 & 0 & 0 & 0 \\
\hline fs & $\mathrm{fd}$ & $\mathrm{dc}$ & $\mathrm{vc}$ & $\mathrm{vdc}$ & penchk & bt & $\mathrm{dt}$ \\
\hline 0.2 & 0 & 0 & 0 & 0 & 0 & 0 & $1 \mathrm{E}+20$ \\
\hline sfs & $\mathrm{sfm}$ & sst & mst & sfst & sfmt & fsf & vsf \\
\hline 1 & 1 & 0 & 0 & 1 & 1 & 1 & \\
\hline soft & sofscl & lcidab & maxpar & sbopt & depth & bsort & frcfrq \\
\hline 1 & 0.1 & 0 & 1.025 & 2 & 2 & 0 & 1 \\
\hline
\end{tabular}

\begin{tabular}{llllllll}
\multicolumn{7}{l}{ *CONTACT_ERODING_SINGLE_SURFACE_ID } \\
cid & title & & & & \\
5 & SHEAR TIE-SHEAR TIE & & & & \\
ssid & msid & sstyp & mstyp & sboxid & mboxid & spr & mpr \\
4 & 4 & 3 & 3 & 0 & 0 & 0 & 0 \\
fs & fd & dc & vc & vdc & penchk & bt & dt \\
0.2 & 0 & 0 & 0 & 0 & 0 & 0 & 1 E+20 \\
sfs & sfm & sst & mst & sfst & sfmt & fsf & vsf \\
1 & 1 & 0 & 0 & 1 & 1 & 1 & 1 \\
isym & erosop & iadj & & & & & \\
0 & 0 & 0 & & & & &
\end{tabular}

\footnotetext{
*CONTACT_ERODING_SINGLE_SURFACE_ID

cid title

6 SHEAR TIE-FRAME

ssid msid sstyp mstyp sboxid mboxid spr mpr
} 


$\begin{array}{llllllll}4 & 3 & 3 & 3 & 0 & 0 & 0 & 0 \\ \text { fs } & \mathrm{fd} & \mathrm{dc} & \mathrm{vc} & \mathrm{vdc} & \text { penchk } & \mathrm{bt} & \mathrm{dt} \\ 0.2 & 0 & 0 & 0 & 0 & 0 & 0 & 1 \mathrm{E}+20 \\ \text { sfs } & \text { sfm } & \text { sst } & \text { mst } & \text { sfst } & \text { sfmt } & \text { fsf } & \text { vsf } \\ 1 & 1 & 0 & 0 & 1 & 1 & 1 & 1 \\ \text { isym } & \text { erosop } & \text { iadj } & & & & & \\ 0 & 0 & 0 & & & & & \end{array}$

\begin{tabular}{|c|c|c|c|c|c|c|c|}
\hline \multicolumn{8}{|c|}{ *CONTACT_ERODING_SINGLE_SURFACE_ID } \\
\hline 7 & \multicolumn{7}{|c|}{ SHEAR TIE-STRINGER } \\
\hline ssid & msid & sstyp & mstyp & sboxid & mboxid & spr & $\mathrm{mpr}$ \\
\hline 4 & 2 & 3 & 3 & 0 & 0 & 0 & 0 \\
\hline fs & $\mathrm{fd}$ & $\mathrm{dc}$ & $\mathrm{vc}$ & $\mathrm{vdc}$ & penchk & bt & $\mathrm{dt}$ \\
\hline 0.2 & 0 & 0 & 0 & 0 & 0 & 0 & $1 E+20$ \\
\hline sfs & sfm & sst & mst & sfst & sfmt & fsf & vsf \\
\hline 1 & 1 & 0 & 0 & 1 & 1 & 1 & 1 \\
\hline isym & erosop & iadj & & & & & \\
\hline 0 & 0 & 0 & & & & & \\
\hline
\end{tabular}

\begin{tabular}{|c|c|c|c|c|c|c|c|}
\hline \multicolumn{8}{|c|}{ *CONTACT_ERODING_SINGLE_SURFACE_ID } \\
\hline cid & title & & & - & & & \\
\hline 8 & \multicolumn{7}{|c|}{ SHEAR TIE-SKIN } \\
\hline ssid & msid & sstyp & mstyp & sboxid & mboxid & spr & $\mathrm{mpr}$ \\
\hline 4 & 1 & 3 & 3 & 0 & 0 & 0 & 0 \\
\hline fs & $\mathrm{fd}$ & $\mathrm{dc}$ & $\mathrm{vc}$ & $\mathrm{vdc}$ & penchk & bt & $\mathrm{dt}$ \\
\hline 0.2 & 0 & 0 & 0 & 0 & 0 & 0 & $1 E+20$ \\
\hline sfs & $\mathrm{sfm}$ & sst & mst & sfst & sfmt & fsf & vsf \\
\hline 1 & 1 & 0 & 0 & 1 & 1 & 1 & 1 \\
\hline isym & erosop & iadj & & & & & \\
\hline 0 & 0 & 0 & & & & & \\
\hline
\end{tabular}

\begin{tabular}{|c|c|c|c|c|c|c|c|}
\hline \multicolumn{8}{|c|}{ CONTACT_AUTOMATIC_NODES_TO_SURFACE_ID } \\
\hline 9 & \multicolumn{7}{|c|}{ SKIN-SHEAR TIE } \\
\hline ssid & msid & sstyp & mstyp & sboxid & mboxid & spr & $\mathrm{mpr}$ \\
\hline 4 & 1 & 3 & 3 & 0 & 0 & 0 & 0 \\
\hline fs & $\mathrm{fd}$ & $\mathrm{dc}$ & $\mathrm{vc}$ & $\mathrm{vdc}$ & penchk & bt & $\mathrm{dt}$ \\
\hline 0.2 & 0 & 0 & 0 & 0 & 0 & 0 & $1 \mathrm{E}+20$ \\
\hline sfs & $\mathrm{sfm}$ & sst & mst & sfst & sfmt & fsf & vsf \\
\hline 1 & 1 & 0 & 0 & 1 & 1 & 1 & 1 \\
\hline
\end{tabular}

\begin{tabular}{|c|c|c|c|c|c|c|c|}
\hline \\
\hline \multirow{2}{*}{\multicolumn{8}{|c|}{$\begin{array}{ll}\text { cid } & \text { title } \\
10 & \text { SKIN-IMPACTOR }\end{array}$}} \\
\hline & & & & & & & \\
\hline ssid & msid & sstyp & mstyp & sboxid & mboxid & spr & $\mathrm{mpr}$ \\
\hline 1 & 5 & 3 & 3 & 0 & 0 & 0 & 0 \\
\hline fs & $\mathrm{fd}$ & $\mathrm{dc}$ & $\mathrm{vc}$ & $\mathrm{vdc}$ & penchk & $\mathrm{bt}$ & $\mathrm{dt}$ \\
\hline 0.2 & 0 & 0 & 0 & 0 & 0 & 0 & $1 \mathrm{E}+20$ \\
\hline sfs & sfm & sst & mst & sfst & sfmt & fsf & vsf \\
\hline 1 & 1 & 0 & 0 & 1 & 1 & 1 & 1 \\
\hline
\end{tabular}




\begin{tabular}{|c|c|c|c|c|c|c|c|}
\hline \multicolumn{8}{|c|}{ *PART_COMPOSITE } \\
\hline \multicolumn{8}{|c|}{ SKIN } \\
\hline pid & elform & shrf & nloc & marea & hgid & adpopt & ithelfrm \\
\hline 1 & 16 & 1 & 0 & 0 & 1 & 0 & 0 \\
\hline mid1 & thick1 & b1 & ithid1 & $\operatorname{mid} 2$ & thick2 & $\mathrm{b} 2$ & ithid2 \\
\hline 2 & $2.113 \mathrm{E}-4$ & 0 & 0 & 0 & 0 & 0 & 0 \\
\hline 1 & $1.499 \mathrm{E}-4$ & 0 & 0 & 0 & 0 & 0 & 0 \\
\hline 1 & $1.499 \mathrm{E}-4$ & 45 & 0 & 0 & 0 & 0 & 0 \\
\hline 1 & $1.499 \mathrm{E}-4$ & 90 & 0 & 0 & 0 & 0 & 0 \\
\hline 1 & $1.499 \mathrm{E}-4$ & -45 & 0 & 0 & 0 & 0 & 0 \\
\hline 1 & $1.499 \mathrm{E}-4$ & -45 & 0 & 0 & 0 & 0 & 0 \\
\hline 1 & $1.499 \mathrm{E}-4$ & 90 & 0 & 0 & 0 & 0 & 0 \\
\hline 1 & $1.499 \mathrm{E}-4$ & 45 & 0 & 0 & 0 & 0 & 0 \\
\hline 1 & $1.499 \mathrm{E}-4$ & 0 & 0 & 0 & 0 & 0 & 0 \\
\hline 1 & $1.499 \mathrm{E}-4$ & 0 & 0 & 0 & 0 & 0 & 0 \\
\hline 1 & $1.499 \mathrm{E}-4$ & 45 & 0 & 0 & 0 & 0 & 0 \\
\hline 1 & $1.499 \mathrm{E}-4$ & 90 & 0 & 0 & 0 & 0 & 0 \\
\hline 1 & $1.499 \mathrm{E}-4$ & -45 & 0 & 0 & 0 & 0 & 0 \\
\hline 1 & $1.499 \mathrm{E}-4$ & -45 & 0 & 0 & 0 & 0 & 0 \\
\hline 1 & $1.499 \mathrm{E}-4$ & 90 & 0 & 0 & 0 & 0 & 0 \\
\hline 1 & $1.499 \mathrm{E}-4$ & 45 & 0 & 0 & 0 & 0 & 0 \\
\hline 1 & $1.499 \mathrm{E}-4$ & 0 & 0 & 0 & 0 & 0 & 0 \\
\hline 2 & $2.113 \mathrm{E}-4$ & 0 & 0 & 0 & 0 & 0 & 0 \\
\hline
\end{tabular}

*PART_COMPOSITE

STRINGER

$\begin{array}{llllllll}\text { pid } & \text { elform } & \text { shrf } & \text { nloc } & \text { marea } & \text { hgid } & \text { adpopt } & \text { ithelfrm } \\ 2 & 16 & 1 & 0 & 0 & 1 & 0 & 0 \\ \text { mid1 } & \text { thick1 } & \text { b1 } & \text { ithid1 } & \text { mid2 } & \text { thick2 } & \text { b2 } & \text { ithid2 } \\ 1 & 1.499 \mathrm{E}-4 & 0 & 0 & 0 & 0 & 0 & 0 \\ 1 & 1.499 \mathrm{E}-4 & 45 & 0 & 0 & 0 & 0 & 0 \\ 1 & 1.499 \mathrm{E}-4 & -45 & 0 & 0 & 0 & 0 & 0 \\ 1 & 1.499 \mathrm{E}-4 & 90 & 0 & 0 & 0 & 0 & 0 \\ 1 & 1.499 \mathrm{E}-4 & 45 & 0 & 0 & 0 & 0 & 0 \\ 1 & 1.499 \mathrm{E}-4 & -45 & 0 & 0 & 0 & 0 & 0 \\ 1 & 1.499 \mathrm{E}-4 & 0 & 0 & 0 & 0 & 0 & 0 \\ 1 & 1.499 \mathrm{E}-4 & 0 & 0 & 0 & 0 & 0 & 0 \\ 1 & 1.499 \mathrm{E}-4 & -45 & 0 & 0 & 0 & 0 & 0 \\ 1 & 1.499 \mathrm{E}-4 & 45 & 0 & 0 & 0 & 0 & 0 \\ 1 & 1.499 \mathrm{E}-4 & 90 & 0 & 0 & 0 & 0 & 0 \\ 1 & 1.499 \mathrm{E}-4 & -45 & 0 & 0 & 0 & 0 & 0 \\ 1 & 1.499 \mathrm{E}-4 & 45 & 0 & 0 & 0 & 0 & 0 \\ 1 & 1.499 \mathrm{E}-4 & 0 & 0 & 0 & 0 & 0 & 0\end{array}$

*PART_COMPOSITE

FRAME

$\begin{array}{llllllll}\text { pid } & \text { elform } & \text { shrf } & \text { nloc } & \text { marea } & \text { hgid } & \text { adpopt } & \text { ithelfrm } \\ 3 & 16 & 1 & 0 & 0 & 1 & 0 & 0\end{array}$




$\begin{array}{llllllll}\text { mid1 } & \text { thick1 } & \mathrm{b} 1 & \text { ithid1 } & \text { mid2 } & \text { thick2 } & \mathrm{b} 2 & \text { ithid2 } \\ 2 & 2.113 \mathrm{E}-4 & 0 & 0 & 0 & 0 & 0 & 0 \\ 2 & 2.113 \mathrm{E}-4 & 45 & 0 & 0 & 0 & 0 & 0 \\ 2 & 2.113 \mathrm{E}-4 & 0 & 0 & 0 & 0 & 0 & 0 \\ 2 & 2.113 \mathrm{E}-4 & 0 & 0 & 0 & 0 & 0 & 0 \\ 2 & 2.113 \mathrm{E}-4 & 45 & 0 & 0 & 0 & 0 & 0 \\ 2 & 2.113 \mathrm{E}-4 & 45 & 0 & 0 & 0 & 0 & 0 \\ 2 & 2.113 \mathrm{E}-4 & 0 & 0 & 0 & 0 & 0 & 0 \\ 2 & 2.113 \mathrm{E}-4 & 0 & 0 & 0 & 0 & 0 & 0 \\ 2 & 2.113 \mathrm{E}-4 & 45 & 0 & 0 & 0 & 0 & 0 \\ 2 & 2.113 \mathrm{E}-4 & 45 & 0 & 0 & 0 & 0 & 0 \\ 2 & 2.113 \mathrm{E}-4 & 0 & 0 & 0 & 0 & 0 & 0 \\ 2 & 2.113 \mathrm{E}-4 & 0 & 0 & 0 & 0 & 0 & 0 \\ 2 & 2.113 \mathrm{E}-4 & 45 & 0 & 0 & 0 & 0 & 0 \\ 2 & 2.113 \mathrm{E}-4 & 0 & 0 & 0 & 0 & 0 & 0\end{array}$

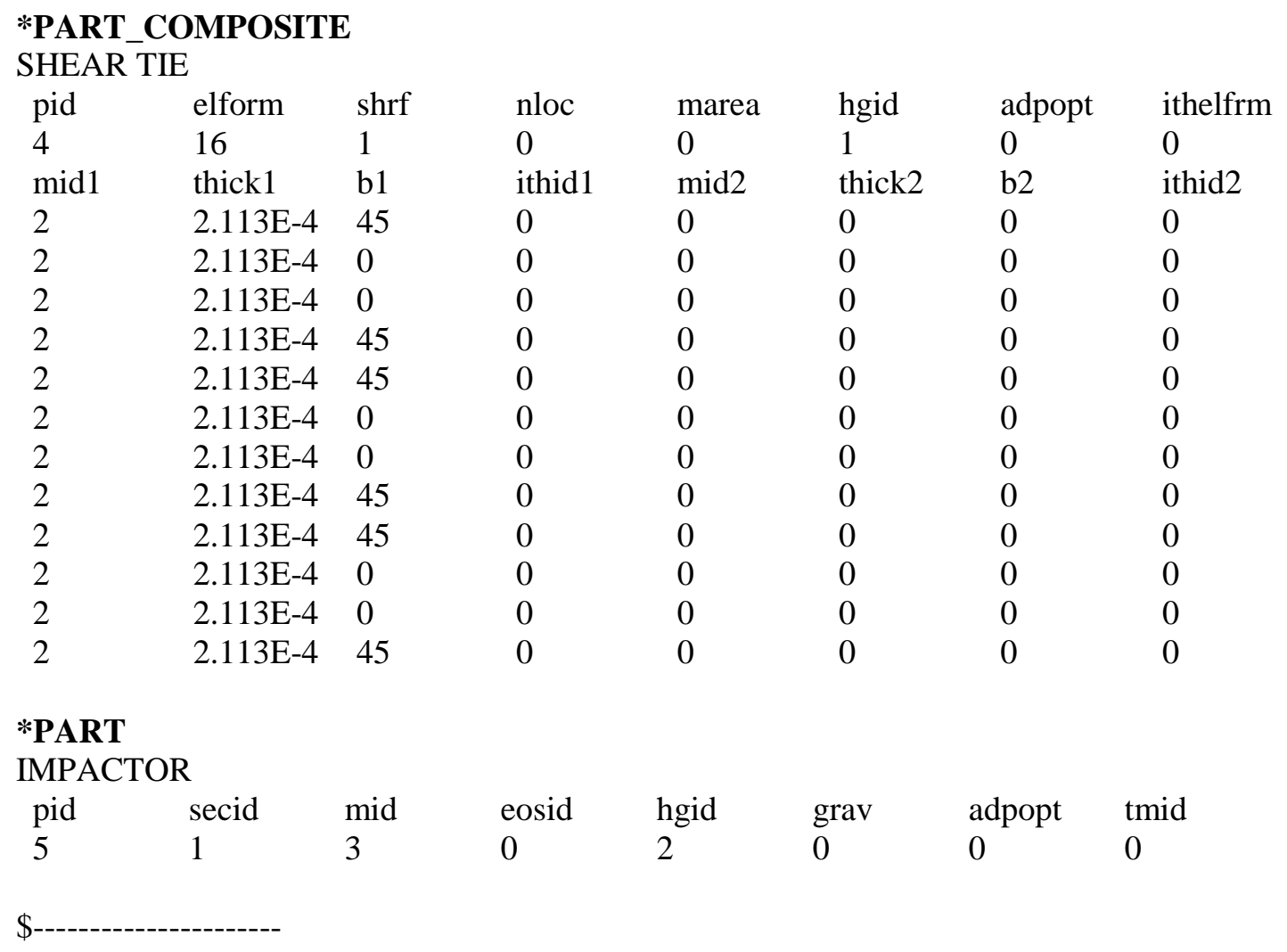

\section{*SECTION_SOLID_TITLE \\ SOLID SEC \\ secid elform aet

$1 \quad 1 \quad 0$

\$-----------------------

*MAT_ENHANCED_COMPOSITE_DAMAGE_TITLE

UD CF

mid ro ea eb (ec) prba $\quad$ (prca) (prcb) 


\begin{tabular}{|c|c|c|c|c|c|c|c|}
\hline $\begin{array}{l}1 \\
\text { gab } \\
4.206 \mathrm{E}+9\end{array}$ & $\begin{array}{l}1540 \\
\mathrm{gbc}\end{array}$ & $\begin{array}{l}1.248 \mathrm{E}+11 \\
\text { gca }\end{array}$ & $\begin{array}{l}8.412 E+9 \\
(k f) \\
0\end{array}$ & $\begin{array}{l}\text { aopt } \\
0\end{array}$ & 0.0205 & 0.0205 & 0.4 \\
\hline $\mathrm{xp}$ & yp & $z p$ & a1 & $\mathrm{a} 2$ & a3 & mangle & \\
\hline 0 & 0 & 0 & 0 & 0 & 0 & 0 & \\
\hline v1 & v2 & v3 & $\mathrm{d} 1$ & $\mathrm{~d} 2$ & d3 & dfailm & dfails \\
\hline 0 & 0 & 0 & 0 & 0 & 0 & 0.024 & 0.03 \\
\hline tfail & alph & soft & fbrt & ycfac & dfailt & dfailc & efs \\
\hline $1.153 \mathrm{E}-9$ & 0.1 & 0 & 0.5 & 1.2 & 0.0174 & -0.0116 & 0 \\
\hline & $\mathrm{xt}$ & yc & yt & $\mathrm{sc}$ & crit & beta & \\
\hline $\begin{array}{l}1.448 E+9 \\
\text { pel }\end{array}$ & $\begin{array}{l}2.199 E+9 \\
\text { epsf }\end{array}$ & $\begin{array}{l}1.986 \mathrm{E}+8 \\
\text { epsr }\end{array}$ & $\begin{array}{l}4.888 E+7 \\
\text { tsmd }\end{array}$ & $\begin{array}{l}1.544 \mathrm{E}+8 \\
\text { soft } 2\end{array}$ & 54 & 0.5 & \\
\hline 0 & 0 & 0 & 0 & 1 & & & \\
\hline slimt 1 & slimc1 & slimt2 & slimc2 & slims & ncyred & softg & \\
\hline 0 & 0 & 0 & 0 & 0 & 0 & 1 & \\
\hline
\end{tabular}

\begin{tabular}{|c|c|c|c|c|c|c|c|}
\hline mid & ro & ea & $\mathrm{eb}$ & (ec) & prba & (prca) & (prcb) \\
\hline 2 & 1500 & $5.592 \mathrm{E}+10$ & $5.440 \mathrm{E}+10$ & & 0.043 & 0.043 & 0.4 \\
\hline gab & $\mathrm{gbc}$ & gca & (kf) & aopt & & & \\
\hline $4.199 E+9$ & & & 0 & 0 & & & \\
\hline$x p$ & ур & $z p$ & a1 & $\mathrm{a} 2$ & a3 & mangle & \\
\hline 0 & 0 & 0 & 0 & 0 & 0 & 0 & \\
\hline $\mathrm{v} 1$ & v2 & v3 & $\mathrm{d} 1$ & $\mathrm{~d} 2$ & d3 & dfailm & dfails \\
\hline 0 & 0 & 0 & 0 & 0 & 0 & 0.014 & 0.03 \\
\hline tfail & alph & soft & fbrt & ycfac & dfailt & dfailc & efs \\
\hline $1.153 \mathrm{E}-9$ & 0.1 & 0 & 0.5 & 1.2 & 0.0164 & -0.013 & 0 \\
\hline $\mathrm{xc}$ & $\mathrm{xt}$ & yc & $\mathrm{yt}$ & $\mathrm{sc}$ & crit & beta & \\
\hline $\begin{array}{l}7.102 \mathrm{E}+8 \\
\text { pel }\end{array}$ & $\begin{array}{l}9.101 \mathrm{E}+8 \\
\text { epsf }\end{array}$ & $\begin{array}{l}7.033 E+8 \\
\text { epsr }\end{array}$ & $\begin{array}{l}7.722 E+8 \\
\text { tsmd }\end{array}$ & $\begin{array}{l}1.310 \mathrm{E}+8 \\
\text { soft } 2\end{array}$ & 54 & 0.5 & \\
\hline 0 & 0 & 0 & 0 & 1 & & & \\
\hline slimt1 & slimc1 & slimt2 & slimc2 & slims & ncyred & softg & \\
\hline 0 & 0 & 0 & 0 & 0 & 0 & 1 & \\
\hline
\end{tabular}

\begin{tabular}{|c|c|c|c|c|c|c|c|}
\hline mid & ro & $\mathrm{e}$ & $\mathrm{pr}$ & $\mathrm{n}$ & couple & $\mathrm{m}$ & alias \\
\hline 3 & 29520 & $4.51 \mathrm{E}+11$ & 0.19 & 0 & 0 & 0 & 0 \\
\hline $\mathrm{cmo}$ & con1 & $\operatorname{con} 2$ & & & & & \\
\hline 0 & 0 & 0 & & & & & \\
\hline lco or a 1 & $\mathrm{a} 2$ & a3 & v1 & v2 & v3 & & \\
\hline 0 & 0 & 0 & 0 & 0 & 0 & & \\
\hline
\end{tabular}

\$------------------------

*HOURGLASS_TITLE

HOURGLASS

$\begin{array}{llllllll}\text { hgid } & \text { ihq } & \text { qm } & \text { ibq } & \text { q1 } & \text { q2 } & \text { qb/vdc } & \text { qw } \\ 1 & 8 & 0.1 & 0 & 1.5 & 0.06 & 0.1 & 0.1\end{array}$


*HOURGLASS_TITLE

SOLID HOURGLASS

hoid ihq

2

4

$\mathrm{qm}$

$\mathrm{ibq}$

q1 $\quad$ q2

$\mathrm{qb} / \mathrm{vdc}$

1.5

0.06

0.1

qw

\$-------------------

\section{*INITIAL_VELOCITY_RIGID_BODY}

$\begin{array}{llllllll}\text { pid } & \text { vx } & \text { vy } & \text { vz } & \text { vxr } & \text { vyr } & \text { vzr } & \text { icid } \\ 5 & 0 & 0 & 1 & 0 & 0 & 0 & 0\end{array}$

\$-----------------------

*END 
Source Code 2: Supernodes - Part A (Original Case - Without Supernodes)

*KEYWORD MEMORY=180000000 NCPU=4

\$-----------------------

*TITLE

CASE A

\$----------------------

\section{*CONTROL_ACCURACY}

$\begin{array}{lll}\text { osu } & \text { inn } & \text { pidosu } \\ 0 & 4 & 0\end{array}$

\section{*CONTROL_CONTACT}

$\begin{array}{llllllll}\text { slsfac } & \text { rwpnal } & \text { islchk } & \text { shlthk } & \text { penopt } & \text { thkchg } & \text { orien } & \text { enmass } \\ 0.1 & 0 & 2 & 2 & 0 & 1 & 1 & 0 \\ \text { usrstr } & \text { usrfrc } & \text { nsbcs } & \text { interm } & \text { xpene } & \text { ssthk } & \text { ecdt } & \text { tiedprj } \\ 0 & 0 & 0 & 0 & 4 & 0 & 0 & 0 \\ \text { sfric } & \text { dfric } & \text { edc } & \text { vfc } & \text { th } & \text { th } & \text { _sf } & \text { pen_sf } \\ 0 & 0 & 0 & 0 & 0 & 0 & 0 & 0 \\ \text { ignore } & \text { frceng } & \text { skiprwg } & \text { outseg } & \text { spotstp } & \text { spotdel } & \text { spothin } & \\ 0 & 1 & 0 & 0 & 0 & 0 & 0 & \\ \text { isym } & \text { nserod } & \text { rwgaps } & \text { rwgdth } & \text { rwksf } & \text { icov } & \text { swradf } & \text { ithoff } \\ 0 & 0 & 0 & 0 & 1 & 0 & 0 & 0 \\ \text { shledg } & \text { pstiff } & \text { ithcnt } & \text { tdcnof } & \text { ftall } & \text { unused } & \text { shltrw } & \\ 0 & 0 & 0 & 0 & 0 & 0 & 0 & \end{array}$

*CONTROL_ENERGY

hgen rwen slnten rylen

$2 \quad 2 \quad 2 \quad 1$

*CONTROL_SHELL

$\begin{array}{llllllll}\text { wrpang } & \text { esort } & \text { irnxx } & \text { istupd } & \text { theory } & \text { bwc } & \text { miter } & \text { proj } \\ 20 & 0 & -1 & 4 & 2 & 2 & 1 & 0 \\ \text { rotascl } & \text { intgrd } & \text { lamsht } & \text { cstyp6 } & \text { tshell } & & & \\ 1 & 0 & 1 & 1 & 0 & & & \\ \text { psstupd } & \text { sidt4tu } & \text { cntco } & \text { itsflg } & \text { irquad } & & & \\ 0 & 0 & 0 & 0 & 2 & & & \\ \text { nfail1 } & \text { nfail4 } & \text { psnfail } & \text { keepcs } & \text { delfr } & \text { drcpsid } & \text { drcprm } & \\ 1 & 1 & 0 & 0 & 0 & 0 & 1 & \end{array}$

*CONTROL_TERMINATION

endtim endcyc dtmin endeng endmas

$\begin{array}{lllll}0.0225 & 0 & 0 & 0 & 0\end{array}$

$\$$

*DATABASE_GLSTAT 


\begin{tabular}{|c|c|c|c|c|c|}
\hline $\mathrm{dt}$ & binary & lcur & ioopt & & \\
\hline $3 \mathrm{E}-4$ & 1 & 0 & 1 & & \\
\hline \multicolumn{6}{|c|}{ *DATABASE_NODOUT } \\
\hline $\mathrm{dt}$ & binary & lcur & ioopt & option 1 & option2 \\
\hline $3 \mathrm{E}-4$ & 1 & 0 & 1 & 0 & 0 \\
\hline \multicolumn{6}{|c|}{ *DATABASE_RCFORC } \\
\hline $\mathrm{dt}$ & binary & lcur & ioopt & & \\
\hline $3 \mathrm{E}-4$ & 1 & 0 & 1 & & \\
\hline
\end{tabular}

$\begin{array}{lllll}\text { *DATABASE_BINARY_D3PLOT } & \\ \text { dt } & \text { lcdt } & \text { beam } & \text { npltc } & \text { psetid } \\ 3 \mathrm{E}-4 & 0 & 0 & 0 & 0 \\ \text { Ioopt } & & & & \\ 0 & & & & \end{array}$

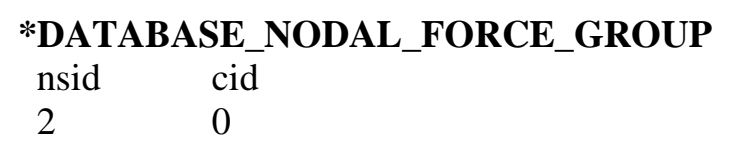

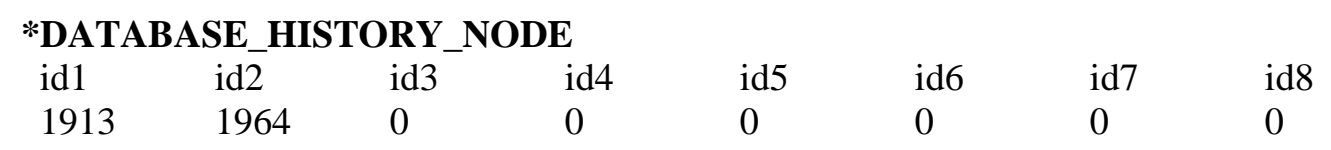

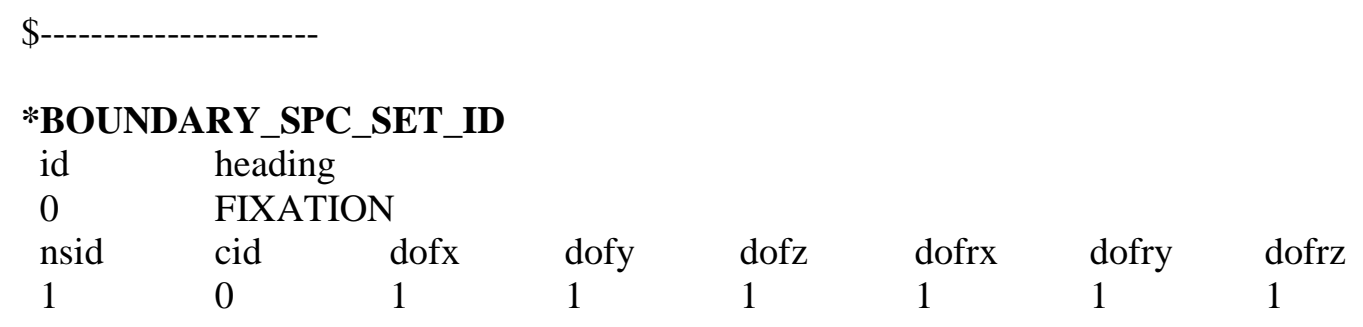




$\begin{array}{llllllll}\text { mid1 } & \text { thick1 } & \mathrm{b} 1 & \text { ithid1 } & \text { mid2 } & \text { thick2 } & \mathrm{b} 2 & \text { ithid2 } \\ 1 & 1.25 \mathrm{E}-4 & 0 & 0 & 0 & 0 & 0 & 0 \\ 1 & 1.25 \mathrm{E}-4 & 90 & 0 & 0 & 0 & 0 & 0 \\ 1 & 1.25 \mathrm{E}-4 & 0 & 0 & 0 & 0 & 0 & 0 \\ 1 & 1.25 \mathrm{E}-4 & 0 & 0 & 0 & 0 & 0 & 0 \\ 1 & 1.25 \mathrm{E}-4 & 90 & 0 & 0 & 0 & 0 & 0 \\ 1 & 1.25 \mathrm{E}-4 & 0 & 0 & 0 & 0 & 0 & 0\end{array}$

*PART
$\begin{array}{llllllll}\text { IMPACTOR } & & & & & & \\ \text { pid } & \text { secid } & \text { mid } & \text { eosid } & \text { hgid } & \text { grav } & \text { adpopt } & \text { tmid } \\ 2 & 1 & 2 & 0 & 1 & 0 & 0 & 0\end{array}$

$\$$

*MAT_ENHANCED_COMPOSITE_DAMAGE_TITLE

HTA/6376C

$\begin{array}{llllllll}\text { mid } & \text { ro } & \text { ea } & \text { eb } & \text { (ec) } & \text { prba } & \text { (prca) } & \text { (prcb) } \\ 1 & 1590 & 1.45 \mathrm{E}+11 & 1.03 \mathrm{E}+10 & 1.21 \mathrm{E}+10 & 0.0214 & 0.0417 & 0.5815 \\ \text { gab } & \text { gbc } & \text { gca } & (\mathrm{kf}) & \mathrm{aopt} & & & \\ 5.3 \mathrm{E}+9 & 3.95 \mathrm{E}+9 & 5.275 \mathrm{E}+9 & 0 & 0 & & & \\ \text { xp } & \text { yp } & \text { zp } & \mathrm{a} 1 & \mathrm{a} 2 & \mathrm{a} 3 & \text { mangle } & \\ 0 & 0 & 0 & 0 & 0 & 0 & 0 & \\ \text { v1 } & \mathrm{v} 2 & \mathrm{v} 3 & \mathrm{~d} 1 & \mathrm{~d} 2 & \mathrm{~d} 3 & \text { dfailm } & \text { dfails } \\ 0 & 0 & 0 & 0 & 0 & 0 & 0.024 & 0.03 \\ \text { tfail } & \text { alph } & \text { soft } & \text { fbrt } & \text { ycfac } & \text { dfailt } & \text { dfailc } & \text { efs } \\ 1.153 \mathrm{E}-9 & 0.1 & 0 & 0.5 & 1.2 & 0.0174 & -0.0116 & 0 \\ \text { xc } & \text { xt } & \text { yc } & \text { yt } & \text { sc } & \text { crit } & \text { beta } & \\ 1.6 \mathrm{E}+9 & 2 \mathrm{E}+9 & 2.9 \mathrm{E}+8 & 6.4 \mathrm{E}+7 & 9.8 \mathrm{E}+7 & 54 & 0.5 & \\ \text { pel } & \text { epsf } & \text { epsr } & \text { tsmd } & \text { soft2 } & & & \\ 0 & 0 & 0 & 0 & 1 & & & \\ \text { slimt } 1 & \text { slimc1 } & \text { slimt2 } & \text { slimc2 } & \text { slims } & \text { ncyred } & \text { softg } & \\ 0 & 0 & 0 & 0 & 0 & 0 & 1 & \end{array}$

*MAT_RIGID_TITLE

AL 7075 - T6

$\begin{array}{llllllll}\text { mid } & \text { ro } & \text { e } & \text { pr } & \text { n } & \text { couple } & \text { m } & \text { alias } \\ 2 & 2810 & 7.17 \mathrm{E}+10 & 0.33 & 0 & 0 & 0 & 0 \\ \text { cmo } & \text { con1 } & \text { con2 } & & & & & \\ 0 & 0 & 0 & & & & & \\ \text { lco or a1 } & \text { a2 } & \text { a3 } & \text { v1 } & \text { v2 } & \text { v3 } & & \\ 0 & 0 & 0 & 0 & 0 & 0 & \end{array}$

\$---------------------

*HOURGLASS_TITLE

SHELL HOURGLASS

$\begin{array}{llllllll}\text { hgid } & \text { ihq } & \text { qm } & \text { ibq } & \text { q1 } & \text { q2 } & \text { qb/vdc } & \text { qw } \\ 1 & 8 & 0.1 & 0 & 1.5 & 0.06 & 0.1 & 0.1\end{array}$

\$---------------------- 


\begin{tabular}{llllllll}
\multicolumn{2}{l}{ *INITIAL_VELOCITY_RIGID_BODY } & & & & \\
pid & $\mathrm{vx}$ & $\mathrm{vy}$ & $\mathrm{vz}$ & $\mathrm{vxr}$ & $\mathrm{vyr}$ & $\mathrm{vzr}$ & icid \\
2 & 0 & 0 & -3.3774 & 0 & 0 & 0 & 0
\end{tabular}

\$---------------------

*END 
Source Code 2: Supernodes - Part B1 (Creation of Supernodes)

*KEYWORD MEMORY=180000000 NCPU=4

\$-----------------------

*TITLE

CASE B1

\$----------------------

\section{*CONTROL_ACCURACY}

$\begin{array}{lll}\text { osu } & \text { inn } & \text { pidosu } \\ 0 & 4 & 0\end{array}$

\section{*CONTROL_CONTACT}

$\begin{array}{llllllll}\text { slsfac } & \text { rwpnal } & \text { islchk } & \text { shlthk } & \text { penopt } & \text { thkchg } & \text { orien } & \text { enmass } \\ 0.1 & 0 & 2 & 2 & 0 & 1 & 1 & 0 \\ \text { usrstr } & \text { usrfrc } & \text { nsbcs } & \text { interm } & \text { xpene } & \text { ssthk } & \text { ecdt } & \text { tiedprj } \\ 0 & 0 & 0 & 0 & 4 & 0 & 0 & 0 \\ \text { sfric } & \text { dfric } & \text { edc } & \text { vfc } & \text { th } & \text { th } & \text { _sf } & \text { pen_sf } \\ 0 & 0 & 0 & 0 & 0 & 0 & 0 & 0 \\ \text { ignore } & \text { frceng } & \text { skiprwg } & \text { outseg } & \text { spotstp } & \text { spotdel } & \text { spothin } & \\ 0 & 1 & 0 & 0 & 0 & 0 & 0 & \\ \text { isym } & \text { nserod } & \text { rwgaps } & \text { rwgdth } & \text { rwksf } & \text { icov } & \text { swradf } & \text { ithoff } \\ 0 & 0 & 0 & 0 & 1 & 0 & 0 & 0 \\ \text { shledg } & \text { pstiff } & \text { ithcnt } & \text { tdcnof } & \text { ftall } & \text { unused } & \text { shltrw } & \\ 0 & 0 & 0 & 0 & 0 & 0 & 0 & \end{array}$

*CONTROL_ENERGY

hgen rwen slnten rylen

$\begin{array}{llll}2 & 2 & 2 & 1\end{array}$

$\begin{array}{cccccccc}\text { *CONTROL_IMPLICIT_GENERAL } & & & & \\ \text { imflag } & \text { imform } & \mathrm{dt} 0 & \text { nsbs } & \text { igs } & \text { cnstn } & \text { form } & \text { zero_v } \\ 1 & 0 & 2 & 1 & 2 & 0 & 0 & 1\end{array}$

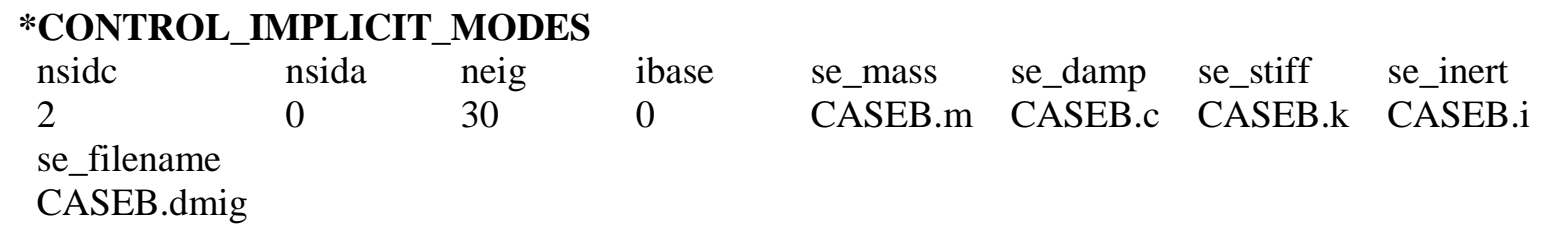

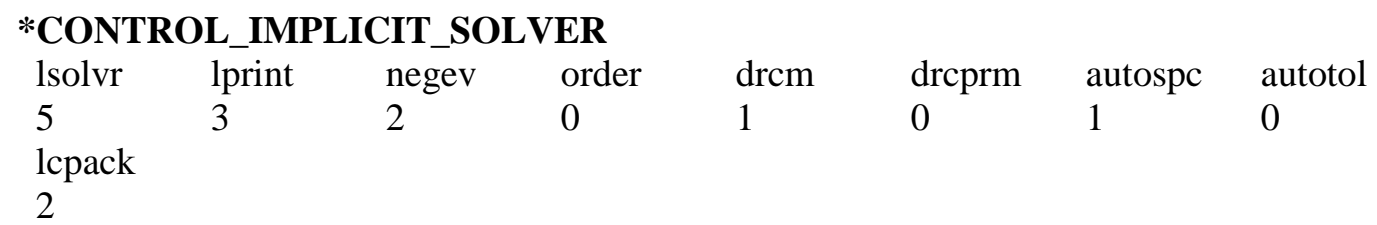

*CONTROL_SHELL 


$\begin{array}{llllllll}\text { wrpang } & \text { esort } & \text { irnxx } & \text { istupd } & \text { theory } & \text { bwc } & \text { miter } & \text { proj } \\ 20 & 0 & -1 & 4 & 2 & 2 & 1 & 0 \\ \text { rotascl } & \text { intgrd } & \text { lamsht } & \text { cstyp6 } & \text { tshell } & & & \\ 1 & 0 & 1 & 1 & 0 & & & \\ \text { psstupd } & \text { sidt4tu } & \text { cntco } & \text { itsflg } & \text { irquad } & & & \\ 0 & 0 & 0 & 0 & 2 & & & \\ \text { nfail1 } & \text { nfail4 } & \text { psnfail } & \text { keepcs } & \text { delfr } & \text { drcpsid } & \text { drcprm } & \\ 1 & 1 & 0 & 0 & 0 & 0 & 1 & \end{array}$

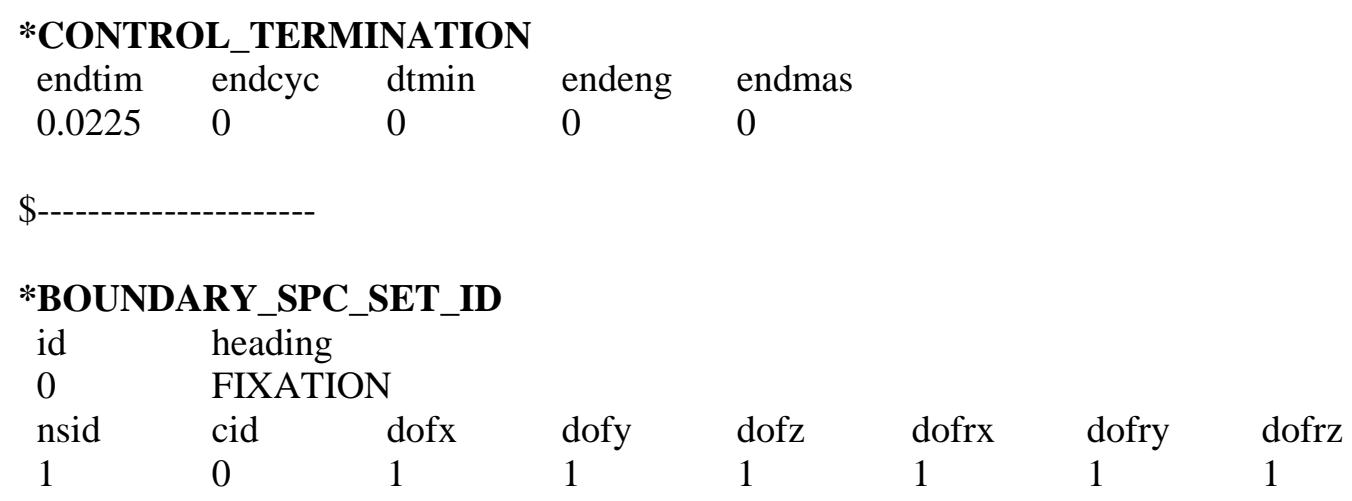

\$----------------------

*PART_COMPOSITE

SKIN

$\begin{array}{llllllll}\text { pid } & \text { elform } & \text { shrf } & \text { nloc } & \text { marea } & \text { hgid } & \text { adpopt } & \text { ithelfrm } \\ 1 & 16 & 1 & 0 & 0 & 1 & 0 & 0 \\ \text { mid1 } & \text { thick1 } & \text { b1 } & \text { ithid1 } & \text { mid2 } & \text { thick2 } & \text { b2 } & \text { ithid2 } \\ 1 & 1.25 \mathrm{E}-4 & 0 & 0 & 0 & 0 & 0 & 0 \\ 1 & 1.25 \mathrm{E}-4 & 90 & 0 & 0 & 0 & 0 & 0 \\ 1 & 1.25 \mathrm{E}-4 & 0 & 0 & 0 & 0 & 0 & 0 \\ 1 & 1.25 \mathrm{E}-4 & 0 & 0 & 0 & 0 & 0 & 0 \\ 1 & 1.25 \mathrm{E}-4 & 90 & 0 & 0 & 0 & 0 & 0 \\ 1 & 1.25 \mathrm{E}-4 & 0 & 0 & 0 & 0 & 0 & 0\end{array}$

\$-----------------------

*HOURGLASS_TITLE

SHELL HOURGLASS

$\begin{array}{llllllll}\text { hgid } & \text { ihq } & \text { qm } & \text { ibq } & \text { q1 } & \text { q2 } & \text { qb/vdc } & \text { qw } \\ 1 & 8 & 0.1 & 0 & 1.5 & 0.06 & 0.1 & 0.1\end{array}$

\$----------------------

*MAT_ENHANCED_COMPOSITE_DAMAGE_TITLE

HTA/6376C

$\begin{array}{llllllll}\text { mid } & \text { ro } & \text { ea } & \text { eb } & (\mathrm{ec}) & \text { prba } & \text { (prca) } & \text { (prcb) } \\ 1 & 1590 & 1.45 \mathrm{E}+11 & 1.03 \mathrm{E}+10 & 1.21 \mathrm{E}+10 & 0.0214 & 0.0417 & 0.5815 \\ \text { gab } & \text { gbc } & \text { gca } & (\mathrm{kf}) & \text { aopt } & & & \\ 5.3 \mathrm{E}+9 & 3.95 \mathrm{E}+9 & 5.275 \mathrm{E}+9 & 0 & 0 & & & \\ \text { xp } & \text { yp } & \text { zp } & \text { a1 } & \text { a2 } & \text { a3 } & \text { mangle } & \end{array}$




$\begin{array}{llllllll}0 & 0 & 0 & 0 & 0 & 0 & 0 & \\ \text { v1 } & \text { v2 } & \text { v3 } & \text { d1 } & \text { d2 } & \text { d3 } & \text { dfailm } & \text { dfails } \\ 0 & 0 & 0 & 0 & 0 & 0 & 0.024 & 0.03 \\ \text { tfail } & \text { alph } & \text { soft } & \text { fbrt } & \text { ycfac } & \text { dfailt } & \text { dfailc } & \text { efs } \\ 1.153 \mathrm{E}-9 & 0.1 & 0 & 0.5 & 1.2 & 0.0174 & -0.0116 & 0 \\ \text { xc } & \text { xt } & \text { yc } & \text { yt } & \text { sc } & \text { crit } & \text { beta } & \\ 1.6 \mathrm{E}+9 & 2 \mathrm{E}+9 & 2.9 \mathrm{E}+8 & 6.4 \mathrm{E}+7 & 9.8 \mathrm{E}+7 & 54 & 0.5 \\ \text { pel } & \text { epsf } & \text { epsr } & \text { tsmd } & \text { soft2 } & & \\ 0 & 0 & 0 & 0 & 1 & & \\ \text { slimt } 1 & \text { slimc1 } & \text { slimt2 } & \text { slimc2 } & \text { slims } & \text { ncyred } & \text { softg } \\ 0 & 0 & 0 & 0 & 0 & 0 & 1\end{array}$

\$-----------------------

*SET_NODE_LIST_TITLE

SUPERNODES

$\begin{array}{llllllll}\text { sid } & \text { da1 } & \text { da2 } & \text { da3 } & \text { da4 } & \text { solver } & & \\ 2 & 0 & 0 & 0 & 0 & \text { MECH } & & \\ \text { nid1 } & \text { nid2 } & \text { nid3 } & \text { nid4 } & \text { nid5 } & \text { nid6 } & \text { nid7 } & \text { nid8 } \\ 50001 & 50002 & 50003 & 50004 & 50005 & 50006 & 50007 & 50008 \\ 50009 & 50010 & 50011 & 0 & 0 & 0 & 0 & 0\end{array}$

\$------------------------

*END 
Source Code 2: Supernodes - Part B2 (Supernode Implementation)

*KEYWORD MEMORY=180000000 NCPU $=4$

\$-----------------------

*TITLE

CASE B2

\$----------------------

\section{*CONTROL_ACCURACY}

$\begin{array}{lll}\text { osu } & \text { inn } & \text { pidosu } \\ 0 & 4 & 0\end{array}$

\section{*CONTROL_CONTACT}

$\begin{array}{llllllll}\text { slsfac } & \text { rwpnal } & \text { islchk } & \text { shlthk } & \text { penopt } & \text { thkchg } & \text { orien } & \text { enmass } \\ 0.1 & 0 & 2 & 2 & 0 & 1 & 1 & 0 \\ \text { usrstr } & \text { usrfrc } & \text { nsbcs } & \text { interm } & \text { xpene } & \text { ssthk } & \text { ecdt } & \text { tiedprj } \\ 0 & 0 & 0 & 0 & 4 & 0 & 0 & 0 \\ \text { sfric } & \text { dfric } & \text { edc } & \text { vfc } & \text { th } & \text { th } & \text { _sf } & \text { pen_sf } \\ 0 & 0 & 0 & 0 & 0 & 0 & 0 & 0 \\ \text { ignore } & \text { frceng } & \text { skiprwg } & \text { outseg } & \text { spotstp } & \text { spotdel } & \text { spothin } & \\ 0 & 1 & 0 & 0 & 0 & 0 & 0 & \\ \text { isym } & \text { nserod } & \text { rwgaps } & \text { rwgdth } & \text { rwksf } & \text { icov } & \text { swradf } & \text { ithoff } \\ 0 & 0 & 0 & 0 & 1 & 0 & 0 & 0 \\ \text { shledg } & \text { pstiff } & \text { ithent } & \text { tdcnof } & \text { ftall } & \text { unused } & \text { shltrw } & \\ 0 & 0 & 0 & 0 & 0 & 0 & 0 & \end{array}$

*CONTROL_ENERGY

hgen rwen slnten rylen

$\begin{array}{llll}2 & 2 & 2 & 1\end{array}$

*CONTROL_SHELL

$\begin{array}{llllllll}\text { wrpang } & \text { esort } & \text { irnxx } & \text { istupd } & \text { theory } & \text { bwc } & \text { miter } & \text { proj } \\ 20 & 0 & -1 & 4 & 2 & 2 & 1 & 0 \\ \text { rotascl } & \text { intgrd } & \text { lamsht } & \text { cstyp6 } & \text { tshell } & & & \\ 1 & 0 & 1 & 1 & 0 & & & \\ \text { psstupd } & \text { sidt4tu } & \text { cntco } & \text { itsflg } & \text { irquad } & & & \\ 0 & 0 & 0 & 0 & 2 & & & \\ \text { nfail1 } & \text { nfail4 } & \text { psnfail } & \text { keepcs } & \text { delfr } & \text { drcpsid } & \text { drcprm } & \\ 1 & 1 & 0 & 0 & 0 & 0 & 1 & \end{array}$

*CONTROL_TERMINATION

endtim endcyc dtmin endeng endmas

$\begin{array}{lllll}0.0225 & 0 & 0 & 0 & 0\end{array}$

$\$$

*DATABASE_GLSTAT 


\begin{tabular}{llllll}
$\mathrm{dt}$ & binary & lcur & ioopt & & \\
3E-4 & 1 & 0 & 1 & & \\
\multicolumn{7}{c}{} \\
*DATABASE_NODOUT & & & \\
$\mathrm{dt}$ & binary & lcur & ioopt & option1 & option2 \\
3E-4 & 1 & 0 & 1 & 0 & 0
\end{tabular}

$\begin{array}{llll}\text { *DATABASE_RCFORC } & \\ \mathrm{dt} & \text { binary } & \text { lcur } & \text { ioopt } \\ 3 \mathrm{E}-4 & 1 & 0 & 1\end{array}$
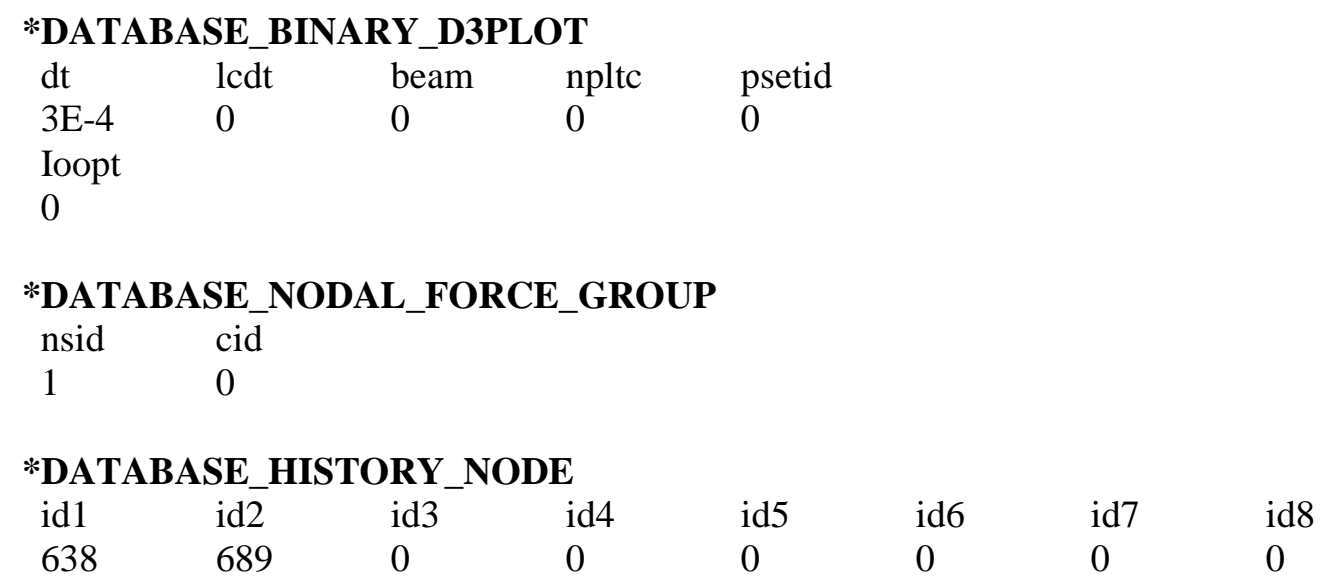

\$-----------------------

\begin{tabular}{|c|c|c|c|c|c|c|c|}
\hline \multirow{2}{*}{\multicolumn{8}{|c|}{ *CONTACT_AUTOMATIC_SURFACE_TO_SURFACE_ID }} \\
\hline & & & & & & & \\
\hline 1 & \multicolumn{7}{|c|}{ IMPACTOR-SKIN } \\
\hline ssid & msid & sstyp & mstyp & sboxid & mboxid & $\mathrm{spr}$ & $\mathrm{mpr}$ \\
\hline 1 & 2 & 3 & 3 & 0 & 0 & 0 & 0 \\
\hline fs & $\mathrm{fd}$ & $\mathrm{dc}$ & $\mathrm{vc}$ & $\mathrm{vdc}$ & penchk & bt & $\mathrm{dt}$ \\
\hline 0.3 & 0 & 0 & 0 & 0 & 0 & 0 & $1 \mathrm{E}+20$ \\
\hline sfs & $\mathrm{sfm}$ & sst & mst & sfst & sfmt & fsf & vsf \\
\hline 1 & 1 & 0 & 0 & 1 & 1 & 1 & 1 \\
\hline
\end{tabular}

\$-----------------------

$\begin{array}{llllllll}\begin{array}{l}\text { *PART_COMPOSITE } \\ \text { SKIN } \\ \text { pid }\end{array} & \text { elform } & \text { shrf } & \text { nloc } & \text { marea } & \text { hgid } & \text { adpopt } & \text { ithelfrm } \\ 1 & 16 & 1 & 0 & 0 & 1 & 0 & 0 \\ \text { mid1 } & \text { thick1 } & \text { b1 } & \text { ithid1 } & \text { mid2 } & \text { thick2 } & \text { b2 } & \text { ithid2 } \\ 1 & 1.25 \mathrm{E}-4 & 0 & 0 & 0 & 0 & 0 & 0 \\ 1 & 1.25 \mathrm{E}-4 & 90 & 0 & 0 & 0 & 0 & 0 \\ 1 & 1.25 \mathrm{E}-4 & 0 & 0 & 0 & 0 & 0 & 0 \\ 1 & 1.25 \mathrm{E}-4 & 0 & 0 & 0 & 0 & 0 & 0 \\ 1 & 1.25 \mathrm{E}-4 & 90 & 0 & 0 & 0 & 0 & 0 \\ 1 & 1.25 \mathrm{E}-4 & 0 & 0 & 0 & 0 & 0 & 0\end{array}$




$\begin{aligned} & \text { *PART } \\ & \text { IMPACTOR }\end{aligned}$
$\begin{array}{llllllll}\text { IMid } & \text { secid } & \text { mid } & \text { eosid } & \text { hgid } & \text { grav } & \text { adpopt } & \text { tmid } \\ 2 & 1 & 2 & 0 & 1 & 0 & 0 & 0\end{array}$

\$-----------------------

*HOURGLASS_TITLE

SHELL HOURGLASS

$\begin{array}{llllllll}\text { hgid } & \text { ihq } & \text { qm } & \text { ibq } & \text { q1 } & \text { q2 } & \text { qb/vdc } & \text { qw } \\ 1 & 8 & 0.1 & 0 & 1.5 & 0.06 & 0.1 & 0.1\end{array}$

$\$$

*MAT_ENHANCED_COMPOSITE_DAMAGE_TITLE

HTA/6376C

$\begin{array}{llllllll}\text { mid } & \text { ro } & \text { ea } & \text { eb } & (\mathrm{ec}) & \text { prba } & \text { (prca) } & \text { (prcb) } \\ 1 & 1590 & 1.45 \mathrm{E}+11 & 1.03 \mathrm{E}+10 & 1.21 \mathrm{E}+10 & 0.0214 & 0.0417 & 0.5815 \\ \text { gab } & \text { gbc } & \text { gca } & (\mathrm{kf}) & \text { aopt } & & & \\ 5.3 \mathrm{E}+9 & 3.95 \mathrm{E}+9 & 5.275 \mathrm{E}+9 & 0 & 0 & & & \\ \text { xp } & \text { yp } & \text { zp } & \mathrm{a} 1 & \mathrm{a} 2 & \mathrm{a} 3 & \text { mangle } & \\ 0 & 0 & 0 & 0 & 0 & 0 & 0 & \\ \text { v1 } & \text { v2 } & \mathrm{v} 3 & \mathrm{~d} 1 & \mathrm{~d} 2 & \mathrm{~d} 3 & \text { dfailm } & \text { dfails } \\ 0 & 0 & 0 & 0 & 0 & 0 & 0.024 & 0.03 \\ \text { tfail } & \text { alph } & \text { soft } & \text { fbrt } & \text { ycfac } & \text { dfailt } & \text { dfailc } & \text { efs } \\ 1.153 \mathrm{E}-9 & 0.1 & 0 & 0.5 & 1.2 & 0.0174 & -0.0116 & 0 \\ \text { xc } & \text { xt } & \text { yc } & \text { yt } & \text { sc } & \text { crit } & \text { beta } & \\ 1.6 \mathrm{E}+9 & 2 \mathrm{E}+9 & 2.9 \mathrm{E}+8 & 6.4 \mathrm{E}+7 & 9.8 \mathrm{E}+7 & 54 & 0.5 & \\ \text { pel } & \text { epsf } & \text { epsr } & \text { tsmd } & \text { soft2 } & & & \\ 0 & 0 & 0 & 0 & 1 & & & \\ \text { slimt } 1 & \text { slimc1 } & \text { slimt2 } & \text { slimc2 } & \text { slims } & \text { ncyred } & \text { softg } & \\ 0 & 0 & 0 & 0 & 0 & 0 & 1 & \end{array}$

*MAT_RIGID_TITLE

AL 7075 - T6

$\begin{array}{llllllll}\text { mid } & \text { ro } & \mathrm{e} & \mathrm{pr} & \mathrm{n} & \text { couple } & \mathrm{m} & \text { alias } \\ 2 & 2810 & 7.17 \mathrm{E}+10 & 0.33 & 0 & 0 & 0 & 0 \\ \text { cmo } & \text { con1 } & \text { con2 } & & & & & \\ 0 & 0 & 0 & & & & & \\ \text { lco or a1 } & \mathrm{a} 2 & \mathrm{a} 3 & \mathrm{v} 1 & \mathrm{v} 2 & \mathrm{v} 3 & & \\ 0 & 0 & 0 & 0 & 0 & 0 & \end{array}$

\$-----------------------

*INITIAL_VELOCITY_RIGID_BODY

$\begin{array}{llllllll}\text { pid } & \text { vx } & \text { vy } & \text { vz } & \text { vxr } & \text { vyr } & \text { vzr } & \text { icid } \\ 2 & 0 & 0 & -3.3774 & 0 & 0 & 0 & 0\end{array}$

\$----------------------

*ELEMENT_DIRECT_MATRIX_INPUT 


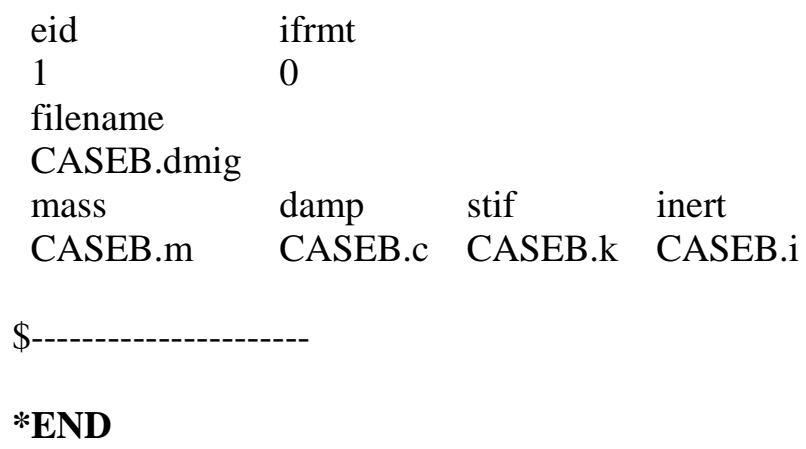


Source Code 3: Ply Compaction and Mesh Refinement

$*$ KEYWORD MEMORY=40000000 NCPU $=4$

$\$$

*TITLE

24 PLIES IMPACT

\$----------------------

*CONTROL_ACCURACY

osu inn pidosu

$\begin{array}{lll}0 & 4 & 0\end{array}$

\section{*CONTROL_CONTACT}

$\begin{array}{llllllll}\text { slsfac } & \text { rwpnal } & \text { islchk } & \text { shlthk } & \text { penopt } & \text { thkchg } & \text { orien } & \text { enmass } \\ 0.1 & 0 & 2 & 2 & 0 & 1 & 1 & 0 \\ \text { usrstr } & \text { usrfrc } & \text { nsbcs } & \text { interm } & \text { xpene } & \text { ssthk } & \text { ecdt } & \text { tiedprj } \\ 0 & 0 & 0 & 0 & 4 & 0 & 0 & 0 \\ \text { sfric } & \text { dfric } & \text { edc } & \text { vfc } & \text { th } & \text { th } & \text { _sf } & \text { pen_sf } \\ 0 & 0 & 0 & 0 & 0 & 0 & 0 & 0 \\ \text { ignore } & \text { frceng } & \text { skiprwg } & \text { outseg } & \text { spotstp } & \text { spotdel } & \text { spothin } & \\ 0 & 1 & 0 & 0 & 0 & 0 & 0 & \\ \text { isym } & \text { nserod } & \text { rwgaps } & \text { rwgdth } & \text { rwksf } & \text { icov } & \text { swradf } & \text { ithoff } \\ 0 & 0 & 0 & 0 & 1 & 0 & 0 & 0 \\ \text { shledg } & \text { pstiff } & \text { ithent } & \text { tdcnof } & \text { ftall } & \text { unused } & \text { shltrw } & \\ 0 & 0 & 0 & 0 & 0 & 0 & 0 & \end{array}$

*CONTROL_ENERGY

$\begin{array}{llll}\text { hgen } & \text { rwen } & \text { slnten } & \text { rylen } \\ 2 & 2 & 2 & 1\end{array}$

\section{*CONTROL_SHELL}

$\begin{array}{llllllll}\text { wrpang } & \text { esort } & \text { irnxx } & \text { istupd } & \text { theory } & \text { bwc } & \text { miter } & \text { proj } \\ 20 & 0 & -1 & 4 & 2 & 2 & 1 & 0 \\ \text { rotascl } & \text { intgrd } & \text { lamsht } & \text { cstyp6 } & \text { tshell } & & & \\ 1 & 0 & 1 & 1 & 0 & & & \\ \text { psstupd } & \text { sidt4tu } & \text { cntco } & \text { itsflg } & \text { irquad } & & & \\ 0 & 0 & 0 & 0 & 2 & & & \\ \text { nfail1 } & \text { nfail4 } & \text { psnfail } & \text { keepcs } & \text { delfr } & \text { drcpsid } & \text { drcprm } & \\ 1 & 1 & 0 & 0 & 0 & 0 & 1 & \end{array}$

*CONTROL_TERMINATION

endtim endcyc dtmin endeng endmas

$\begin{array}{lllll}0.00696 & 0 & 0 & 0 & 0\end{array}$

$\$-$ 


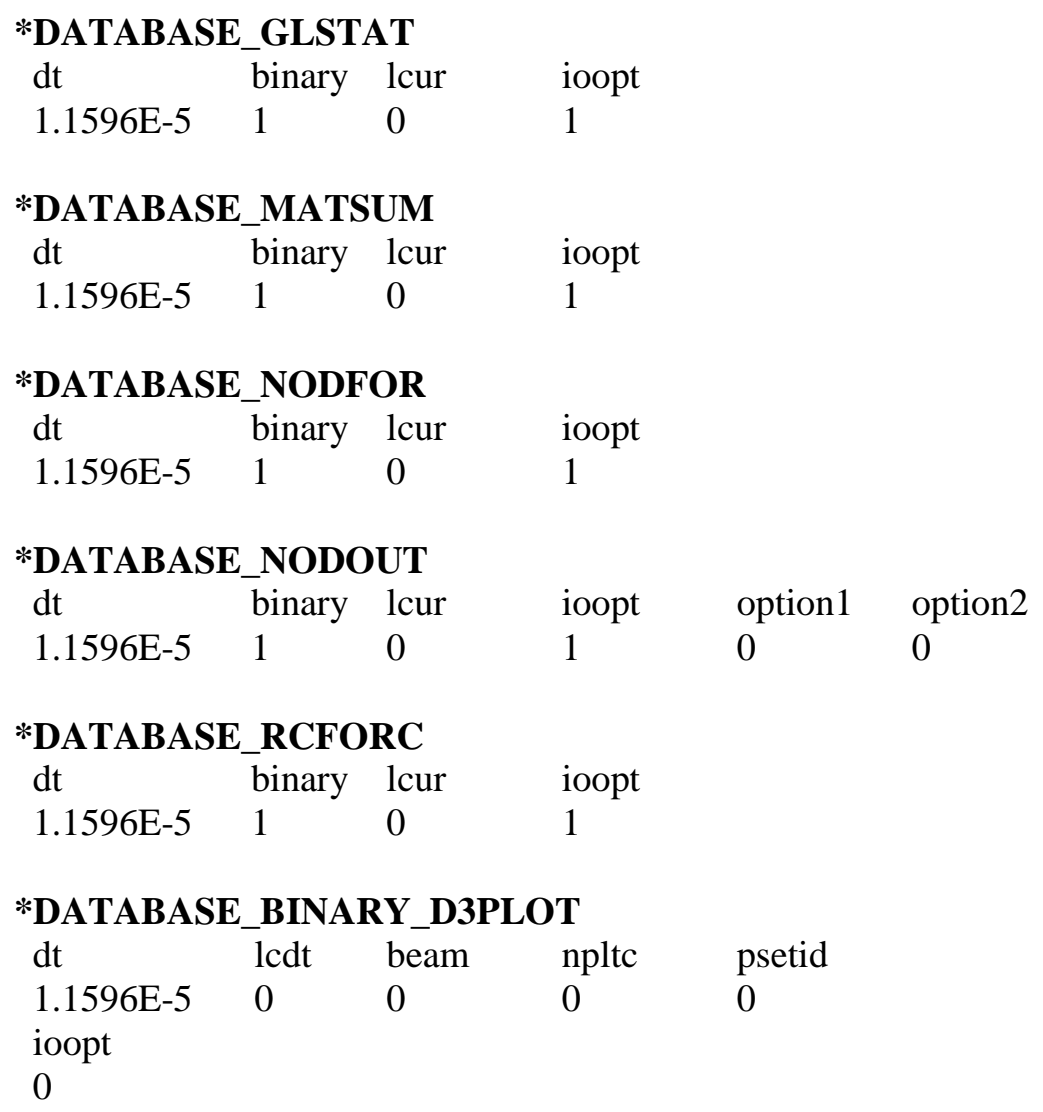




\begin{tabular}{|c|c|c|c|c|c|c|c|}
\hline sfs & sfm & sst & mst & sfst & sfmt & fsf & vsf \\
\hline 1 & 1 & 0 & 0 & 1 & 1 & 1 & 1 \\
\hline \multicolumn{8}{|c|}{ *CONTACT_AUTOMATIC_SURFACE_TO_SURFACE_ID } \\
\hline cid & title & & & & & & \\
\hline 2 & IMP & - PLIE & Т 2 & & & & \\
\hline ssid & msid & sstyp & mstyp & sboxid & mboxid & spr & mpr \\
\hline 2 & 7 & 3 & 3 & 0 & 0 & 0 & 0 \\
\hline fs & fd & $\mathrm{dc}$ & $\mathrm{vc}$ & $\operatorname{vdc}$ & penchk & bt & dt \\
\hline 0.2 & 0 & 0 & 0 & 0 & 0 & 0 & $1 E+20$ \\
\hline sfs & $\mathrm{sfm}$ & sst & mst & sfst & sfmt & fsf & vsf \\
\hline 1 & 1 & 0 & 0 & 1 & 1 & 1 & 1 \\
\hline
\end{tabular}

\begin{tabular}{|c|c|c|c|c|c|c|c|}
\hline \multicolumn{8}{|c|}{$\underset{\text { cid }}{* \text { CONTACT_AUTOMATIC_SURFACE_TO_SURFACE_ID }}$} \\
\hline 3 & \multicolumn{7}{|c|}{ IMPACTOR - PLIES SET 3} \\
\hline ssid & msid & sstyp & mstyp & sboxid & mboxid & spr & $\mathrm{mpr}$ \\
\hline 3 & 7 & 3 & 3 & 0 & 0 & 0 & 0 \\
\hline fs & $\mathrm{fd}$ & $\mathrm{dc}$ & $\mathrm{vc}$ & $\mathrm{vdc}$ & penchk & bt & $\mathrm{dt}$ \\
\hline 0.2 & 0 & 0 & 0 & 0 & 0 & 0 & $1 \mathrm{E}+20$ \\
\hline sfs & $\mathrm{sfm}$ & sst & mst & sfst & sfmt & fsf & vsf \\
\hline 1 & 1 & 0 & 0 & 1 & 1 & 1 & 1 \\
\hline
\end{tabular}

\begin{tabular}{|c|c|c|c|c|c|c|c|}
\hline \multicolumn{8}{|c|}{$\begin{array}{l}\text { *CONTACT_AUTOMATIC_SURFACE_TO_SURFACE_ID } \\
\text { cid title }\end{array}$} \\
\hline 4 & \multicolumn{7}{|c|}{ IMPACTOR - PLIES SET 4} \\
\hline ssid & msid & sstyp & mstyp & sboxid & mboxid & spr & $\mathrm{mpr}$ \\
\hline 4 & 7 & 3 & 3 & 0 & 0 & 0 & 0 \\
\hline fs & $\mathrm{fd}$ & $\mathrm{dc}$ & $\mathrm{vc}$ & $\mathrm{vdc}$ & penchk & bt & $\mathrm{dt}$ \\
\hline 0.2 & 0 & 0 & 0 & 0 & 0 & 0 & $1 \mathrm{E}+20$ \\
\hline sfs & $\mathrm{sfm}$ & sst & $\mathrm{mst}$ & sfst & sfmt & fsf & vsf \\
\hline 1 & 1 & 0 & 0 & 1 & 1 & 1 & 1 \\
\hline
\end{tabular}

\begin{tabular}{|c|c|c|c|c|c|c|c|}
\hline \multicolumn{8}{|c|}{ *CONTACT_AUTOMATIC_SURFACE_TO_SURFACE_ID } \\
\hline 5 & \multicolumn{7}{|c|}{ IMPACTOR - PLIES SET 5} \\
\hline ssid & msid & sstyp & mstyp & sboxid & mboxid & spr & mpr \\
\hline 5 & 7 & 3 & 3 & 0 & 0 & 0 & 0 \\
\hline fs & $\mathrm{fd}$ & $\mathrm{dc}$ & $\mathrm{vc}$ & $\mathrm{vdc}$ & penchk & bt & dt \\
\hline 0.2 & 0 & 0 & 0 & 0 & 0 & 0 & $1 \mathrm{E}+20$ \\
\hline sfs & $\mathrm{sfm}$ & sst & mst & sfst & sfmt & fsf & vsf \\
\hline 1 & 1 & 0 & 0 & 1 & 1 & 1 & 1 \\
\hline
\end{tabular}

\begin{tabular}{|c|c|c|c|c|c|c|c|}
\hline \\
\hline \multirow{2}{*}{\multicolumn{8}{|c|}{$\begin{array}{l}\text { cid } \\
6\end{array}$}} \\
\hline & & & & & & & \\
\hline & msid & sstyp & mstyp & sboxid & mboxid & spr & $\mathrm{mpr}$ \\
\hline 6 & 7 & 3 & 3 & 0 & 0 & 0 & 0 \\
\hline fs & $\mathrm{fd}$ & $\mathrm{dc}$ & $\mathrm{vc}$ & vdc & penchk & bt & $\mathrm{dt}$ \\
\hline 0.2 & 0 & 0 & 0 & 0 & 0 & 0 & $1 \mathrm{E}+20$ \\
\hline sfs & $\mathrm{sfm}$ & sst & mst & sfst & sfmt & fsf & vsf \\
\hline
\end{tabular}




\begin{tabular}{|c|c|c|c|c|c|c|c|}
\hline 1 & 1 & 0 & 0 & 1 & 1 & 1 & 1 \\
\hline \multicolumn{8}{|c|}{ *CONTACT_AUTOMATIC_SURFACE_TO_SURFACE_TIEBREAK_ID } \\
\hline cid & \multirow{2}{*}{\multicolumn{7}{|c|}{$\begin{array}{l}\text { title } \\
\text { PLIES SET } 1 \text { - PLIES SET } 2\end{array}$}} \\
\hline 7 & & & & & & & \\
\hline ssid & msid & sstyp & mstyp & sboxid & mboxid & spr & mpr \\
\hline 2 & 1 & 3 & 3 & 0 & 0 & 0 & 0 \\
\hline fs & $\mathrm{fd}$ & $\mathrm{dc}$ & $\mathrm{vc}$ & $\mathrm{vdc}$ & penchk & bt & $\mathrm{dt}$ \\
\hline 0.2 & 0 & 0 & 0 & 0 & 0 & 0 & $1 \mathrm{E}+20$ \\
\hline sfs & sfm & sst & mst & sfst & sfmt & fsf & vsf \\
\hline 1 & 1 & 0 & 0 & 1 & 1 & 1 & 1 \\
\hline option & nfls & sfls & param & eraten & erates & $\operatorname{ct} 2 \mathrm{cn}$ & $\mathrm{cn}$ \\
\hline 8 & $5.60 \mathrm{E}+7$ & $4.40 \mathrm{E}+7$ & 0 & 0 & 0 & 0 & 0 \\
\hline \multicolumn{8}{|c|}{ *CONTACT_AUTOMATIC_SURFACE_TO_SURFACE_TIEBREAK_ID } \\
\hline cid & \multirow{2}{*}{\multicolumn{7}{|c|}{$\begin{array}{l}\text { title } \\
\text { PLIES SET } 2 \text { - PLIES SET } 3\end{array}$}} \\
\hline 8 & & & & & & & \\
\hline ssid & msid & sstyp & mstyp & sboxid & mboxid & spr & mpr \\
\hline 3 & 2 & 3 & 3 & 0 & 0 & 0 & 0 \\
\hline fs & $\mathrm{fd}$ & $\mathrm{dc}$ & $\mathrm{vc}$ & $\mathrm{vdc}$ & penchk & bt & $\mathrm{dt}$ \\
\hline 0.2 & 0 & 0 & 0 & 0 & 0 & 0 & $1 \mathrm{E}+20$ \\
\hline sfs & $\mathrm{sfm}$ & sst & $\mathrm{mst}$ & sfst & sfmt & fsf & vsf \\
\hline 1 & 1 & 0 & 0 & 1 & 1 & 1 & 1 \\
\hline option & nfls & sfls & param & eraten & erates & $\operatorname{ct} 2 \mathrm{cn}$ & $\mathrm{cn}$ \\
\hline & $5.60 \mathrm{E}+7$ & $4.40 \mathrm{E}+7$ & & & & & 0 \\
\hline
\end{tabular}

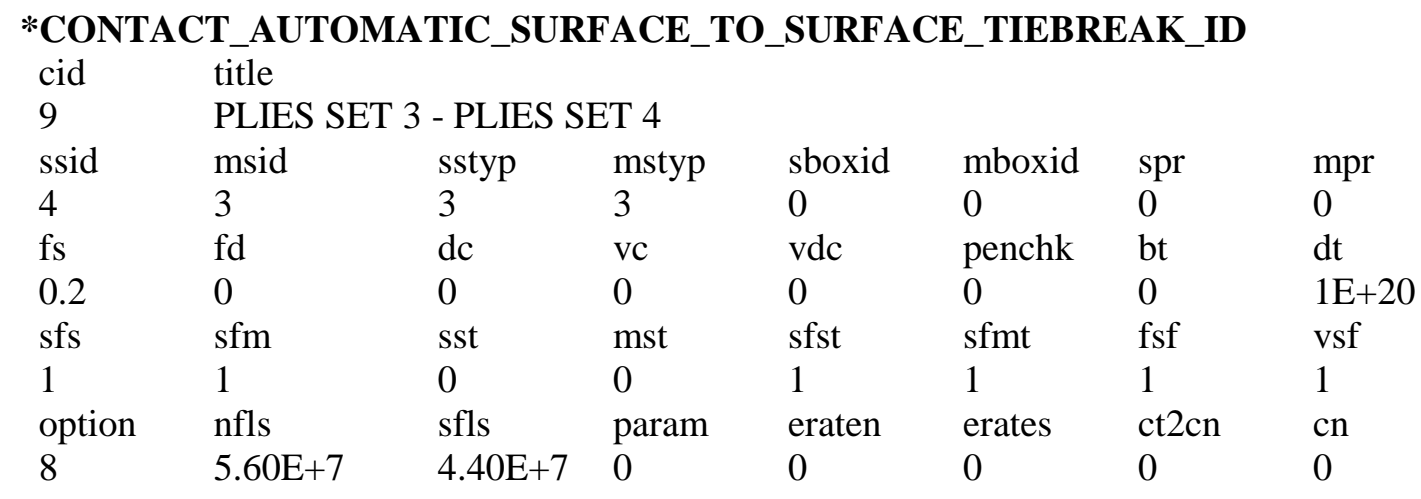

\begin{tabular}{|c|c|c|c|c|c|c|c|}
\hline \multicolumn{8}{|c|}{ *CONTACT_AUTOMATIC_SURFACE_TO_SURFACE_TIEBREAK_ID } \\
\hline cid & title & & & & & & \\
\hline 10 & PLIES S & - PLIES S & $\mathrm{ET} 5$ & & & & \\
\hline ssid & msid & sstyp & mstyp & sboxid & mboxid & $\mathrm{spr}$ & $\mathrm{mpr}$ \\
\hline 5 & 4 & 3 & 3 & 0 & 0 & 0 & 0 \\
\hline fs & $\mathrm{fd}$ & $\mathrm{dc}$ & $\mathrm{vc}$ & vdc & penchk & bt & $\mathrm{dt}$ \\
\hline 0.2 & 0 & 0 & 0 & 0 & 0 & 0 & $1 \mathrm{E}+20$ \\
\hline sfs & sfm & sst & mst & sfst & sfmt & fsf & vsf \\
\hline 1 & 1 & 0 & 0 & 1 & 1 & 1 & 1 \\
\hline option & nfls & sfls & param & eraten & erates & $\mathrm{ct} 2 \mathrm{cn}$ & $\mathrm{cn}$ \\
\hline 8 & $5.60 \mathrm{E}+7$ & $4.40 \mathrm{E}+7$ & 0 & 0 & 0 & 0 & 0 \\
\hline
\end{tabular}

*CONTACT_AUTOMATIC_SURFACE_TO_SURFACE_TIEBREAK_ID 


\begin{tabular}{|c|c|c|c|c|c|c|c|}
\hline cid & title & & & & & & \\
\hline 11 & PLIES SE & - PLIES S & TT 6 & & & & \\
\hline ssid & msid & sstyp & mstyp & sboxid & mboxid & spr & $\mathrm{mpr}$ \\
\hline 6 & 5 & 3 & 3 & 0 & 0 & 0 & 0 \\
\hline fs & $\mathrm{fd}$ & $\mathrm{dc}$ & $\mathrm{vc}$ & $\mathrm{vdc}$ & penchk & bt & $\mathrm{dt}$ \\
\hline 0.2 & 0 & 0 & 0 & 0 & 0 & 0 & $1 E+20$ \\
\hline sfs & sfm & sst & mst & sfst & sfmt & fsf & vsf \\
\hline 1 & 1 & 0 & 0 & 1 & 1 & 1 & 1 \\
\hline option & nfls & sfls & param & eraten & erates & $\mathrm{ct} 2 \mathrm{cn}$ & $\mathrm{cn}$ \\
\hline 8 & $5.60 \mathrm{E}+7$ & $4.40 \mathrm{E}+7$ & 0 & 0 & 0 & 0 & 0 \\
\hline${ }^{*}$ CONT & T_EROD & _SURFA & E_TO & RFACE & & & \\
\hline cid & title & & & & & & \\
\hline 12 & IMPACT & PLIES SI & T 1 & & & & \\
\hline ssid & msid & sstyp & mstyp & sboxid & mboxid & spr & $\mathrm{mpr}$ \\
\hline 1 & 7 & 3 & 3 & 0 & 0 & 0 & 0 \\
\hline fs & $\mathrm{fd}$ & $\mathrm{dc}$ & $\mathrm{vc}$ & $\mathrm{vdc}$ & penchk & bt & $\mathrm{dt}$ \\
\hline 0.2 & 0 & 0 & 0 & 0 & 0 & 0 & $1 \mathrm{E}+20$ \\
\hline sfs & $\mathrm{sfm}$ & sst & mst & sfst & sfmt & fsf & vsf \\
\hline 1 & 1 & 0 & 0 & 1 & 1 & 1 & 1 \\
\hline isym & erosop & iadj & & & & & \\
\hline 0 & 0 & 0 & & & & & \\
\hline
\end{tabular}

\begin{tabular}{|c|c|c|c|c|c|c|c|}
\hline \multicolumn{8}{|c|}{ *CONTACT_ERODING_SURFACE_TO_SURFACE_ID } \\
\hline cid & title & - & - & & & & \\
\hline 13 & IMPAC & PLIE & T 2 & & & & \\
\hline ssid & msid & sstyp & mstyp & sboxid & mboxid & spr & $\mathrm{mpr}$ \\
\hline 2 & 7 & 3 & 3 & 0 & 0 & 0 & 0 \\
\hline fs & $\mathrm{fd}$ & $\mathrm{dc}$ & $\mathrm{vc}$ & $\mathrm{vdc}$ & penchk & bt & dt \\
\hline 0.2 & 0 & 0 & 0 & 0 & 0 & 0 & $1 \mathrm{E}+20$ \\
\hline sfs & $\mathrm{sfm}$ & sst & mst & sfst & sfmt & fsf & vsf \\
\hline 1 & 1 & 0 & 0 & 1 & 1 & 1 & 1 \\
\hline isym & erosop & iadj & & & & & \\
\hline 0 & 0 & 0 & & & & & \\
\hline
\end{tabular}

\begin{tabular}{|c|c|c|c|c|c|c|c|}
\hline \multicolumn{8}{|c|}{ *CONTACT_ERODING_SURFACE_TO_SURFACE_ID } \\
\hline 14 & \multicolumn{7}{|c|}{ IMPACTOR - PLIES SET 3} \\
\hline ssid & msid & sstyp & mstyp & sboxid & mboxid & $\mathrm{spr}$ & $\mathrm{mpr}$ \\
\hline 3 & 7 & 3 & 3 & 0 & 0 & 0 & 0 \\
\hline fs & $\mathrm{fd}$ & $\mathrm{dc}$ & $\mathrm{vc}$ & $\mathrm{vdc}$ & penchk & bt & $\mathrm{dt}$ \\
\hline 0.2 & 0 & 0 & 0 & 0 & 0 & 0 & $1 \mathrm{E}+20$ \\
\hline sfs & $\mathrm{sfm}$ & sst & mst & sfst & sfmt & fsf & vsf \\
\hline 1 & 1 & 0 & 0 & 1 & 1 & 1 & 1 \\
\hline isym & erosop & iadj & & & & & \\
\hline 0 & 0 & 0 & & & & & \\
\hline
\end{tabular}

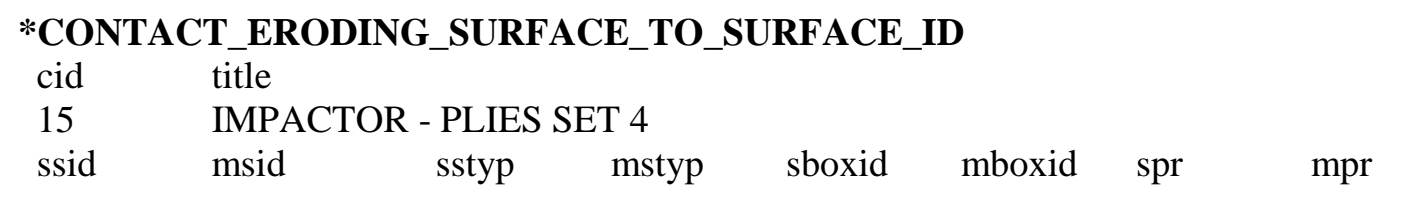




$\begin{array}{llllllll}4 & 7 & 3 & 3 & 0 & 0 & 0 & 0 \\ \text { fs } & \mathrm{fd} & \mathrm{dc} & \mathrm{vc} & \mathrm{vdc} & \text { penchk } & \mathrm{bt} & \mathrm{dt} \\ 0.2 & 0 & 0 & 0 & 0 & 0 & 0 & 1 \mathrm{E}+20 \\ \text { sfs } & \text { sfm } & \text { sst } & \text { mst } & \text { sfst } & \text { sfmt } & \text { fsf } & \text { vsf } \\ 1 & 1 & 0 & 0 & 1 & 1 & 1 & 1 \\ \text { isym } & \text { erosop } & \text { iadj } & & & & & \\ 0 & 0 & 0 & & & & & \end{array}$

\begin{tabular}{|c|c|c|c|c|c|c|c|}
\hline \multicolumn{8}{|c|}{ *CONTACT_ERODING_SURFACE_TO_SURFACE_ID } \\
\hline 16 & \multicolumn{7}{|c|}{ IMPACTOR - PLIES SET 5} \\
\hline ssid & msid & sstyp & mstyp & sboxid & mboxid & spr & mpr \\
\hline 5 & 7 & 3 & 3 & 0 & 0 & 0 & 0 \\
\hline fs & $\mathrm{fd}$ & $\mathrm{dc}$ & $\mathrm{vc}$ & $\mathrm{vdc}$ & penchk & bt & $\mathrm{dt}$ \\
\hline 0.2 & 0 & 0 & 0 & 0 & 0 & 0 & $1 \mathrm{E}+20$ \\
\hline sfs & sfm & sst & mst & sfst & sfmt & fsf & vsf \\
\hline 1 & 1 & 0 & 0 & 1 & 1 & 1 & 1 \\
\hline isym & erosop & iadj & & & & & \\
\hline 0 & 0 & 0 & & & & & \\
\hline
\end{tabular}

\begin{tabular}{|c|c|c|c|c|c|c|c|}
\hline \multicolumn{8}{|c|}{ *CONTACT_ERODING_SURFACE_TO_SURFACE_ID } \\
\hline cid & title & - & & & & & \\
\hline 17 & IMPA & - PLIE & T 6 & & & & \\
\hline ssid & msid & sstyp & mstyp & sboxid & mboxid & spr & $\mathrm{mpr}$ \\
\hline 6 & 7 & 3 & 3 & 0 & 0 & 0 & 0 \\
\hline fs & $\mathrm{fd}$ & $\mathrm{dc}$ & $\mathrm{vc}$ & $\mathrm{vdc}$ & penchk & bt & dt \\
\hline 0.2 & 0 & 0 & 0 & 0 & 0 & 0 & $1 E+20$ \\
\hline sfs & $\mathrm{sfm}$ & sst & mst & sfst & sfmt & fsf & vsf \\
\hline 1 & 1 & 0 & 0 & 1 & 1 & 1 & 1 \\
\hline isym & erosop & iadj & & & & & \\
\hline 0 & 0 & 0 & & & & & \\
\hline
\end{tabular}

\begin{tabular}{|c|c|c|c|c|c|c|c|}
\hline cid & title & & & & & & \\
\hline 18 & PLIES & - PLIE & ET 2 & & & & \\
\hline ssid & msid & sstyp & mstyp & sboxid & mboxid & spr & $\mathrm{mpr}$ \\
\hline 2 & 1 & 3 & 3 & 0 & 0 & 0 & 0 \\
\hline fs & $\mathrm{fd}$ & $\mathrm{dc}$ & $\mathrm{vc}$ & $\mathrm{vdc}$ & penchk & bt & $\mathrm{dt}$ \\
\hline 0.2 & 0 & 0 & 0 & 0 & 0 & 0 & $1 \mathrm{E}+20$ \\
\hline sfs & sfm & sst & mst & sfst & sfmt & fsf & vsf \\
\hline 1 & 1 & 0 & 0 & 1 & 1 & 1 & 1 \\
\hline isym & erosop & iadj & & & & & \\
\hline 0 & 0 & 0 & & & & & \\
\hline
\end{tabular}

$\begin{array}{llllllll}\text { *CONTACT_ERODING_SURFACE_TO_SURFACE_ID } & & \\ \text { cid } & \text { title } & & & & & \\ 19 & \text { PLIES SET } & 1 & - \text { PLIES SET } 3 & & & & \\ \text { ssid } & \text { msid } & \text { sstyp } & \text { mstyp } & \text { sboxid } & \text { mboxid } & \text { spr } & \text { mpr } \\ 3 & 1 & 3 & 3 & 0 & 0 & 0 & 0 \\ \text { fs } & \text { fd } & \text { dc } & \text { vc } & \text { vdc } & \text { penchk } & \text { bt } & \text { dt } \\ 0.2 & 0 & 0 & 0 & 0 & 0 & 0 & \text { 1E+20 }\end{array}$




$\begin{array}{llllllll}\text { sfs } & \text { sfm } & \text { sst } & \text { mst } & \text { sfst } & \text { sfmt } & \text { fsf } & \text { vsf } \\ 1 & 1 & 0 & 0 & 1 & 1 & 1 & 1 \\ \text { isym } & \text { erosop } & \text { iadj } & & & & & \\ 0 & 0 & 0 & & & & \end{array}$

\begin{tabular}{|c|c|c|c|c|c|c|c|}
\hline \multicolumn{8}{|c|}{ *CONTACT_ERODING_SURFACE_TO_SURFACE_ID } \\
\hline cid & title & & & & & & \\
\hline 20 & PLIES & - PLIE & ET 4 & & & & \\
\hline ssid & msid & sstyp & mstyp & sboxid & mboxid & spr & $\mathrm{mpr}$ \\
\hline 4 & 1 & 3 & 3 & 0 & 0 & 0 & 0 \\
\hline fs & $\mathrm{fd}$ & $\mathrm{dc}$ & $\mathrm{vc}$ & vdc & penchk & bt & $\mathrm{dt}$ \\
\hline 0.2 & 0 & 0 & 0 & 0 & 0 & 0 & $1 \mathrm{E}+20$ \\
\hline sfs & $\mathrm{sfm}$ & sst & mst & sfst & sfmt & fsf & vsf \\
\hline 1 & 1 & 0 & 0 & 1 & 1 & 1 & 1 \\
\hline isym & erosop & iadj & & & & & \\
\hline 0 & 0 & 0 & & & & & \\
\hline
\end{tabular}

$\begin{array}{llllllll}\text { *CONTACT_ERODING_SURFACE_TO_SURFACE_ID } & & \\ \text { cid } & \text { title } & & & & \\ 21 & \text { PLIES SET } & 1 & \text { - PLIES SET } 5 & & & & \\ \text { ssid } & \text { msid } & \text { sstyp } & \text { mstyp } & \text { sboxid } & \text { mboxid } & \text { spr } & \text { mpr } \\ 5 & 1 & 3 & 3 & 0 & 0 & 0 & 0 \\ \text { fs } & \text { fd } & \text { dc } & \text { vc } & \text { vdc } & \text { penchk } & \text { bt } & \text { dt } \\ 0.2 & 0 & 0 & 0 & 0 & 0 & 0 & 1 \text { E+20 } \\ \text { sfs } & \text { sfm } & \text { sst } & \text { mst } & \text { sfst } & \text { sfmt } & \text { fsf } & \text { vsf } \\ 1 & 1 & 0 & 0 & 1 & 1 & 1 & 1 \\ \text { isym } & \text { erosop } & \text { iadj } & & & & & \\ 0 & 0 & 0 & & & & & \end{array}$

\begin{tabular}{|c|c|c|c|c|c|c|c|}
\hline cid & title & & & & & & \\
\hline 22 & PLIES & - PLIF & ET 6 & & & & \\
\hline ssid & msid & sstyp & mstyp & sboxid & mboxid & spr & $\mathrm{mpr}$ \\
\hline 6 & 1 & 3 & 3 & 0 & 0 & 0 & 0 \\
\hline fs & $\mathrm{fd}$ & $\mathrm{dc}$ & $\mathrm{vc}$ & $\mathrm{vdc}$ & penchk & bt & $\mathrm{dt}$ \\
\hline 0.2 & 0 & 0 & 0 & 0 & 0 & 0 & $1 \mathrm{E}+20$ \\
\hline sfs & $\mathrm{sfm}$ & sst & mst & sfst & sfmt & fsf & vsf \\
\hline 1 & 1 & 0 & 0 & 1 & 1 & 1 & 1 \\
\hline isym & erosop & iadj & & & & & \\
\hline 0 & 0 & 0 & & & & & \\
\hline
\end{tabular}

\begin{tabular}{|c|c|c|c|c|c|c|c|}
\hline \multicolumn{8}{|c|}{ *CONTACT_ERODING_SURFACE_TO_SURFACE_ID } \\
\hline 23 & PLIES & - PLIF & ET 3 & & & & \\
\hline ssid & msid & sstyp & mstyp & sboxid & mboxid & spr & $\mathrm{mpr}$ \\
\hline 3 & 2 & 3 & 3 & 0 & 0 & 0 & 0 \\
\hline fs & $\mathrm{fd}$ & $\mathrm{dc}$ & $\mathrm{vc}$ & $\mathrm{vdc}$ & penchk & bt & $\mathrm{dt}$ \\
\hline 0.2 & 0 & 0 & 0 & 0 & 0 & 0 & $1 E+20$ \\
\hline sfs & $\mathrm{sfm}$ & sst & mst & sfst & sfmt & fsf & vsf \\
\hline 1 & 1 & 0 & 0 & 1 & 1 & 1 & 1 \\
\hline isym & erosop & iadj & & & & & \\
\hline
\end{tabular}




\begin{tabular}{|c|c|c|c|c|c|c|c|}
\hline 0 & 0 & 0 & & & & & \\
\hline \multicolumn{8}{|c|}{ *CONTACT_ERODING_SURFACE_TO_SURFACE_ID } \\
\hline cid & title & & & & & & \\
\hline 24 & PLIES & - PLIE & $\mathrm{ET} 4$ & & & & \\
\hline ssid & msid & sstyp & mstyp & sboxid & mboxid & $\mathrm{spr}$ & $\mathrm{mpr}$ \\
\hline 4 & 2 & 3 & 3 & 0 & 0 & 0 & 0 \\
\hline fs & $\mathrm{fd}$ & $\mathrm{dc}$ & $\mathrm{vc}$ & $\mathrm{vdc}$ & penchk & bt & $\mathrm{dt}$ \\
\hline 0.2 & 0 & 0 & 0 & 0 & 0 & 0 & $1 \mathrm{E}+20$ \\
\hline sfs & sfm & sst & $\mathrm{mst}$ & sfst & sfmt & fsf & vsf \\
\hline 1 & 1 & 0 & 0 & 1 & 1 & 1 & 1 \\
\hline isym & erosop & iadj & & & & & \\
\hline 0 & 0 & 0 & & & & & \\
\hline
\end{tabular}

\begin{tabular}{|c|c|c|c|c|c|c|c|}
\hline cid & title & & & & & & \\
\hline 25 & PLIES & - PLIE & $\mathrm{ET} 5$ & & & & \\
\hline ssid & msid & sstyp & mstyp & sboxid & mboxid & spr & $\mathrm{mpr}$ \\
\hline 5 & 2 & 3 & 3 & 0 & 0 & 0 & 0 \\
\hline fs & $\mathrm{fd}$ & $\mathrm{dc}$ & $\mathrm{vc}$ & vdc & penchk & bt & $\mathrm{dt}$ \\
\hline 0.2 & 0 & 0 & 0 & 0 & 0 & 0 & $1 E+20$ \\
\hline sfs & $\mathrm{sfm}$ & sst & $\mathrm{mst}$ & sfst & sfmt & fsf & vsf \\
\hline 1 & 1 & 0 & 0 & 1 & 1 & 1 & 1 \\
\hline isym & erosop & iadj & & & & & \\
\hline 0 & 0 & 0 & & & & & \\
\hline
\end{tabular}

\begin{tabular}{|c|c|c|c|c|c|c|c|}
\hline \multicolumn{8}{|c|}{ *CONTACT_ERODING_SURFACE_TO_SURFACE_ID } \\
\hline cid & title & - & & & & & \\
\hline 26 & PLIES & - PLIF & $\mathrm{ET} 6$ & & & & \\
\hline ssid & msid & sstyp & mstyp & sboxid & mboxid & spr & $\mathrm{mpr}$ \\
\hline 6 & 2 & 3 & 3 & 0 & 0 & 0 & 0 \\
\hline fs & $\mathrm{fd}$ & $\mathrm{dc}$ & $\mathrm{vc}$ & $\mathrm{vdc}$ & penchk & bt & $\mathrm{dt}$ \\
\hline 0.2 & 0 & 0 & 0 & 0 & 0 & 0 & $1 \mathrm{E}+20$ \\
\hline sfs & $\mathrm{sfm}$ & sst & $\mathrm{mst}$ & sfst & sfmt & fsf & vsf \\
\hline 1 & 1 & 0 & 0 & 1 & 1 & 1 & 1 \\
\hline isym & erosop & iadj & & & & & \\
\hline 0 & 0 & 0 & & & & & \\
\hline
\end{tabular}

\begin{tabular}{|c|c|c|c|c|c|c|c|}
\hline \multicolumn{8}{|c|}{$\underset{\mathrm{cid}}{* \text { CONTACT_ERODING_SURFACE_TO_SURFACE_ID }}$} \\
\hline 27 & \multicolumn{7}{|c|}{ PLIES SET 3 - PLIES SET 4} \\
\hline ssid & msid & sstyp & mstyp & sboxid & mboxid & spr & $\mathrm{mpr}$ \\
\hline 4 & 3 & 3 & 3 & 0 & 0 & 0 & 0 \\
\hline fs & $\mathrm{fd}$ & $\mathrm{dc}$ & $\mathrm{vc}$ & $\mathrm{vdc}$ & penchk & bt & $\mathrm{dt}$ \\
\hline 0.2 & 0 & 0 & 0 & 0 & 0 & 0 & $1 \mathrm{E}+2 \mathrm{C}$ \\
\hline sfs & $\mathrm{sfm}$ & sst & mst & sfst & sfmt & fsf & vsf \\
\hline 1 & 1 & 0 & 0 & 1 & 1 & 1 & 1 \\
\hline isym & erosop & iadj & & & & & \\
\hline 0 & 0 & 0 & & & & & \\
\hline
\end{tabular}

*CONTACT_ERODING_SURFACE_TO_SURFACE_ID 


\begin{tabular}{llllllll} 
cid & title & \multicolumn{1}{l}{ ( } & & & & & \\
28 & PLIES SET & - PLIES SET 5 & & & & \\
ssid & msid & sstyp & mstyp & sboxid & mboxid & spr & mpr \\
5 & 3 & 3 & 3 & 0 & 0 & 0 & 0 \\
fs & fd & dc & vc & vdc & penchk & bt & dt \\
0.2 & 0 & 0 & 0 & 0 & 0 & 0 & 1 E+20 \\
sfs & sfm & sst & mst & sfst & sfmt & fsf & vsf \\
1 & 1 & 0 & 0 & 1 & 1 & 1 & 1 \\
isym & erosop & iadj & & & & & \\
0 & 0 & 0 & & & & &
\end{tabular}

\begin{tabular}{|c|c|c|c|c|c|c|c|}
\hline \multicolumn{8}{|c|}{ *CONTACT_ERODING_SURFACE_TO_SURFACE_ID } \\
\hline 29 & \multicolumn{7}{|c|}{ PLIES SET 3 - PLIES SET 6} \\
\hline ssid & msid & sstyp & mstyp & sboxid & mboxid & $\mathrm{spr}$ & $\mathrm{mpr}$ \\
\hline 6 & 3 & 3 & 3 & 0 & 0 & 0 & 0 \\
\hline fs & $\mathrm{fd}$ & $\mathrm{dc}$ & $\mathrm{vc}$ & $\mathrm{vdc}$ & penchk & bt & $\mathrm{dt}$ \\
\hline 0.2 & 0 & 0 & 0 & 0 & 0 & 0 & $1 \mathrm{E}+20$ \\
\hline sfs & $\mathrm{sfm}$ & sst & mst & sfst & sfmt & fsf & vsf \\
\hline 1 & 1 & 0 & 0 & 1 & 1 & 1 & 1 \\
\hline isym & erosop & iadj & & & & & \\
\hline 0 & 0 & 0 & & & & & \\
\hline
\end{tabular}

\begin{tabular}{|c|c|c|c|c|c|c|c|}
\hline \multicolumn{8}{|c|}{ 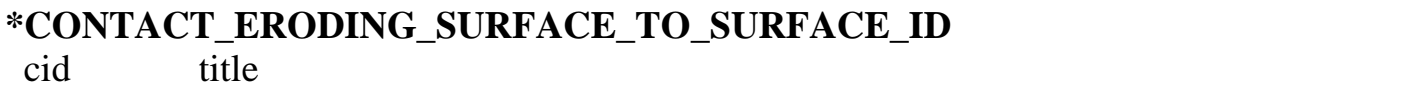 } \\
\hline 30 & \multicolumn{7}{|c|}{ PLIES SET 4 - PLIES SET 5} \\
\hline ssid & msid & sstyp & mstyp & sboxid & mboxid & spr & $\mathrm{mpr}$ \\
\hline 5 & 4 & 3 & 3 & 0 & 0 & 0 & 0 \\
\hline fs & $\mathrm{fd}$ & $\mathrm{dc}$ & $\mathrm{vc}$ & $\mathrm{vdc}$ & penchk & bt & $\mathrm{dt}$ \\
\hline 0.2 & 0 & 0 & 0 & 0 & 0 & 0 & $1 \mathrm{E}+20$ \\
\hline sfs & $\mathrm{sfm}$ & sst & mst & sfst & sfmt & fsf & vsf \\
\hline 1 & 1 & 0 & 0 & 1 & 1 & 1 & 1 \\
\hline isym & erosop & iadj & & & & & \\
\hline 0 & 0 & 0 & & & & & \\
\hline
\end{tabular}

\begin{tabular}{|c|c|c|c|c|c|c|c|}
\hline \multicolumn{8}{|c|}{$\begin{array}{c}\text { *CONTACT_ERODING_SURFACE_TO_SURFACE_ID } \\
\text { cid }\end{array}$} \\
\hline 31 & \multicolumn{7}{|c|}{ PLIES SET 4 - PLIES SET 6} \\
\hline ssid & msid & sstyp & mstyp & sboxid & mboxid & spr & $\mathrm{mpr}$ \\
\hline 6 & 4 & 3 & 3 & 0 & 0 & 0 & 0 \\
\hline fs & $\mathrm{fd}$ & $\mathrm{dc}$ & $\mathrm{vc}$ & vdc & penchk & bt & $\mathrm{dt}$ \\
\hline 0.2 & 0 & 0 & 0 & 0 & 0 & 0 & $1 \mathrm{E}+20$ \\
\hline sfs & $\mathrm{sfm}$ & sst & mst & sfst & sfmt & fsf & vsf \\
\hline 1 & 1 & 0 & 0 & 1 & 1 & 1 & 1 \\
\hline isym & erosop & iadj & & & & & \\
\hline 0 & 0 & 0 & & & & & \\
\hline
\end{tabular}

\footnotetext{
*CONTACT_ERODING_SURFACE_TO_SURFACE_ID

cid title

$32 \quad$ PLIES SET 5 - PLIES SET 6

ssid msid sstyp mstyp sboxid mboxid $\mathrm{spr}$ mpr
} 


$\begin{array}{llllllll}6 & 5 & 3 & 3 & 0 & 0 & 0 & 0 \\ \text { fs } & \text { fd } & \text { dc } & \text { vc } & \text { vdc } & \text { penchk } & \text { bt } & \text { dt } \\ 0.2 & 0 & 0 & 0 & 0 & 0 & 0 & 1 \text { E+20 } \\ \text { sfs } & \text { sfm } & \text { sst } & \text { mst } & \text { sfst } & \text { sfmt } & \text { fsf } & \text { vsf } \\ 1 & 1 & 0 & 0 & 1 & 1 & 1 & 1 \\ \text { isym } & \text { erosop } & \text { iadj } & & & & & \\ 0 & 0 & 0 & & & & & \end{array}$

\begin{tabular}{|c|c|c|c|c|c|c|c|}
\hline \multicolumn{8}{|c|}{ *PART_COMPOSITE } \\
\hline \multicolumn{8}{|c|}{ PLIES SET 1} \\
\hline pid & elform & shrf & nloc & marea & hgid & adpopt & ithelfrm \\
\hline 1 & 16 & 1 & 0 & 0 & 1 & 0 & 0 \\
\hline mid1 & thick1 & b1 & ithid1 & $\operatorname{mid} 2$ & thick2 & b2 & ithid2 \\
\hline 1 & $1.400 \mathrm{E}-4$ & 90 & 0 & 0 & 0 & 0 & 0 \\
\hline 1 & $1.400 \mathrm{E}-4$ & 0 & 0 & 0 & 0 & 0 & 0 \\
\hline 1 & $1.400 \mathrm{E}-4$ & 90 & 0 & 0 & 0 & 0 & 0 \\
\hline 1 & $1.400 \mathrm{E}-4$ & 0 & 0 & 0 & 0 & 0 & 0 \\
\hline
\end{tabular}

*PART_COMPOSITE

\section{PLIES SET 2}

$\begin{array}{llllllll}\text { pid } & \text { elform } & \text { shrf } & \text { nloc } & \text { marea } & \text { hgid } & \text { adpopt } & \text { ithelfrm } \\ 2 & 16 & 1 & 0 & 0 & 1 & 0 & 0 \\ \text { mid1 } & \text { thick1 } & \text { b1 } & \text { ithid1 } & \text { mid2 } & \text { thick2 } & \text { b2 } & \text { ithid2 } \\ 1 & 1.400 \mathrm{E}-4 & 90 & 0 & 0 & 0 & 0 & 0 \\ 1 & 1.400 \mathrm{E}-4 & 0 & 0 & 0 & 0 & 0 & 0 \\ 1 & 1.400 \mathrm{E}-4 & 90 & 0 & 0 & 0 & 0 & 0 \\ 1 & 1.400 \mathrm{E}-4 & 0 & 0 & 0 & 0 & 0 & 0\end{array}$

\section{*PART_COMPOSITE}

\section{PLIES SET 3}

$\begin{array}{llllllll}\text { pid } & \text { elform } & \text { shrf } & \text { nloc } & \text { marea } & \text { hgid } & \text { adpopt } & \text { ithelfrm } \\ 3 & 16 & 1 & 0 & 0 & 1 & 0 & 0 \\ \text { mid1 } & \text { thick1 } & \text { b1 } & \text { ithid1 } & \text { mid2 } & \text { thick2 } & \text { b2 } & \text { ithid2 } \\ 1 & 1.400 \mathrm{E}-4 & 90 & 0 & 0 & 0 & 0 & 0 \\ 1 & 1.400 \mathrm{E}-4 & 0 & 0 & 0 & 0 & 0 & 0 \\ 1 & 1.400 \mathrm{E}-4 & 90 & 0 & 0 & 0 & 0 & 0 \\ 1 & 1.400 \mathrm{E}-4 & 0 & 0 & 0 & 0 & 0 & 0\end{array}$

*PART_COMPOSITE

PLIES SET 4

$\begin{array}{llllllll}\text { pid } & \text { elform } & \text { shrf } & \text { nloc } & \text { marea } & \text { hgid } & \text { adpopt } & \text { ithelfrm } \\ 4 & 16 & 1 & 0 & 0 & 1 & 0 & 0 \\ \text { mid1 } & \text { thick1 } & \text { b1 } & \text { ithid1 } & \text { mid2 } & \text { thick2 } & \text { b2 } & \text { ithid2 } \\ 1 & 1.400 \mathrm{E}-4 & 90 & 0 & 0 & 0 & 0 & 0 \\ 1 & 1.400 \mathrm{E}-4 & 0 & 0 & 0 & 0 & 0 & 0 \\ 1 & 1.400 \mathrm{E}-4 & 90 & 0 & 0 & 0 & 0 & 0 \\ 1 & 1.400 \mathrm{E}-4 & 0 & 0 & 0 & 0 & 0 & 0\end{array}$

*PART_COMPOSITE 


$\begin{array}{llllllll}\begin{array}{l}\text { PLIES SET } \\ \text { pid }\end{array} & \text { elform } & \text { shrf } & \text { nloc } & \text { marea } & \text { hgid } & \text { adpopt } & \text { ithelfrm } \\ 5 & 16 & 1 & 0 & 0 & 1 & 0 & 0 \\ \text { mid1 } & \text { thick1 } & \text { b1 } & \text { ithid1 } & \text { mid2 } & \text { thick2 } & \text { b2 } & \text { ithid2 } \\ 1 & 1.400 \mathrm{E}-4 & 90 & 0 & 0 & 0 & 0 & 0 \\ 1 & 1.400 \mathrm{E}-4 & 0 & 0 & 0 & 0 & 0 & 0 \\ 1 & 1.400 \mathrm{E}-4 & 90 & 0 & 0 & 0 & 0 & 0 \\ 1 & 1.400 \mathrm{E}-4 & 0 & 0 & 0 & 0 & 0 & 0\end{array}$

*PART_COMPOSITE

\section{PLIES SET 6}

$\begin{array}{llllllll}\text { pid } & \text { elform } & \text { shrf } & \text { nloc } & \text { marea } & \text { hgid } & \text { adpopt } & \text { ithelfrm } \\ 6 & 16 & 1 & 0 & 0 & 1 & 0 & 0 \\ \text { mid1 } & \text { thick1 } & \text { b1 } & \text { ithid1 } & \text { mid2 } & \text { thick2 } & \text { b2 } & \text { ithid2 } \\ 1 & 1.400 \mathrm{E}-4 & 90 & 0 & 0 & 0 & 0 & 0 \\ 1 & 1.400 \mathrm{E}-4 & 0 & 0 & 0 & 0 & 0 & 0 \\ 1 & 1.400 \mathrm{E}-4 & 90 & 0 & 0 & 0 & 0 & 0 \\ 1 & 1.400 \mathrm{E}-4 & 0 & 0 & 0 & 0 & 0 & 0\end{array}$

\begin{tabular}{|c|c|c|c|c|c|c|c|}
\hline \multicolumn{8}{|c|}{ *PART } \\
\hline pid & secid & mid & eosid & hgid & grav & adpopt & tmid \\
\hline 7 & 1 & 2 & 0 & 2 & 0 & 0 & 0 \\
\hline
\end{tabular}

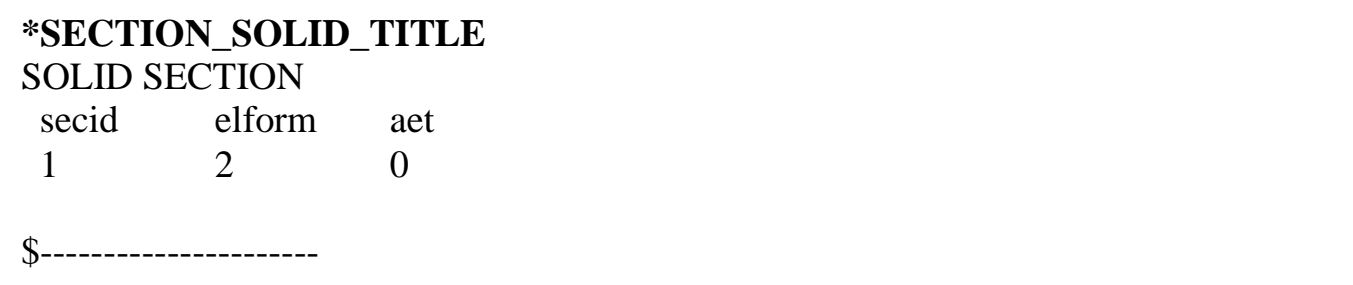

$\begin{array}{llllllll}\text { *MAT_ENHANCED_COMPOSITE_DAMAGE_TITLE } & & & \\ \begin{array}{llllll}\text { AS4/3506-1 CF-EPOXY } \\ \text { mid }\end{array} & \text { ro } & \text { ea } & \text { eb } & \text { (ec) } & \text { prba } & \text { (prca) } & \text { (prcb) } \\ 1 & 1580 & 1.444 \mathrm{E}+11 & 9.690 \mathrm{E}+9 & & 0.020125 & 0.020125 & 0.365 \\ \text { gab } & \text { gbc } & \text { gca } & (\mathrm{kf}) & \text { aopt } & & & \\ 5.760 \mathrm{E}+9 & & & 0 & 0 & & & \\ \text { xp } & \text { yp } & \text { zp } & \text { a1 } & \text { a2 } & \text { a3 } & \text { mangle } & \\ 0 & 0 & 0 & 0 & 0 & 0 & 0 & \\ \text { v1 } & \text { v2 } & \text { v3 } & \text { d1 } & \text { d2 } & \text { d3 } & \text { dfailm } & \text { dfails } \\ 0 & 0 & 0 & 0 & 0 & 0 & 0.024 & 0.03 \\ \text { tfail } & \text { alph } & \text { soft } & \text { fbrt } & \text { ycfac } & \text { dfailt } & \text { dfailc } & \text { efs } \\ 1.153 \mathrm{E}-9 & 0.1 & 0 & 0.5 & 1.2 & 0.0174 & -0.0116 & 0 \\ \text { xc } & \text { xt } & \text { yc } & \text { yt } & \text { sc } & \text { crit } & \text { beta } & \\ 1.440 \mathrm{E}+9 & 2.280 \mathrm{E}+9 & 2.280 \mathrm{E}+8 & 5.700 \mathrm{E}+7 & 7.100 \mathrm{E}+7 & 54 & 0.5 & \\ \text { pel } & \text { epsf } & \text { epsr } & \text { tsmd } & \text { soft2 } & & & \\ 0 & 0 & 0 & 0 & 1 & & & \\ \text { slimt1 } & \text { slimc1 } & \text { slimt2 } & \text { slimc2 } & \text { slims } & \text { ncyred } & \text { softg } & \\ 0 & 0 & 0 & 0 & 0 & 0 & 1 & \end{array}$




\begin{tabular}{|c|c|c|c|c|c|c|c|}
\hline & \multicolumn{6}{|c|}{ HARDENED STEEL } \\
\hline mid & ro & $\mathrm{e}$ & $\mathrm{pr}$ & $\mathrm{n}$ & couple & $\mathrm{m}$ & alias \\
\hline $\begin{array}{l}2 \\
\mathrm{cmo}\end{array}$ & $\begin{array}{l}3.682 \mathrm{E}+5 \\
\text { con } 1\end{array}$ & $\begin{array}{l}2.05 E+11 \\
\operatorname{con} 2\end{array}$ & 0.29 & 0 & 0 & 0 & 0 \\
\hline 0 & 0 & 0 & & & & & \\
\hline lco or al & $\mathrm{a} 2$ & $\mathrm{a} 3$ & v1 & $\mathrm{v} 2$ & v3 & & \\
\hline 0 & 0 & 0 & 0 & 0 & 0 & & \\
\hline
\end{tabular}

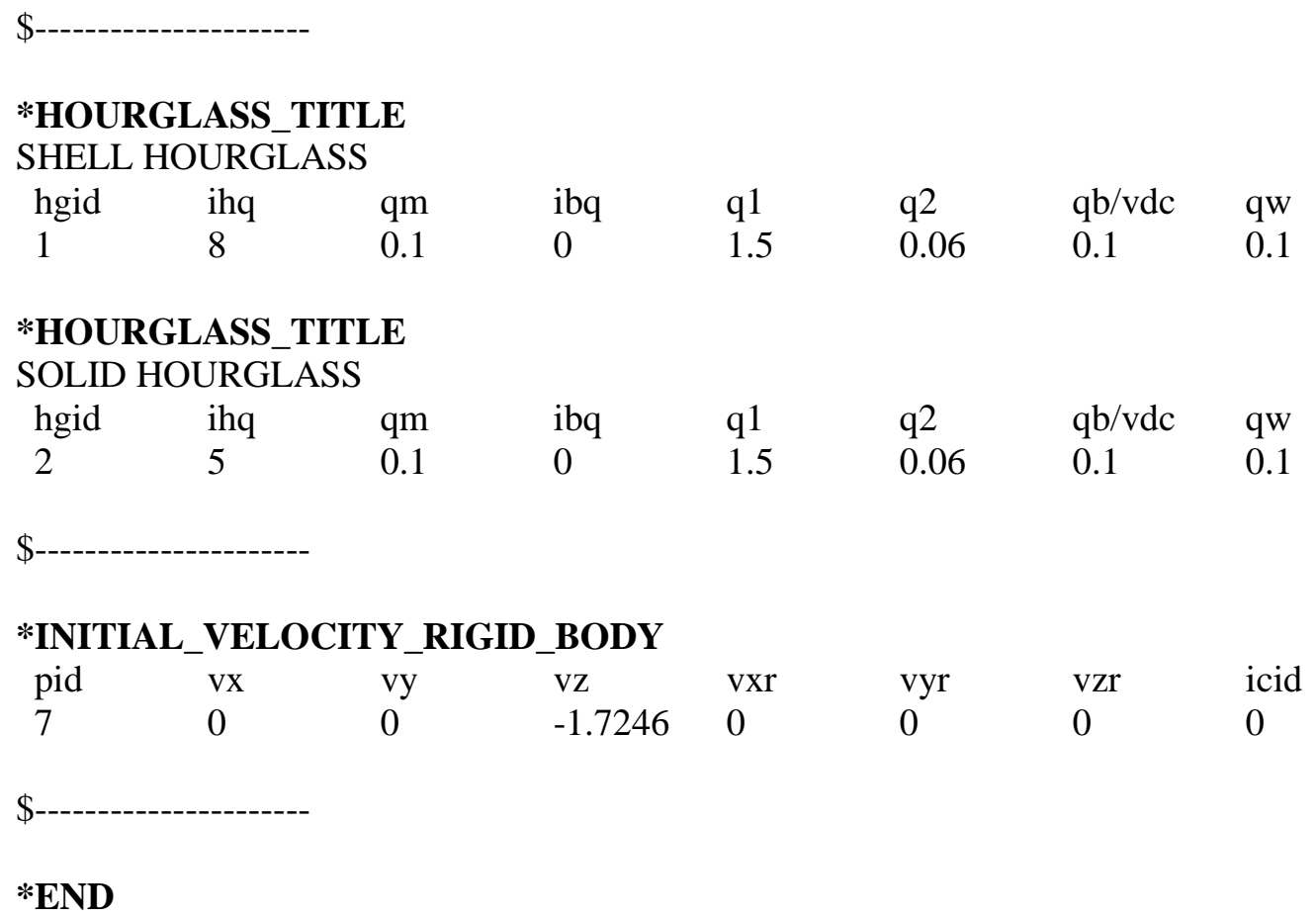

NOTE:

The only difference between the $\mathrm{H} 28$ and $\mathrm{H} 29$ specimen is the impact energy. The difference in the impact energy is accounted for by increasing the impact velocity. Therefore, the only difference in the $\mathrm{H} 28$ and $\mathrm{H} 29$ source code is the following:

\begin{tabular}{llllllll}
\multicolumn{2}{l}{ *INITIAL_VELOCITY_RIGID_BODY } & & & & \\
pid & vX & vy & vz & vxr & vyr & vzr & icid \\
7 & 0 & 0 & -2.00644 & 0 & 0 & 0 & 0
\end{tabular}



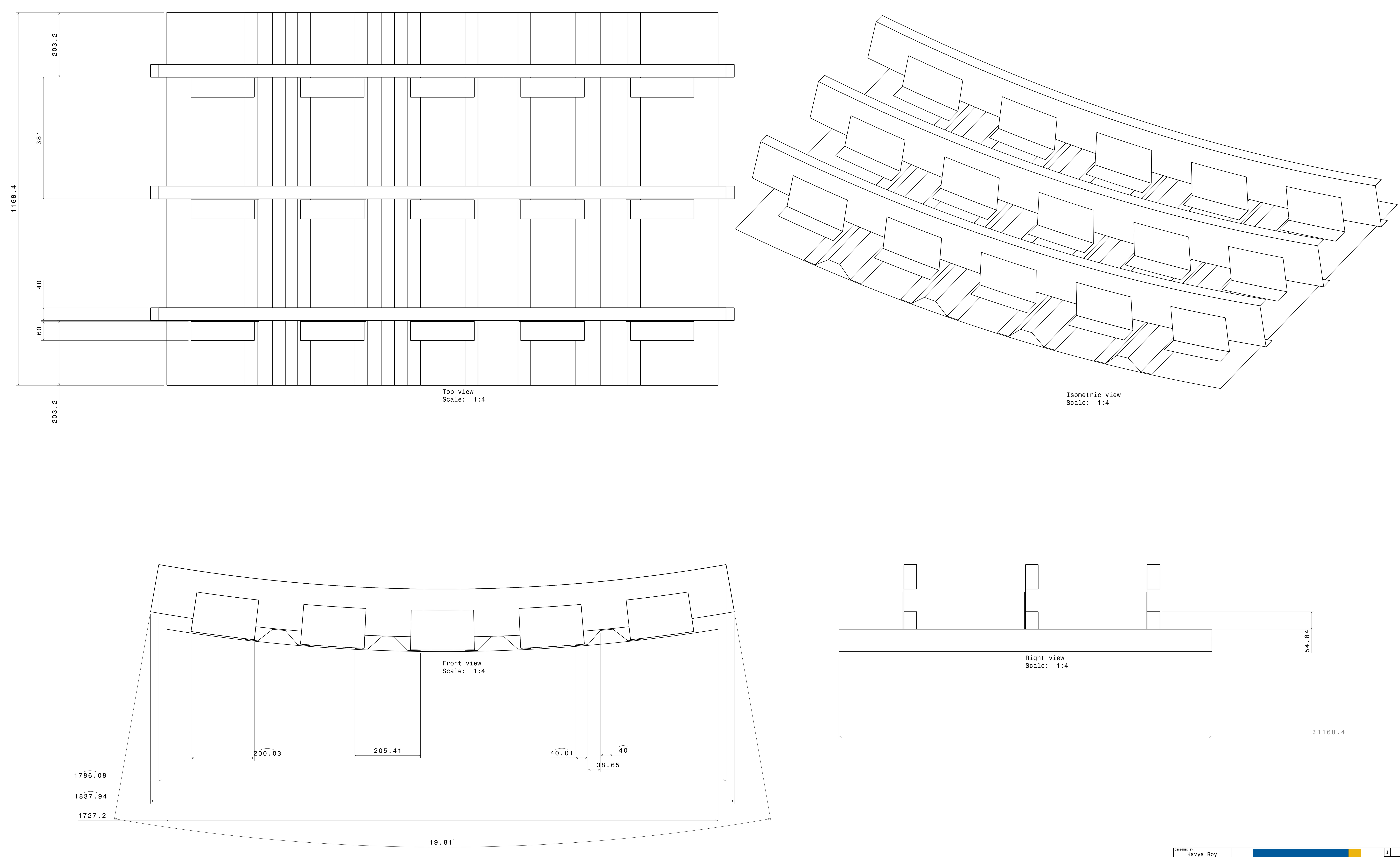


\section{REFERENCES}

[1] F. Dogan, H. Hadavinia, T. Donchev and P. Bhonge, "Delamination of impacted composite structures by cohesive zone interface elements and tiebreak contact," Cent. Eur. J. Eng., vol. 2, pp. 612-626, 2012.

[2] E. Moncayo, H. Wagner and K. Drechsler, "Benchmarks for Composite Delamination Using LSDYNA 971: Low Velocity Impact," in 6th German LS-DYNA Forum 2007, Frankenthal, 2007.

[3] D. Kreculj and B. Rasuo, "Review of impact damages modelling in laminated composite aircraft structures," Technical Gazette, vol. 20, pp. 485-495, 2013.

[4] I. Smojver and J. Soric, "Impact Damage Analysis of Layered Composite Plates," in International Design Conference, Dubrovnik, 2002.

[5] A. Faggiani and B. Falzon, "Predicting Low-velocity Impact Damage on a Stiffened Composite Panel," Composites Part A, vol. 41, pp. 737-749, 2010.

[6] G. Schoeppner and S. Abrate, "Delamination threshold loads for low velocity impact on composite laminates," Composites Part A, vol. 31, pp. 903-915, 2000.

[7] S. Her and Y. Liang, "The Finite Element Analysis of Composite Laminates and Shell Structures Subjected to Low Velocity Impact," Compos. Struct., vol. 66, pp. 277-285, 2004.

[8] V. Balasubramania, S. Boopathy and R. Vasudevan, "Numerical Analysis of Low Velocity Impact on Laminated Composite Plates," Procedia Engineering, vol. 64, pp. 1089-1098, 2013.

[9] V. Tita, J. Carvalho and D. Vandepitte, "Failure analysis of low velocity impact on thin composite laminates," Compos. Struct., vol. 83, pp. 413-428, 2008.

[10] H. Hadavinia, F. Dogan, A. Elmarakbi and S. Khalili, "Modelling of Low Velocity Impact of Laminated Composite Substructures," Int. J. Vehicle Structures \& Systems, vol. 3, pp. 96-106, 2011.

[11] G. Bibo, P. Hogg, R. Backhouse and A. Mills, "Carbon-fibre Non-crimp Fabric Laminates for Cost-effective Damage-tolerant Structures," Compos. Sci. Technol., vol. 58, pp. 129-143, 1998.

[12] E. Greenhalgh and M. Hiley, "The Assessment of Novel Materials and Processes for the Impact Tolerant Design of a Stiffened Composite Aerospace Structure," Composites Part A, vol. 34, pp. 151-161, 2003.

[13] M. Morell, "Advanced Primary Composite Structures," Nouvelle Revue Aeronautique et Astronautique, vol. 2, pp. 71-75, 1998. 
[14] C. Buizer, Low-velocity impact analysis of composite plates with a buffer-zone interface between micro- and macro-modeling, Eindhoven: Master Internship Report, MT 10.04, 2010.

[15] G. F. M. Zumpano, W. Stronge and M. Sutcliffe, "Impact Damage in Hybrid Braided Twill Composites," Journal of Materials Science, vol. 43, pp. 6668-6675, 2008.

[16] A. Martinez, G. Xiang and D. Arencon, "Flexed-plate Low Energy Impact of an Epoxy-Carbon Fibre Laminate," Polym. Polym. Compos., vol. 20, pp. 581-587, 2012.

[17] J. Carruthers, A. Kettle and A. Robinson, "Energy Absorption Capability and Crashworthiness of Composite Material Structures: A Review," Applied Mechanics Reviews, vol. 51, pp. 635-349, 1998.

[18] D. Hull, "Unified Approach to Progressive Crushing of Fibre-reinforced Composite Tubes," Composites Science and Technology, vol. 40, pp. 377-421, 1991.

[19] T. Sinmazcelik, A. Armagan and V. Gunay, "Impact-fatigue Behaviour of Unidirectional Carbon Fibre Reinforced Polyetherimide (PEI) Composites," Journal of Materials Science, vol. 41, pp. 6237-6244, 2006.

[20] C. Breen, F. Guild and M. Pavier, "Impact Damage to Thick Carbon Fibre Reinforced Plastic Composite Laminates," Journal of Materials Science, vol. 41, pp. 6718-6724, 2006.

[21] S. Wang, L. Wu and L. Ma, "Low-velocity Impact and Residual Tensile Strength Analysis to Carbon Fiber Composite Laminates," Materials and Design, vol. 31, pp. 118-125, 2009.

[22] A. Pacios, C. Ouyang and S. Shah, "Rate Effect on Interfacial Response between Fibres and Matrix," Materials and Structures, vol. 28, pp. 1359-1397, 1995.

[23] D. Ghelli and G. Minka, "'Low Velocity Impact and Compression after Impact Tests on Thin Carbon/epoxy Laminates," Composites: Part B, vol. 42, pp. 2067-2079, 2011.

[24] A. Askari, K. Nelson, O. Weckner, J. Xu and S. Silling, "Hail Impact Characteristics of a Hybrid Material by Advanced Analysis Techniques and Testing," J. Aerosp. Eng., vol. 24, pp. 210-217, 2011.

[25] J. Kepler, "Impact Penetration of Sandwich Panels at Different Velocities - an Experimental Parameter Study: Part 1 - Parameters and Results," J. Sandw. Struct. Mater., vol. 6, pp. 357-374, 2004.

[26] W. Cantwell and J. Morton, "The Impact Resistance of Composite Materials - a Review," Composites, vol. 22, pp. 347-362, 1991. 
[27] R. Olsson, "Mass Criterion for Wave Controlled Impact Response of Composite Plates," Composites Part A, vol. 31, pp. 879-887, 2000.

[28] X. Xiao, "Modeling Energy Absorption with a Damage Mechanics Based Composite Material Model," J. Compos. Mater., vol. 43, pp. 427-443, 2009.

[29] F. Silva, D. Zhu, B. Mobasher and R. Filho, "Impact Behaviour of Sisal Fiber Cement Composites under Flexural Load," ACI Mater. J., vol. 108, pp. 168-177, 2011.

[30] A. Yaghoubi, Y. Liu and B. Liaw, "Low-velocity Impact on GLARE 5 Fiber-Metal Laminates: Influences of Specimen Thickness and Impactor Mass," Journal of Aerospace Engineering, vol. 25, pp. 409-420, 2012.

[31] R. Hosseinzadeh, M. Shokrieh and L. Lessard, "Damage Behaviour of Fiber Reinforced Composite Plates Subjected to Drop Weight Impacts," Composites Science and Technology, vol. 66, pp. 61-68, 2006.

[32] J. Rhymer, H. Kim and D. Roach, "The Damage Resistance of Quasi-isotropic Carbon/epoxy Composite Tape Laminates Impacted by High Velocity Ice," Composites: Part A, vol. 43, pp. 1134-1144, 2012.

[33] G. Appleby-Thomas, P. Hazell and G. Dahini, "On the Response of Two Commerciallyimportant CFRP Structures to Multiple Ice Impacts," Compos. Struct., vol. 93, pp. 2619-2627, 2011.

[34] T. Kroupa, J. Cerv and F. Vales, "Stress wave propagation in thin long-fiber carbon/epoxy composite panel. Numerical and experimental solutions," Applied and Computational Mechanics 1, vol. 1, pp. 127-136, 2007.

[35] J. Lopez-Puente, R. Zaera and C. Navarro, "Experimental and numerical analysis of normal and oblique ballistic impacts on thin carbon/epoxy woven laminates," Composites Part A, vol. 39, pp. 374-387, 2008.

[36] O. David-West, D. Nash and W. Banks, "An Experimental Study of Damage Accumulation in Balanced CFRP Laminates to Repeated Impact," Compos. Struct., vol. 83, pp. 247-258, 2008.

[37] A. Martinez, G. Xiang, D. Arencon and J. Velasco, "Low Energy Impact Indentation of an Epoxy-Carbon Fiber Laminate," Polymers and Polymer Composites, vol. 57, pp. 553-557, 2011.

[38] R. Mair, "Advanced composite structures research in Australia," Compos. Struct., vol. 57, pp. 3$10,2002$. 
[39] S. Zike, K. Kalnins, O. Ozolins and M. Knite, "An Experimental and Numerical Study of Low Velocity Impact of Unsaturated Polyester/Glass Fibre Composite," Materials Science, vol. 17, pp. 384-390, 2011.

[40] T. Franz, V. Balden and G. Nurick, "Numerical investigation into the elastic impact response of carbon-fibre epoxy plates validated with experimental data," in International Conference on Computational Mechanics, Beijing, 2001.

[41] L. Inc., "LS-DYNA Aerospace Working Group," 2013. [Online]. Available: http://awg.lstc.com/tiki/tiki-index.php.

[42] H. Zarei, "Experimental and numerical investigation of crash srtuctures using aluminum alloys," Doctoral Thesis, Göttingen, 2008.

[43] L. Inc., LS-DYNA KEYWORD USER'S MANUAL VOLUME II - Material Models, Livermore: LSTC, 2013.

[44] L. Inc., "LS-DYNA Support - Contact Types," 2013. [Online]. Available: http://www.dynasupport.com/tutorial/contact-modeling-in-ls-dyna/contact-types.

[45] L. S. T. C. (LSTC), LS-DYNA KEYWORD USER'S MANUAL VOLUME 1, Manual Rev. 2645, Livermore, 2013.

[46] L. Inc., "LS-DYNA Support - Shell Formulations," 2013. [Online]. Available: http://www.dynasupport.com/howtos/element/shell-formulations.

[47] L. Inc., "LS-DYNA Support - Hourglass," 2013. [Online]. Available: http://www.dynasupport.com/howtos/element/hourglass.

[48] B. Wade, P. Feraboli and M. Osborne, "Simulating laminated composites using LS-DYNA material model MAT54 part I: [0] and [90] ply single-element investigation," in Federal Aviation Administration Joint Advanced Materials \& Structures (JAMS) 2012 Technical Review Meeting, Baltimore, 2012.

[49] H. Kim, "Impact Damage Formation on Composite Aircraft Structures," in Federal Aviation Administration Joint Advanced Materials \& Structures (JAMS) 2011 Technical Review Meeting, San Diego, 2011.

[50] G. DeFrancisci, Z. Chen and H. Kim, "Blunt Impact Damage Formation in Frame and Stringer Stiffened Composite Panels," in 18th International Conference on Composite Materials, Jeju, 2011. 
[51] H. Kim, G. DeFrancisci, Z. Chen, J. Rhymer and J. Tippmann, "Impact Damage Formation on Composite Aircraft Structures," in Federal Aviation Administration Joint Advanced Materials \& Structures (JAMS) 2010 Technical Review Meeting, Seattle, 2010.

[52] J. Tomblin, J. Sherraden, W. Seneviratne and K. Raju, "A - Basis and B - Basis Design Allowables for Epoxy - Based Prepreg and TORAY T700GC-12K-31E/\#2510 Unidirectional Tape, Rep. AGATE-WP3.3-033051-132," Wichita State University, Wichita, 2002.

[53] J. Tomblin, J. Sherraden, W. Seneviratne and K. Raju, "A - Basis and B - Basis Design Allowables for Epoxy - Based Prepreg and TORAY T700SC-12K-50C/\#2510 Plain Weave Fabric, Rep. AGATE-WP3.3-033051-134," Wichita State University, Wichita, 2002.

[54] M. Bauccio, ASM Engineered Materials Reference Book, 2nd ed., Materials Park: CRC Press, 1994.

[55] L. Inc., "LS-DYNA Support - How contact works," 2013. [Online]. Available: http://www.dynasupport.com/tutorial/contact-modeling-in-ls-dyna/how-contact-works.

[56] R. Luo, J. Qu, H. Ding and S. Xu, "Static friction properties of carbon/carbon composites," Mater. Lett., vol. 58, pp. 1251-1254, 2004. L. Inc., "Hourglass," 2012. [Online]. Available: http://ftp.lstc.com/anonymous/outgoing/jday/hourglass.pdf.

[58] A. S. A. M. Inc., "Aluminum 7075-T6; 7075-T651," 2013. [Online]. Available: http://asm.matweb.com/search/SpecificMaterial.asp?bassnum=MA7075T6.

[59] L. Inc., "Shell Strain," 2014. [Online]. Available: http://www.dynasupport.com/howtos/element/shell-strain.

[60] L. Inc., "Contact Parameters," 2014. [Online]. Available: http://www.dynasupport.com/tutorial/contact-modeling-in-ls-dyna/contact-parameters.

[61] L. Inc., "Contact Thickness," 2014. [Online]. Available: http://www.dynasupport.com/howtos/contact/contact-thickness.

[62] I. Daniel and O. Ishai, Engineering Mechanics of Composite Materials, 2nd ed., Oxford, England: Oxford University Press, 2005.

[63] H. Boyer, Metals Handbook, Desk ed., Materials Park, USA: American Society for Metals, 1984.

[64] B. Gama and J. Gillespie, "Finite element modeling of impact, damage evolution and penetration of thick-section composites," Int. J. Impact. Eng., vol. 38, pp. 181-197, 2011. 
[65] M. Loikkanen, G. Praveen and D. Powell, "Simulation of Ballistic Impact on Composite Panels," in 10th International LS-DYNA Users Conference, Dearborn, 2008.

[66] B. Thatte, G. Chandekar, A. Kelkar and P. Chaphalkar, "Studies on Behavior of Carbon and Fiberglass Epoxy Composite Laminates under Low Velocity Impact Loading using LS-DYNA," in 10th International LS-DYNA Users Conference, Dearborn, 2008.

[67] Thomasnet, "Types of Fastner Threads," 2014. [Online]. Available: http://www.thomasnet.com/articles/hardware/fastener-threads.

[68] J. Ekh and J. Schon, "Finite element modeling and optimization of load transfer in multi-fastener joints using structural elements," Composite Structures, vol. 82, pp. 245-256, 2008.

[69] E. Szymczyk and J. Godzimirski, "The influence of riveting process on sheets fatigue life - the stress state analysis," Acta Mechanica et Automatica, vol. 6, pp. 74-81, 2012.

[70] R. Barrett, "Stress Concentration Factors for Fasteners and Fastener Joints," American Fastener Journal, vol. 22, pp. 60-61, 2005.

[71] F. Darwish, G. Tashtoush and M. Gharaibeh, "Stress concentration analysis for countersunk rivet holes in orthotropic plates," European Journal of Mechanics A/Solids, vol. 37, pp. 69-78, 2013.

[72] M. Paredes, N. Nefissi and M. Sartor, "Study of an interference fit fastener assembly by finite element modelling, analysis and experiment," Int. J. Interact. Des. Manuf., vol. 6, pp. 171-177, 2012.

[73] F. Darwish, K. Shivakumar, S. Hamoush and D. Hsu, "Performance of Patch Repaired Composite Panels - Static and Fatigue," AIAA, vol. 47, pp. 121-128, 2006.

[74] H. Li, F. Beck, O. Dupouy, I. Herszberg, P. Stoddart, C. Davis and A. Mouritz, "Strain-based Health Assessment of Bonded Composite Repairs," Composite Structures, vol. 71, pp. 234-242, 2006.

[75] W. Chow and S. Atluri, "Composite Patch Repairs of Metal Structure: Adhesive Nonlinearity, Thermal Cycling, and Debonding," AIAA, vol. 35, pp. 1528-1535, 1997.

[76] T. Kam, K. Chu and Y. Tsai, "Fatigue of Cracked Plates Repaired with Single-Sided Composite Patches," AIAA, vol. 36, pp. 645-650, 1998.

[77] C. Duong, S. Verhoeven and C. Guijt, "Analytical and Experimental Study of Load Attractions and Fatigue Crack Growths in Two-sided Bonded Repairs," Composite Structures, vol. 73, pp. 394-402, 2006. 
[78] F. Tanghe, M. Carrier and D. Falandry, "Optimization of Bonded Structural Repairing on CFRP Plates," Composite Interfaces, vol. 7, pp. 301-316, 2000.

[79] E. Botelho, M. Rezende, S. Mayer and H. Voorwald, "Evaluation of Fatigue Behaviour on Repaired Carbon Fiber/epoxy Composites," Journal of Materials Science, vol. 43, pp. 31663172, 2008.

[80] J. Gustin, A. Joneson, M. Mahinfalah and J. Stone, "Low Velocity Impact of Combination Kevlar/carbon Fiber Sandwich Composites," Composite Structures, vol. 69, pp. 396-406, 2005.

[81] A. Harman and A. Rider, "Impact Damage Tolerance of Composite Repairs to Highly-loaded, High Temperature Composite Structures," Composites: Part A, vol. 42, pp. 1321-1334, 2011.

[82] C. Cheung, A. Styuart and K. Lin, "Effect of Repair Quality on Reliability of Damage Tolerant Composite Structure with Damage Growth," AIAA, vol. 49, pp. 111-119, 2008.

[83] H. Composites, "Composite Repair," 1999. [Online]. Available: http://www.hexcel.com/Resources/DataSheets/Brochure-Data-Sheets/Composite_Repair.pdf.

[84] A. Rider, C. Wang and P. Chang, "Bonded Repairs for Carbon/BMI Composite at High Operating Temperatures," Composites: Part A, vol. 41, pp. 902-912, 2010.

[85] C. Chue, L. Chang and J. Tsai, "Bonded Repair of a Plate with Inclined Central Crack under Biaxial Loading," Composite Structures, vol. 28, pp. 39-45, 1994.

[86] P. Molitor, V. Barron and T. Young, "Surface Treatment of Titanium for Adhesive Bonding to Polymer Composites: A Review," International Journal of Adhesion and Adhesives, vol. 21, pp. 129-136, 2001.

[87] A. Baldan, "Review: Adhesively-bonded Joints and Repairs in Metallic Alloys, Polymers and Composite Materials: Adhesives, Adhesion Theories and Surface Pretreatment," Journal of Materials Science, vol. 39, pp. 1-49, 2004.

[88] M. Davis and D. Bond, "Principles and Practices of Adhesive Bonded Structural Joints and Repairs," International Journal of Adhesion and Adhesives, vol. 19, pp. 91-105, 1999.

[89] L. Ye, K. Friedrich, C. Weimer and Y. Mai, "Surface Treatments and Adhesion Bonding between Concrete and a CFRP Composite," Advanced Composite Materials, vol. 7, pp. 47-61, 1998.

[90] W. Johnson, Adhesively Bonded Joints: Testing, Analysis and Design, Baltimore: ASTM, 1986.

[91] W. Reitz and R. Oman, "How to Join Plastics," Advanced Materials and Processes, vol. 158, pp. 49-52, 2000. 
[92] S. Amancio-Filho and J. Santos, "Joining of Polymers and Polymer-Metal Hybrid Structures: Recent Development and Trends," Polymer Engineering and Science, vol. 49, pp. 1461-1476, 2009.

[93] A. Strong, Fundamentals of Composites Manufacturing: Materials, Methods, and Applications, Dearborn: Society of Manufacturing Engineers, 1989. 